Prepared in cooperation with the Illinois Environmental Protection Agency

\title{
Continuous Monitoring of Sediment and Nutrients in the Illinois River at Florence, Illinois, 2012-13
}

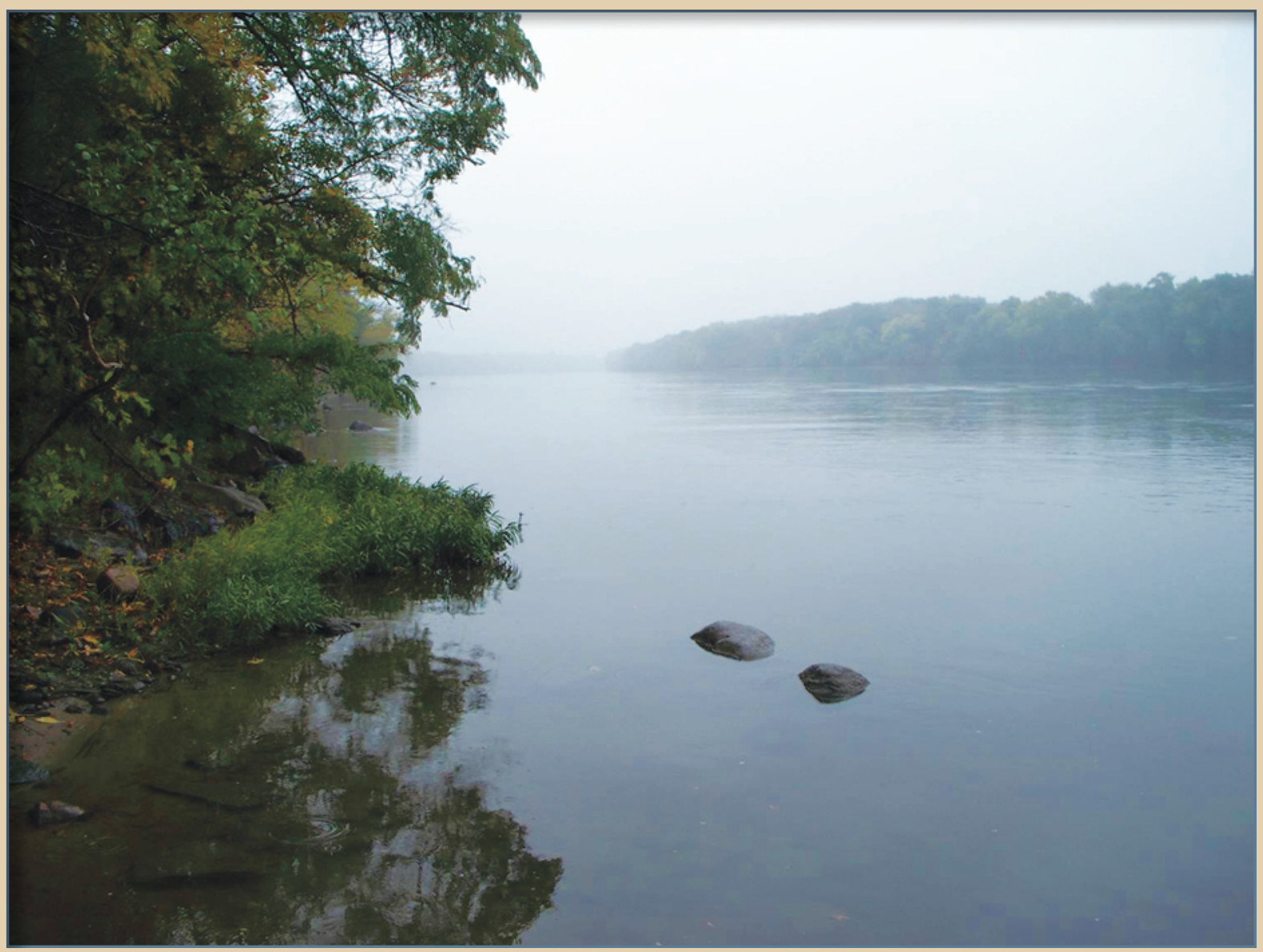

Scientific Investigations Report 2015-5040 
Cover. A tranquil morning on the Illinois River. Photograph by Tim Straub, U.S. Geological Society, Illinois Water Science Center. 


\section{Continuous Monitoring of Sediment and Nutrients in the Illinois River at Florence, Illinois, 2012-13}

By Paul J. Terrio, Timothy D. Straub, Marian M. Domanski, and Nicolas A. Siudyla

Prepared in cooperation with the Illinois Environmental Protection Agency

Scientific Investigations Report 2015-5040 


\title{
U.S. Department of the Interior SALLY JEWELL, Secretary
}

\section{U.S. Geological Survey \\ Suzette M. Kimball, Acting Director}

\author{
U.S. Geological Survey, Reston, Virginia: 2015
}

For more information on the USGS - the Federal source for science about the Earth, its natural and living resources, natural hazards, and the environment—visit http://www.usgs.gov or call 1-888-ASK-USGS.

For an overview of USGS information products, including maps, imagery, and publications, visit http://www.usgs.gov/pubprod/.

Any use of trade, firm, or product names is for descriptive purposes only and does not imply endorsement by the U.S. Government.

Although this information product, for the most part, is in the public domain, it also may contain copyrighted materials as noted in the text. Permission to reproduce copyrighted items must be secured from the copyright owner.

Suggested citation:

Terrio, P.J., Straub, T.D., Domanski, M.M., and Siudyla, N.A., 2015, Continuous monitoring of sediment and nutrients in the Illinois River at Florence, Illinois, 2012-13: U.S. Geological Survey Scientific Investigations Report 2015-5040, 61 p., http://dx.doi.org/10.3133/sir20155040.

ISSN 2328-0328 (online) 


\section{Contents}

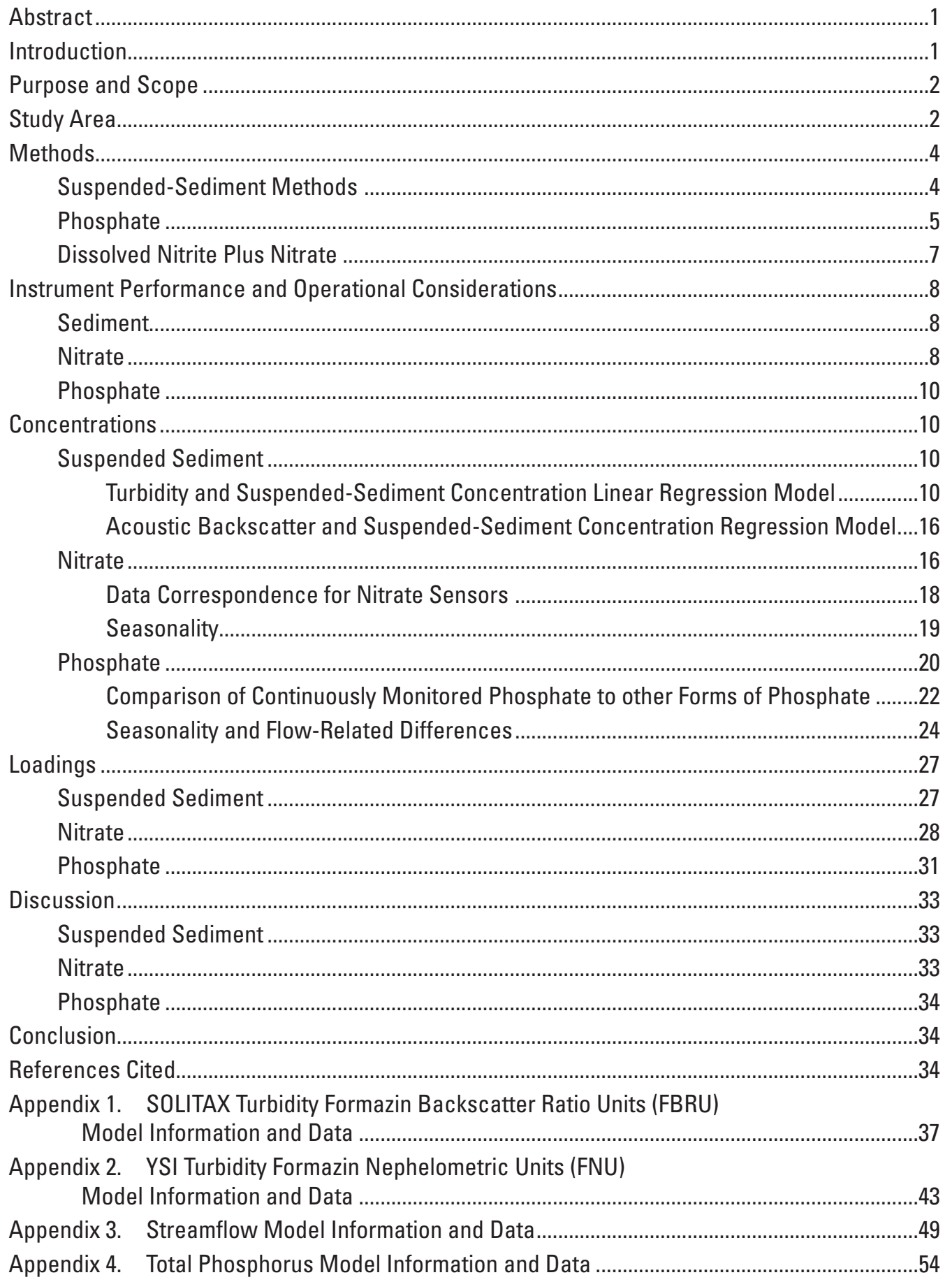




\section{Figures}

1. Map showing the Illinois River Basin and the location of the continuous-monitoring stations at Florence, Illinois (05586300), and Valley City, III. (05586100)

2. Images of $A$. WET Labs Cycle-P04 phosphate analyzer, $B$. Hach NITRATAX nitrate sensor, $C$. Satlantic SUNA nitrate sensor, D. Hach SOLITAX turbidity sensor, E-F. Installation structure at Illinois River at Florence, Illinois (05586100) .6

3. Graphs showing results of the U.S. Geological Survey Illinois Water Science Center experiments to determine the effects of suspended-sediment concentrations on NITRATAX nitrate sensor readings

4. Graph showing suspended-sediment concentration and turbidity linear regression models using turbidity data from the Illinois River at Florence, Illinois (05586300), and samples collected at the Illinois River at Florence, III., (05586300) and the Illinois River at Valley City, III. (05586100).

5. Graphs showing the relations between the regression residuals, estimated suspended-sediment concentrations, and dates for the linear regression models shown in figure 4.

6. Graph showing predicted and observed suspended-sediment concentration using turbidity and streamflow re-transformed linear regression models presented in table 4 using turbidity data from the Illinois River at Florence, Illinois (05586300), and samples collected at the Illinois River at Florence, III. (05586300), and the Illinois River at Valley City, III. (05586100), and streamflow data reported at the Illinois River at Valley City, III. (05586100).

7. Graph showing time series streamflow and suspended-sediment concentration (SSC) for samples, modeled SSC (estimated) for SOLITAX, and Graphical Constituent Loading Analysis System (GCLAS) method.

8. Graph showing observed and predicted suspended-sediment concentration using a linear regression model with an acoustic parameter, the sediment attenuation coefficient, using acoustic data from an ADVM in the Illinois River at Florence, Illinois (05586300), and samples collected at the Illinois River at Florence, III. (05586300), and the Illinois River at Valley City, III. (05586100)...

9. Graph showing concentrations of nitrite plus nitrate nitrogen as determined by the NITRATAX sensor and samples analyzed at the U.S. Geological Survey National Water Quality Laboratory, relative percent differences among concentrations, and streamflow for the period June 1, 2012-0ctober 30, 2013, at the Illinois River at Florence, Illinois (05586300)...

10. Graph showing continuous nitrate data from the NITRATAX and SUNA nitrate sensors at the Illinois River at Florence, Illinois (05586300), October 2012-0ctober 2013

11. Graph showing comparison of continuous nitrate data collected by the NITRATAX and SUNA nitrate sensors at the Illinois River at Florence, Illinois (06686300), October 2012-0ctober 2013.

12. Graph showing concentrations of dissolved phosphate as determined by the Cycle-P04 analyzer and streamflow for April 25, 2013-0ctober 30, 2013, at the Illinois River at Florence, Illinois (05586300).

13. Graph showing concentrations of phosphate measured by the Cycle-PO4 analyzer and dissolved orthophosphate analyzed by the U.S. Geological Survey National Water Quality Laboratory for April 25-0ctober 30, 2013. 


\section{Figures-continued}

14. Graph showing concentrations of various forms of phosphorus in the Illinois River at Valley City, Illinois (05586100), and concurrent continuous phosphate concentrations at the Illinois River at Florence, III. (05586300),

April 25-October 30, 2013

15. Graph showing observed and predicted total phosphorus concentrations using a linear regression model with orthophosphate and suspended sediment prediction variables.

16. Graph showing continuous ophosphate concentrations versus streamflow for April-0ctober 2013 at the Illinois River at Florence, Illinois (05586300)

17. Graph showing monthly suspended-sediment load for each instrument and method used in the study at the Illinois River at Florence, Illinois (0558630).

18. Graph showing annual suspended-sediment loads for the study period and historical data.

19. Graph showing instantaneous nitrate loads computed using data and the LOADEST program for the Illinois River at Florence, Illinois (05586300)

20. Graphs showing instantaneous nitrate loads and the differences in loads computed using continuous data and the LOADEST program for June 2012-October 2013 at the Illinois River at Florence, Illinois (05586300).

21. Graph showing monthly nitrate loads in the Illinois River at Florence, Illinois (05586300), June 2012-October 2013

22. Graph showing phosphate loads at the Illinois River at Florence, Illinois (05586300), April-0ctober 2013.

23. Graph showing relative percent differences and quantitative differences in computed phosphate loads for the Illinois River at Florence, Illinois (05586300), April-October 2013

\section{Tables}

1. Physical and operational characteristics of the Hach NITRATAX and Satlantic SUNA in-situ ultraviolet absorbance nitrate sensors

2. Predictor and response variable statistics for suspended-sediment concentration, turbidity, and streamflow linear regression models.

3. Suspended-sediment concentration, turbidity, and streamflow linear regression models and coefficient of determinations using turbidity data from the Illinois River at Florence (05586300), and samples collected at the Illinois River at Florence (05586300) and the Illinois River at Valley City (05586100)...

4. Suspended-sediment concentration, turbidity, and streamflow re-transformed linear regression models and non-parametric smearing bias correction factor using turbidity data from the Illinois River at Florence (05586300), and samples collected at the Illinois River at Florence (05586300) and the Illinois River at Valley City (05586100)

5. Summary statistics for nitrite plus nitrate nitrogen, as $\mathrm{N}$, measured by the NITRATAX in-situ sensor and point samples analyzed by the U.S. Geological Survey National Water-Quality Laboratory from the Illinois River at Florence, Illinois (05586300), 2012-13 


\section{Tables-continued}

6. Summary statistics for phosphate data measured by the Cycle-PO4 analyzer and discrete samples analyzed by the U.S. Geological Survey National Water-Quality Laboratory for Illinois River at Florence, Illinois (05586300)

7. Concentrations of nitrate plus nitrite and phosphate in samples collected using the equal-width-increment method and in point samples at the location of the in situ instruments at Illinois River at Florence, Illinois (05586300)

8. Summary statistics for dissolved orthophosphate and total phosphorus concentrations from samples collected at Illinois River at Valley City, Illinois (05586100), 1991-2013.

9. Final model equation and predictor and response variable statistics for total phosphorus (TP) concentration multivariate linear regression models developed using data from the Illinois River at Valley City, Illinois (05586100), 1991-2013

10. Calculated suspended-sediment load for each instrumentand method used in the study.

\section{Conversion Factors}

Inch/Pound to International System of Units

\begin{tabular}{|c|c|c|}
\hline Multiply & By & To obtain \\
\hline & Length & \\
\hline inch (in.) & $2.54 \times 10^{7}$ & nanometer (nm) \\
\hline inch (in.) & 2.54 & centimeter $(\mathrm{cm})$ \\
\hline inch (in.) & 25.4 & millimeter $(\mathrm{mm})$ \\
\hline foot $(\mathrm{ft})$ & 0.3048 & meter $(\mathrm{m})$ \\
\hline \multirow[t]{2}{*}{ mile (mi) } & 1.609 & kilometer $(\mathrm{km})$ \\
\hline & Area & \\
\hline acre & 0.4047 & hectare (ha) \\
\hline \multirow[t]{2}{*}{ square mile $\left(\mathrm{mi}^{2}\right)$} & 2.590 & square kilometer $\left(\mathrm{km}^{2}\right)$ \\
\hline & Volume & \\
\hline \multirow[t]{2}{*}{ cubic foot $\left(\mathrm{ft}^{3}\right)$} & 28.317 & liter \\
\hline & Flow rate & \\
\hline \multirow[t]{2}{*}{ cubic foot per second $\left(\mathrm{ft}^{3} / \mathrm{s}\right)$} & 0.02832 & cubic meter per second $\left(\mathrm{m}^{3} / \mathrm{s}\right)$ \\
\hline & Mass & \\
\hline pound, avoirdupois (lb) & 0.4536 & kilogram (kg) \\
\hline pounds per day $(\mathrm{lb} / \mathrm{d})$ & 0.4536 & kilogram per day $(\mathrm{kg} / \mathrm{d})$ \\
\hline ton & 0.9072 & metric ton \\
\hline ton per day (ton/d) & 0.9072 & metric ton per day \\
\hline ton per month (ton/m) & 0.9072 & metric ton per month \\
\hline ton per year (ton/yr) & 0.9072 & metric ton per year \\
\hline
\end{tabular}

Temperature in degrees Celsius $\left({ }^{\circ} \mathrm{C}\right)$ may be converted to degrees Fahrenheit $\left({ }^{\circ} \mathrm{F}\right)$ as:

$$
{ }^{\circ} \mathrm{F}=\left(1.8 \times{ }^{\circ} \mathrm{C}\right)+32 .
$$

Concentrations of chemical constituents in water are given either in milligrams per liter (mg/L) or micrograms per liter $(\mu \mathrm{g} / \mathrm{L})$. 


\section{Abbreviations}

\begin{tabular}{|c|c|}
\hline ADVM & acoustic Doppler velocity meter \\
\hline ASTM & American Society for Testing and Materials \\
\hline $\mathrm{BCF}$ & bias correction factor \\
\hline CDOM & colored dissolved organic matter \\
\hline DCP & data-collection platform \\
\hline DIN & Deutsches Institut für Normung \\
\hline DOP & dissolved orthophosphate \\
\hline EWI & equal width increment \\
\hline FBRU & formazin backscatter ratio units \\
\hline FNU & formazin nephelometric units \\
\hline GB & gigabyte \\
\hline GCLAS & Graphical Constituent Loading Analysis System \\
\hline Illinois EPA & Illinois Environmental Protection Agency \\
\hline IL WSC & Illinois Water Science Center \\
\hline ISO & International Organization for Standardization \\
\hline $\mathrm{kHz}$ & kilohertz \\
\hline LOADEST & load estimator software \\
\hline MC & method code \\
\hline NAWQA & National Water-Quality Assessment \\
\hline NWQL & National Water-Quality Laboratory \\
\hline OBS & optical backscatter \\
\hline OLS & ordinary least squares \\
\hline $\mathrm{PO}_{4}$ & phosphate \\
\hline PVC & polyvinyl chloride \\
\hline $\mathrm{R}^{2}$ & coefficient of determination \\
\hline SSC & suspended-sediment concentration \\
\hline SSL & suspended-sediment load \\
\hline TP & total phosphorus \\
\hline USGS & U.S. Geological Survey \\
\hline$\mu \mathrm{n}$ & micrometer \\
\hline
\end{tabular}





\title{
Continuous Monitoring of Sediment and Nutrients in the Illinois River at Florence, Illinois, 2012-13
}

\author{
By Paul J. Terrio, Timothy D. Straub, Marian M. Domanski, and Nicolas A. Siudyla
}

\begin{abstract}
The Illinois River is the largest river in Illinois and is the primary contributing watershed for nitrogen, phosphorus, and suspended-sediment loading to the upper Mississippi River from Illinois. In addition to streamflow, the following water-quality constituents were monitored at the Illinois River at Florence, Illinois (U.S.Geological Survey station number 05586300), during May 2012-October 2013: phosphate, nitrate, turbidity, temperature, specific conductance, $\mathrm{pH}$, and dissolved oxygen. The objectives of this monitoring were to (1) determine performance capabilities of the in-situ instruments; (2) collect continuous data that would provide an improved understanding of constituent characteristics during normal, low-, and high-flow periods and during different climatic and land-use seasons; (3) evaluate the ability to use continuous turbidity as a surrogate constituent to determine suspended-sediment concentrations; and (4) evaluate the ability to develop a regression model for total phosphorus using phosphate, turbidity, and other measured parameters. Reliable data collection was achieved, following some initial periods of instrument and data-communication difficulties. The resulting regression models for suspended sediment had coefficient of determination $\left(\mathrm{R}^{2}\right)$ values of about 0.9 . Nitrate plus nitrite loads computed using continuous data were found to be approximately 8 percent larger than loads computed using traditional discrete-sampling based models. A regression model for total phosphorus was developed by using historic orthophosphate data (important during periods of low flow and low concentrations) and historic suspended-sediment data (important during periods of high flow and higher concentrations). The $\mathrm{R}^{2}$ of the total phosphorus regression model using orthophosphorus and suspended sediment was 0.8. Data collection and refinement of the regression models is ongoing.
\end{abstract}

\section{Introduction}

There have been significant advancements in the development of in-situ water-quality monitors during the past decade, including instruments for monitoring turbidity, nitrate, and phosphate. These three constituents are particularly important in the biological and ecological production and health of stream systems, are often present in substantial quantity, and are of concern from an ecological and water-resources perspective in Illinois. Nitrate and phosphate are vital nutrients required to support aquatic floral and faunal growth, but can be problematic when present in large amounts. Excessive nutrients can cause eutrophication and subsequent water-column oxygen depletion during the decomposition of plant material and algae. In Illinois, most in-stream turbidity is composed of inorganic soil particulate matter, which can be present in amounts harmful to stream ecosystems by limiting light penetration and euphotic zone depth, transportation of hydrophobic organic compounds, and streambed deposition and sedimentation. The U.S. Geological Survey (USGS) Illinois Water Science Center (IL WSC), in cooperation with the Illinois Environmental Protection Agency (Illinois EPA), operated a suite of in-situ, continuously recording, water-quality instruments at the Illinois River at Florence, Illinois (USGS station number 05586300), during May 2012-October 2013. This continuous nutrient and sediment data record facilitates an improved understanding of annual, seasonal, and storm-event concentrations and loads. The use of continuous in-situ sensors and the associated development of surrogate models to estimate concentrations and loads of other parameters also has the potential to reduce sample collection and laboratory expenses. 


\section{Purpose and Scope}

The purpose of this report is to provide analyses of the following:

- Instrument performance and deployment issues including comparisons of similar data collected by multiple instruments (nitrate, sediment, and phosphate)

- Baseline, seasonal, and storm-event concentrations and loads of nitrogen, phosphorus, and suspended sediment, as determined from periodic samples and continuous data

- Evaluations of applicability of using turbidity data to determine suspended-sediment concentration (SSC) and loads

- Evaluations of applicability of using backscatter data from acoustic Doppler velocity meter (ADVM) instruments to determine SSC and loads

\section{Study Area}

The Illinois River Basin in Illinois, Wisconsin, and Indiana (fig. 1) is often cited as one of the primary contributing watersheds of nitrogen, phosphorus, and sediment to the Upper Mississippi River Basin and, subsequently, to the Gulf of Mexico (Alexander and others, 2008; Sprague and others, 2011; Heimann and others, 2011). The Illinois River Basin encompasses large urban areas, including the Chicago metropolitan area, and extensive agricultural areas including some of the most intensively farmed and productive row-crop corn and soybean acreage in the Nation. Modeling studies related to hypoxia in the Gulf of Mexico have identified subwatersheds in the Illinois River Basin as having some of the highest yields per square mile of nitrogen and phosphorus.

There is a rich historical record of streamflow (since 1938), suspended-sediment (since 1980), and water-quality (since 1974) data for the USGS monitoring station at Illinois River at Valley City, Ill. This location is a critical component of the Illinois EPA, USGS, U.S. Army Corps of Engineers, and other Federal and State agency monitoring programs because it represents the largest single-river outflow from Illinois and includes virtually the entire Chicago metropolitan area, plus approximately 18,500 square miles $\left(\mathrm{mi}^{2}\right)$ of intensively farmed agricultural land. A continuous data record provides information that will allow for a much better understanding and determination of baseline, seasonal, and storm-event loads of nutrients and sediment. Such information is required to assess the degree of success and the downstream effects of best-management practices, regulatory changes, and source reductions of nutrients and sediment in the Illinois River Basin, upstream of the Illinois River contribution to the Mississippi River.

Owing to the site's location in the watershed and historical significance, the USGS planned to install a suite of instruments at the Illinois River at Valley City station to monitor sediment and water-quality parameters on a continuous basis and to improve the density and quality of the data record at this location. The USGS streamgaging station at Valley City, Ill. (05586100), has been maintained in cooperation with multiple Federal and State partners during the many years of operation. The pending installation of continuous water-quality monitoring equipment and the scheduled reconstruction and slight relocation of the streamgaging station at the historical Valley City location prompted consideration of installation of the continuous water-quality monitoring equipment at the State Route 100 bridge near Florence, Ill.; approximately 5.4 miles (mi) downstream of the Valley City station. It was determined that the installation of the continuousmonitoring equipment at the Florence bridge was preferable because of superior protection from debris and ice, a larger working platform, better physical access, and the elimination of access and safety concerns from railroad traffic. A monitoring station-Illinois River at Florence, Ill. (05586300) — was established in May 2012.

There is minimal input to the Illinois River from tributary streams between the two monitoring stations. Blue Creek is the largest tributary in this reach to the Illinois River. Blue Creek drains a watershed of approximately $40 \mathrm{mi}^{2}$ to the west and enters the Illinois River approximately $2.2 \mathrm{mi}$ upstream from the Florence station. The Blue Creek watershed comprises 0.15 percent of the Illinois River at Florence drainage area. During the first year of data collection following the establishment of the Florence monitoring station, comparison samples were collected at both the Valley City and Florence stations and periodically from the mouth of Blue Creek, particularly during high-flow periods. These samples were analyzed for suspended sediment, nitrogen, and phosphorus concentration. The streamflow in Blue Creek also was estimated when samples were collected. It was determined through simple statistical comparisons (means, quartiles, ranges) of waterquality samples and discharge measurements at the Valley City, Ill., and Florence, Ill. locations, as well as samples and measurements from Blue Creek, that the stream-water quality at the two Illinois River station locations was not different and that the input (both water quality and water quantity) from Blue Creek did not significantly affect the water quality of the Illinois River as measured at the Florence monitoring station. 


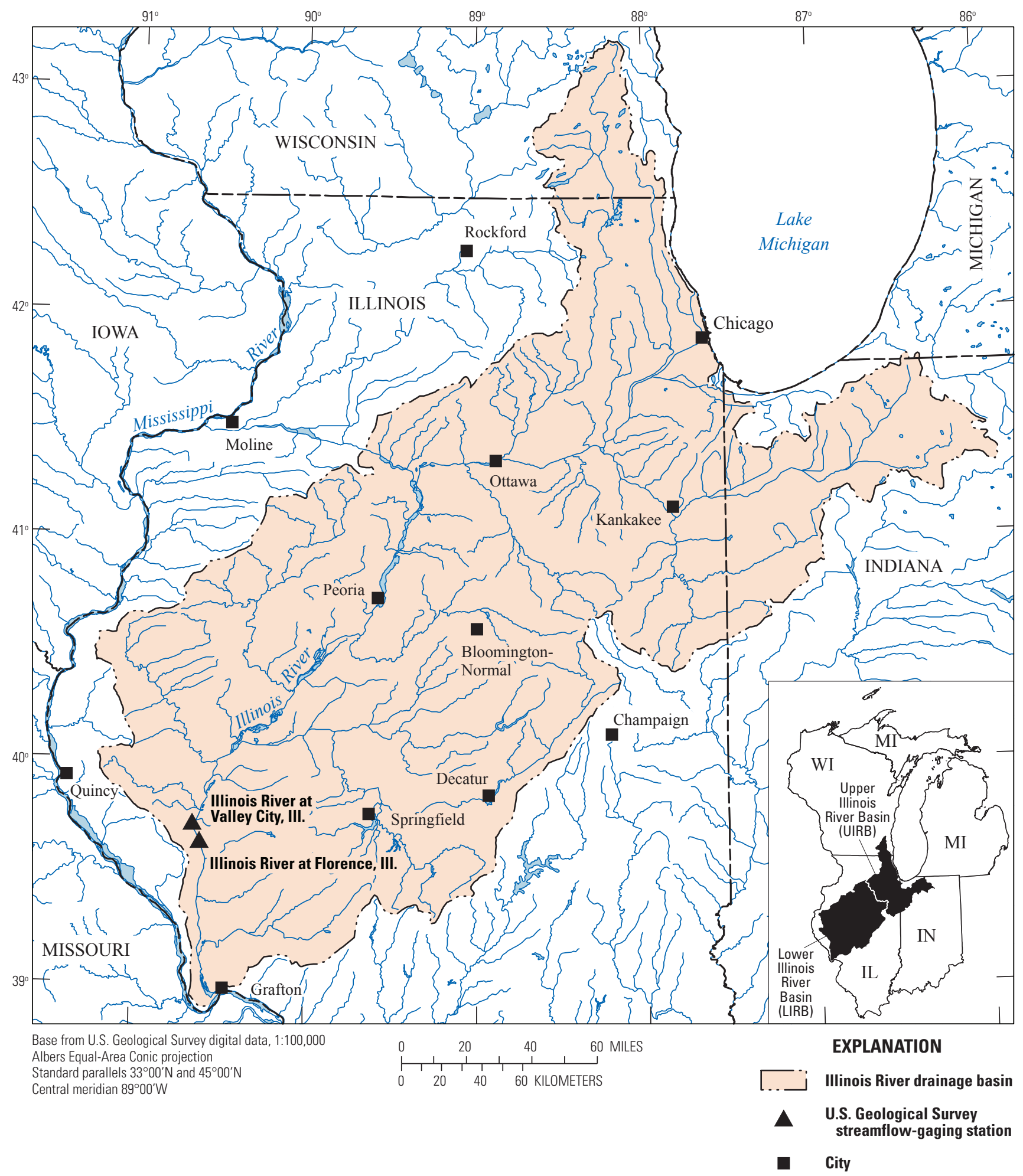

Figure 1. The Illinois River Basin and the location of the continuous-monitoring stations at Florence, Illinois (05586300), and Valley City, III. (05586100). 


\section{Methods}

\section{Suspended-Sediment Methods}

Three instruments were deployed to be used as a surrogate for SSC. Two of the instruments were turbidity sensors and the third was an acoustic device. One of the turbidity sensors used nephelometric principles, YSI 6136 turbidity probe (YSI Incorporated, 2014), and the other used opticalbackscatter (OBS) principles, SOLITAX turbidity probe (Hach Company, 2014). Both turbidity methods are commonly used to measure turbidity as a surrogate for computing SSC (Anderson, 2005; Gray and Gartner, 2006), but OBS principles are recommended where the majority of the suspended-sediment load (SSL) is transported above 2,000 milligrams per liter $(\mathrm{mg} / \mathrm{L})$ (Rasmussen and others, 2009). The nephelometric sensor upper range varies from 1,000 to 2,000 formazin nephelometric units (FNUs) (Rasmussen and others, 2009), and the maximum limit depends upon the particle types in suspension. The maximum recorded value was 1,260 FNU during the study period.

OBS sensors measure light scattering like the nephelometric sensors, except the light detector(s) is at a different angle (Rasmussen and others, 2009; U.S. Environmental Protection Agency, 1999). The units assigned by the USGS to the SOLITAX measurements are formazin backscatter ratio units (FBRU), and the manufacturer denotes an upper range of totalsuspended solids of 50,000 mg/L (Hach Company, 2014). As noted in the Hach information, it is an infrared duo scattered light technique for color-independent turbidity measurement in accordance with Deutsches Institut für Normung (DIN) EN 27027 / TS equivalent DIN 38414 (Hach Company, 2014). The YSI 6136 sensor conforms to the International Organization for Standardization (ISO) Method 7027 and American Society for Testing and Materials (ASTM) D7315 measurement standards (Rasmussen and others, 2009).

Acoustic technology is increasingly being used for velocity measurements, and similar to turbidity sensors, the potential for it to be used also as a surrogate for SSC would be an extraordinary benefit. A fixed-mount side-looking ADVM was installed for this purpose near the turbidity sensors. The ADVM was an Argonaut-SL with a 1,500 kilohertz (kHz) frequency (Sontek, 2014). Unlike turbidity that uses a single value near the instrument, the ADVM method uses values from multiple cells along the acoustic axis of the beam in the computation of a single value for use as a surrogate. For this method, the SSC is assumed to be constant along the acoustic axis of the beam. This method is relatively newer in testing than turbidity, and some of the earliest USGS applications and research were done by Topping and others $(2004,2006)$ and Rubin and others (2007).

Discrete SSC samples are collected across the entire range of stream conditions to relate to the surrogate values. Sampling and lab methods used for discrete SSC samples are outlined in the following reports: Field Methods for
Measurement of Fluvial Sediment (Edwards and Glysson, 1999) and Analysis of Fluvial Sediment by the Northeastern Region, Kentucky Science Center Sediment Lab (Sholar and Shreve, 1998). Suspended sediment daily loads using discrete samples were computed by the subdivided-day method (timedischarge weighted average) (Guy, 1970; Porterfield, 1972) using the Graphical Constituent Loading Analysis System (GCLAS) (Koltun and others, 2006).

For both turbidity and acoustic parameters, a relation between the predictor variable (for example, turbidity) and SSC (response variable) was done using an ordinary least squares (OLS) linear regression. With a linear regression, observed data are fit to a linear model and terms in the model are estimated (Helsel and Hirsch, 2002). The continuous surrogate and discrete sample data collection used for SSC was July 2012-June 2013 (appendixes 1, 2, and 3). One-hundred forty discrete SSC sample results were retrieved and analyzed during July 2012-June 2013 at the Illinois River at Florence (05586300) (125 samples) and the Illinois River at Valley City (05586100) (15 samples). Sample times from results at Valley City were adjusted for time of travel between the gage at Valley City and the gage at Florence ( $4.2 \mathrm{mi})$ using stream velocity data from Florence. All of the discrete samples at Valley City were depth integrated Equal Width Increment (EWI) samples (Method Code (MC) 10 or 15 in appendixes 1, 2, and 3). The discrete samples at Florence were EWI, Equal Discharge Increment (MC-20), Fixed Single Vertical (from box on bridge) (MC-920), Single Vertical (from boat near box on bridge) (MC-30), Grab (near instrument) (MC-70), or Point (near instrument) (MC-50). All discrete samples were included in the linear regression model building.

Given a linear regression model for estimating SSC and a continuous time series of acoustic data, a time series of SSC can be calculated. Then the SSL can be calculated by multiplying the $S S C$, flow $(Q)$, time step $\Delta t$, and conversion factor $(c)$.

$$
S S L=Q \times S S C \times \Delta t \times c
$$

The SSL for each time step can then be added for the time period of interest. Below is an example calculation of a conversion factor to calculate load in tons per day (short tons where 1 ton $=2,000$ pounds) when $S S C$ is in milligrams per liter and $Q$ is in cubic feet per second.

$$
\begin{aligned}
& c=\frac{86400 s}{d a y} \times \frac{28.32 L}{f t^{3}} \times \frac{l b}{453,592 m g} \times \frac{t o n}{2,000 l b}= \\
& 0.0027 \frac{s L \text { ton }}{d a y f t^{3} m g}
\end{aligned}
$$

The SSLs were then compared among the different methods used during this study. Also, the relative loads from previous years were compared with the loads during this study. 


\section{Phosphate}

Continuous (4- to 6-hour interval) phosphate data were collected using a WET Labs Cycle-PO4 (Cycle) in-situ phosphate analyzer. The Cycle analyzer is housed in a cylindrical plastic case measuring approximately $56 \times 18$ centimeters (cm) and weighing approximately 6.8 kilograms (kg) (fig. 2). An external non-rechargeable battery pack is typically used with the analyzer; however, following an initial data-collection period using the external battery pack, the Cycle analyzer used for this deployment was powered from the USGS streamgage power system. The standard battery packs are non-rechargeable and would need to be replaced several times a year at the sampling frequency used for this study. The Cycle analyzer used in this study was equipped from the manufacturer to provide RS-232 serial output. The instrument was modified by WET Labs, at USGS expense, to provide SDI-12 signal output for input into the gaging station data-communications system. The Cycle has 1 gigabyte (GB) of internal data storage. The analyzer has a nominal phosphate concentration detection range of $0-0.31 \mathrm{mg} / \mathrm{L}$, as $\mathrm{P}$, with a larger range up to $1.2 \mathrm{mg} / \mathrm{L}$, as $\mathrm{P}$, with potential variances beyond the instrument specifications of $\pm 0.002 \mathrm{mg} / \mathrm{L}$, as P (WET Labs, Inc., 2011).

Phosphorus is generally present in natural waters in dissolved, particulate, organic, and inorganic forms. Particulate matter that contains phosphorus can include living and dead fauna, phosphorus adsorbed to soil, and other precipitates. Dissolved phosphorus can be associated with either inorganic or organic compounds and is usually present in the oxidized phosphate form $\left(\mathrm{PO}_{4}\right)$. Inorganic phosphates include orthophosphate and polyphosphates (Hem, 1989, p. 127). Dissolved orthophosphate, also called soluble reactive phosphorus or bioavailable phosphorus, is the form most readily available for use by biological organisms. Most analytical determinations of dissolved phosphorus aim to reduce all phosphorus forms to orthophosphate species and express the resultant concentration in terms of elemental phosphorus equivalent.

The Cycle analyzer determines the concentration of phosphate in-situ using ascorbic-acid digestion and colorimetric analysis. To do so, the Cycle pumps a sample of ambient stream water through a 10 micrometer $(\mu \mathrm{m})$ particle filter and into a mixing chamber in the analyzer. A rinse of the analyzer tubing and components with ambient stream water is performed during this initial step prior to collection of the sample. An initial measurement of light transmittance through the sample is made prior to the addition of reagents and a period of mixing and chemical reaction. Phosphate ions $\left(\mathrm{H}_{2} \mathrm{PO}_{4}^{-}, \mathrm{HPO}_{4}{ }^{2-}, \mathrm{PO}_{4}^{3-}, \mathrm{Hem}, 1989\right.$, p. 127) in the sample react with a molybdate reagent to form a phosphomolybdate compound. This compound is then reduced to a molybdenum blue complex, and its colorimetric attributes are measured and compared to those of the initial ambient water sample. The instrument monitors the color of the solution during the reaction and records the final result once the reaction has completed. Another sample of stream water is then pumped through the analyzer to flush the instrument components prior to the next sample. Concentration of phosphate () in the sample is then calculated from a comparison of the transmittance of the native sample water and processed sample. A filter pore size of $0.45 \mu \mathrm{m}$ is commonly used in water-quality analyses to operationally differentiate between a total and dissolved water sample. The Cycle analyzer filters stream water through a particle filter larger than $0.45 \mu \mathrm{m}$. accordingly, concentrations of phosphate determined by the Cycle analyzer will be referred to as phosphate in this report.

The Cycle also can be programmed to initiate a spike of calibration solution into a sample to better define the algorithm used to calculate phosphate concentrations and to accommodate waters of differing matrixes and characteristics. The user is able to select the frequency of samples at which the spiking is performed. It was found that spiking every 3-6 samples was beneficial for data quality and consistency during deployment in the Illinois River.

Servicing and maintenance of the Cycle analyzer was typically performed on a monthly, or greater, frequency in coordination with the USGS National Water-Quality Assessment (NAWQA) sample collection at the site. During these field visits, discrete samples were collected from the Illinois River at the analyzer deployment location and depth using a stainless steel Kemmerer sampler and sent to the National Water-Quality Laboratory (NWQL) for analysis of dissolved orthophosphate. Laboratory analysis for dissolved orthophosphate also was part of the NAWQA program analysis suite from a sample collected as an EWI sample across the entire river cross section. NWQL samples were analyzed using NWQL Method I-2602-90 (Fishman, 1993). 
$\boldsymbol{A}$

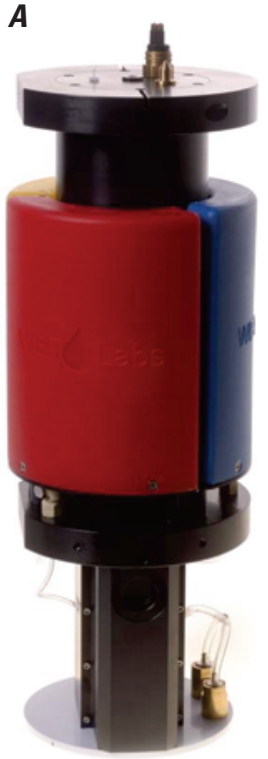

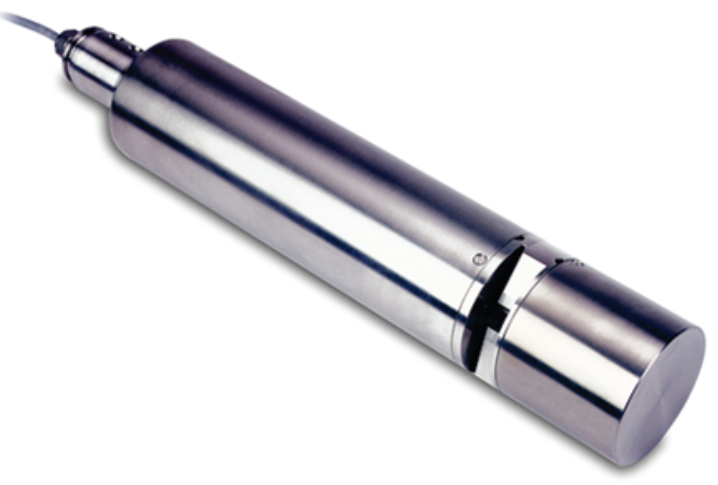

D

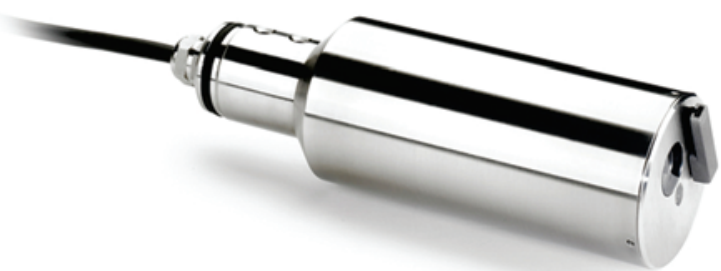

$c$

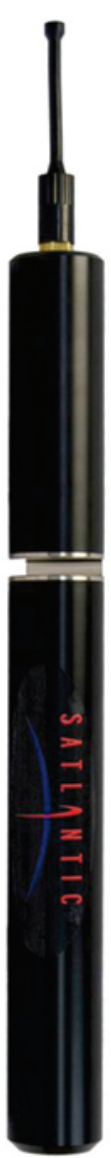

\section{$E$}

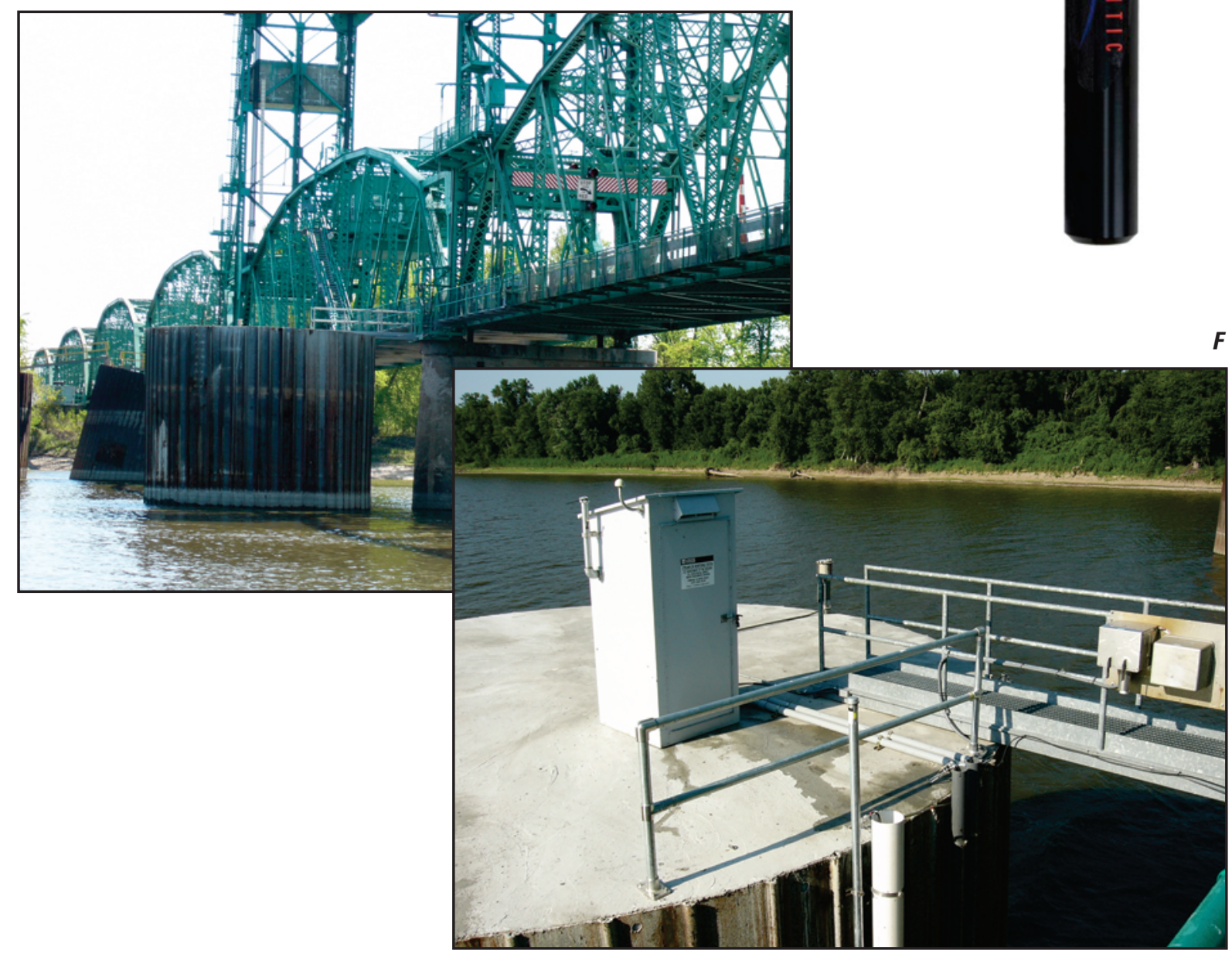

Figure 2. Images of $A$, WET Labs Cycle-P04 phosphate analyzer; $B$, Hach NITRATAX nitrate sensor; $C$, Satlantic SUNA nitrate sensor; $D$, Hach SOLITAX turbidity sensor; and $E-F$, Installation structure at Illinois River at Florence, Illinois (05586100). 


\section{Dissolved Nitrite Plus Nitrate}

Continuous (15-minute interval) dissolved nitrite plus nitrate nitrogen (hereafter referred to as nitrate) data were collected from May 24, 2012 to November 20, 2013, using two sensors. The sensors used were a Hach NITRATAX and a Satlantic SUNA (fig. 2). Both of these nitrate sensors determine nitrite plus nitrate, as $\mathrm{N}$, concentration via ultraviolet light-absorbance measurement. The NITRATAX sensor was deployed in a 4-inch (in.) diameter schedule 80 polyvinyl chloride (PVC) conduit mounted vertically to the pier-protection piling and alongside the Cycle $\mathrm{PO} 4$ analyzer. The SUNA sensor was deployed in an 8-in. diameter schedule $80 \mathrm{PVC}$ conduit mounted alongside the other sensors. The anti-fouling wiper for the SUNA sensor is mounted externally to the sensor housing and requires a larger diameter conduit and customfabricated mounting hardware. The NITRATAX sensor accommodates a user 1-, 2-, or 3-point calibration, whereas the SUNA sensor cannot be calibrated by the user with nitrate standard solutions. However, a clean deionized water solution can be used to re-zero the SUNA sensor readings.
While the two nitrate sensors differ in some specifications and operational details, they use similar physical and chemical principles for the determination of nitrate concentration. A brief summary of the measurement method is provided below and a detailed description of the measurement method and sensor designs and components can be found in Pellerin and others, 2013.

The nitrate ion absorbs light in the 200-250 nanometer (nm) wavelength range, and this absorbance can be measured by passing a beam of light within this wavelength through a small sample of ambient water. The transmittance of light passing through the sample is attenuated by nitrate in the sample and can be measured by a photometer. The light intensity measured by the receiving photometer is converted to output as a voltage signal. An algorithm is used to compute the associated concentration of nitrate from the voltage and remove effects from interferences and other constituents. The NITRATAX and SUNA instruments differ somewhat in the specific components and wavelengths used. Table 1 provides physical and operational characteristics of the Hach NITRATAX and Satlantic SUNA in-situ nitrate sensors.

Table 1. Physical and operational characteristics of the Hach NITRATAX and Satlantic SUNA in-situ ultraviolet absorbance nitrate sensors (Hach Company, 2012; Pellerin and others, 2013; Satlantic Incorporated, 2011).

$\left[\mathrm{mg} / \mathrm{L}\right.$, milligrams per liter; $\mathrm{N}$, nitrate; \pm , plus or minus; $\mathrm{nm}$, nanometer; $\mathrm{mm}$, millimeter; in., inch; ${ }^{\circ} \mathrm{C}$, degrees Celsius; $\mathrm{m}$, meter; VDC, volts direct current]

\begin{tabular}{lll}
\hline \multicolumn{1}{c}{ Characteristic } & \multicolumn{1}{c}{ Hach NITRATAX } & \multicolumn{1}{c}{ Satlantic SUNA v1 } \\
\hline Lower detection limit & $0.1 \mathrm{mg} / \mathrm{L}$ as N & $0.007 \mathrm{mg} / \mathrm{L}$ as N \\
Upper detection limit & $50 \mathrm{mg} / \mathrm{L}$ as N & $28 \mathrm{mg} / \mathrm{L}$ as N \\
Accuracy & $\begin{array}{l}3 \text { percent of reading } \\
\pm 0.05 \mathrm{mg} / \mathrm{L} \text { as N }\end{array}$ & $\begin{array}{c}10 \text { percent of reading or } 0.06 \mathrm{mg} / \mathrm{L} \text { as } \mathrm{N}, \\
\text { whichever is greater }\end{array}$ \\
Precision & $0.1 \mathrm{mg} / \mathrm{L}$ as N & $0.028 \mathrm{mg} / \mathrm{L}$ as N \\
Light source wavelength & $220 \mathrm{~nm}$ (measurement) & $190-370 \mathrm{~nm}$ \\
& $350 \mathrm{~nm}$ (reference) & \\
Lamp type & Xenon & Deuterium \\
Reference beam & Yes & No \\
Measurement path length & $2 \mathrm{~mm}(0.08$ in. $)$ & 5 mm $(0.20$ in. $)$ \\
Wiper & Incorporated, silicon blade & External, nylon brush \\
Communication & Modbus, RS485, RS232, analog & USB, RS232, SDI-12, analog \\
Dimensions (length x diameter) & 13.1 in. by 3.0 in. & 21.0 in. by 2.3 in. \\
Power & 24 VDC & $8-18 \mathrm{VDC}$ \\
Operating temperature & $2-40{ }^{\circ} \mathrm{C}$ & $0-40{ }^{\circ} \mathrm{C}$ \\
Operating depth & $5 \mathrm{~m}$ maximum & $100 \mathrm{~m}$ maximum \\
External materials & Stainless steel & Acetal \\
\hline
\end{tabular}


Continuous Monitoring of Sediment and Nutrients in the Illinois River at Florence, Illinois, 2012-13

\section{Instrument Performance and Operational Considerations}

\section{Sediment}

Both turbidity sensors (Hach SOLITAX, and YSI 6136 as part of the multi-parameter YSI Sonde) had a complete record for the study period except for occasional and unexplained spikes in concentration and some periods of fouling. The stream conditions did reach the upper range (1,000 to 2,000 FNUs) of the YSI 6136 (Rasmussen and others, 2009), but the data never appeared to truncate; this should be a consideration at other sites where higher turbidity values are expected. The SOLITAX requires 24 volt power and needs a separate controller on site to then attach to an external datalogger, as opposed to the YSI 6136 that only requires 12 volt power and can be hooked directly to an external datalogger.

The ADVM had a complete record for the study period; in general, is not as susceptible to fouling; and does not require a wiper. However, at this site there appears to be some condition (environmental or anthropogenic) that has an effect on the backscatter data, but possibly does not affect the final velocity values. These effects are greatest for SSC values less than $155 \mathrm{mg} / \mathrm{L}$. The condition appears to be somewhat masked at $\mathrm{SSC}$ values above $155 \mathrm{mg} / \mathrm{L}$, and a linear regression model was made with these values as will be shown in the Concentrations section. An additional ADVM was added to this site in a less turbulent area, and provisional results indicate that this may have fixed the issue. Additional testing is ongoing to help ensure the problem is identified and fixed.

\section{Nitrate}

The NITRATAX sensor was deployed on May 24, 2012. The NITRATAX sensor provided reliable data for the majority of time it was deployed. The NITRATAX sensor was typically calibrated using deionized water as a zero nitrate standard and a 10.0 or $11.3 \mathrm{mg} / \mathrm{L}$ manufacturer-produced nitrate standard. The NITRATAX sensor generally read accurately at the zero standard and within 5 percent of the 10.0 or $11.3 \mathrm{mg} / \mathrm{L}$ standards. The NITRATAX sensor was recalibrated whenever the readings differed from the nitrate-standard values by more than $0.2 \mathrm{mg} / \mathrm{L}$ as $\mathrm{N}$.

The SUNA sensor was not deployed until November 1, 2012. Prior to deployment, the sensor was sent to the manufacturer for incorporation of a power cable in order to use power provided by the streamgaging station system in preference to the battery pack. Following several months of data collection, the SUNA was pulled from the deployment because of inconsistent and unreliable data values. It was determined that the flash tube (emission light source) had broken (possibly owing to cold temperatures), and the sensor was sent to the manufacturer for repair. The sensor was redeployed following repair, and the SUNA sensor provided data for most of the remaining deployment period. However, measurements by the SUNA were subject to signal interference from sediment and particulates in the water during high-flow and high turbidity events, resulting in some loss of data. The SUNA V1 has a 10 millimeters ( $\mathrm{mm}$ ) path length, which makes it more susceptible to interference from turbidity and particulate matter.

The SUNA provided a consistent data record after the deployment in November 2012. Nitrate concentrations from the SUNA sensor were within the manufacturer specifications when compared to laboratory analyses, but were typically less than nitrate concentrations reported by the NITRATAX sensor. This report will focus primarily on the continuous data record provided from the NITRATAX sensor because of the longer and more consistent period of data record provided by the NITRATAX sensor.

There were two short periods when the NITRATAX sensor failed to provide data: February 9-13, 2013 and May 27-29, 2013. During the February period, ambient water temperatures dropped below 2 degrees Celsius $\left({ }^{\circ} \mathrm{C}\right)$, which is the lower operating temperature specification for the NITRATAX. At the time of failure, a $5 \mathrm{~mm}$ measurement path length sensor was deployed. The $5 \mathrm{~mm}$ sensor was pulled from the site and a $2 \mathrm{~mm}$ path length version sensor was installed in its place. Although both sensor versions have a minimum operating temperature specification of $2{ }^{\circ} \mathrm{C}$, the physical configuration of the sensor and the outer housing are different between the two versions. When the $5 \mathrm{~mm}$ sensor was pulled from the installation, it was noted by the field technician that part of the outer housing was loose. Subsequent manufacturer service indicated damage had occurred to the flash bulb in the sensor, possibly caused by minor water leakage through seals that had contracted and screws that had become loose owing to contraction in the cold temperatures. The housing and configuration of the $2 \mathrm{~mm}$ version of the sensor has proven to be a more robust design, which maintains integrity during cold temperatures.

The failure of the NITRATAX during the May 27-29, 2013, period is believed to have been owing to high in-stream turbidity. High levels of turbidity limit or prohibit the ultra-violet light beam from penetrating through the ambient water sample and reaching the receiving photometer. The NITRATAX sensors include a built-in reference beam to measure the potential interference from an ambient water sample and make adjustments to the final nitrate concentration value reported. However, high levels of turbidity, sediment, or colored dissolved organic matter (CDOM) can overwhelm the sensor's ability to measure light transmitted through the ambient water sample. The IL WSC conducted informal laboratory experiments using local streambed and terrestrial sediments to determine the range of SSC at which the NITRATAX sensors have problems providing reasonable readings of nitrate. From these experiments, the limiting concentrations were found to be around $6,000 \mathrm{mg} / \mathrm{L}$ suspended sediment for the $5 \mathrm{~mm}$ path length version of the NITRATAX and around $35,000 \mathrm{mg} / \mathrm{L}$ suspended sediment for the $2 \mathrm{~mm}$ path length version of the NITRATAX (fig. 3). 


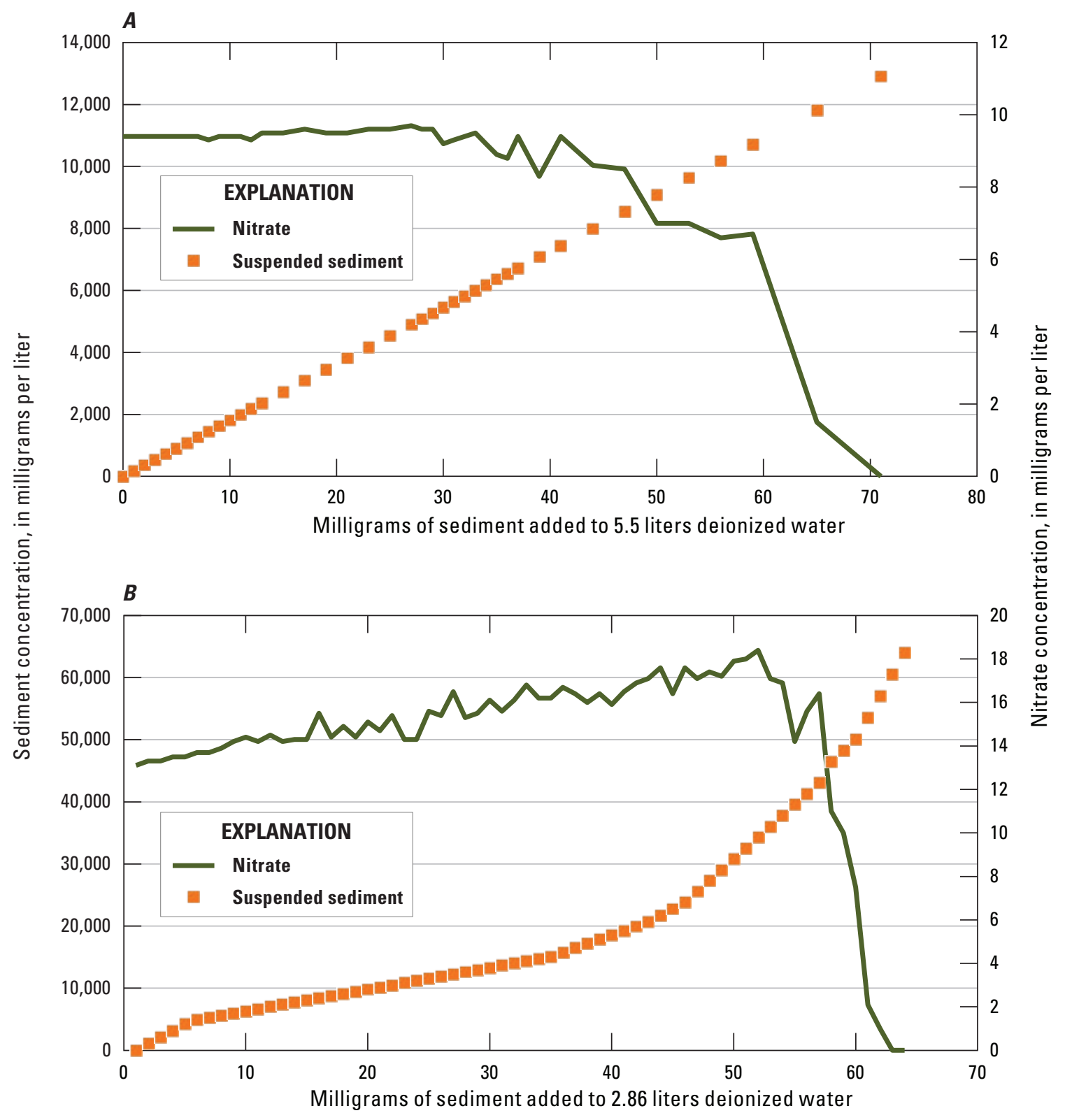

Figure 3. Results of the U.S. Geological Survey Illinois Water Science Center experiments to determine the effects of suspended-sediment concentrations on NITRATAX nitrate sensor readings. A, NITRATAX sc clear with 5 millimeter path length. $B$, NITRATAX sc plus with 2 millimeter path length. 


\section{Phosphate}

The Cycle analyzer was initially deployed on May 24, 2012, with an external battery pack and internal data logging. Reliable and consistent data collection from the analyzer was not initially obtained even though the analyzer was routinely cleansed of algal growth and sediment deposition during maintenance and service visits, and the internal filters were changed several times. The internal clock did not keep accurate time, and inaccurate data values were being determined. The analyzer was not providing useable phosphate concentration data. The instrument was pulled from deployment on August 3, 2012, for more extensive cleaning and evaluation back at the IL WSC. The analyzer was redeployed on September 6, 2012, with new filters, set to sample once every 4 hours, and to initiate a spiked sample with every environmental sample. By September 27, 2012, the analyzer's internal clock had drifted by more than 4 hours. However, the external data-collection platform (DCP) controls the Cycle analyzer sampling time and time-stamps the data stored in the DCP, so that accurate sample times were recorded in the data record. The analyzer was again removed from deployment on November 1, 2012, owing to continued inaccurate data collection. The Cycle analyzer was sent to the manufacturer during the winter months of 2012-13 for functional evaluation and for installation of a communications and power cable that would allow the analyzer to be integrated into the USGS streamgaging station power, data logging, and data-transmission systems. It was determined that the reagent and water pump was not functioning properly. The manufacturer also stated that there was possible air bubble interference in the optical chamber of the analyzer, which could have been caused by the weak pump or lack of water pressure at the analyzer intakes. WET Labs replaced the intake and reagent pump, and the Cycle analyzer was redeployed with at least 4 feet (ft) of head above the pump intakes to help purge air bubbles from the optical chamber. The Cycle was again deployed at the Florence station on April 25, 2013. The analyzer provided satisfactory phosphate concentration data from April 25 to November 20, 2013. At a 4-hour sampling frequency, the reagent cartridges lasted about 3.5 months. Occasional periods of missing data resulted when the reagent supply was exhausted more quickly than anticipated during the initial periods of deployment. Extensive cleaning and flushing of the instrument and flow-path components was performed every field visit. Sample measurements were made every 4 hours with a spike executed every six samples.

\section{Concentrations}

\section{Suspended Sediment}

One-hundred forty discrete SSC sample results were collected and analyzed during July 2012-June 2013 at the Illinois River at Florence (05586300) (125 samples) and the Illinois River at Valley City (05586100) (15 samples); they were available for linear regression model building with turbidity, streamflow, and acoustic parameters, as described in the Methods section. Times associated with samples collected at Valley City were adjusted to account for the time of travel between Valley City, Ill., and Florence, Ill., as discussed in the Methods section. The SSC values (response variable) were matched with the nearest-in-time predictor variable value (turbidity, streamflow, or acoustic parameter). The statistics for the data and models are discussed in the following sections.

\section{Turbidity and Suspended-Sediment Concentration Linear Regression Model}

Linear regression models for SSC as the response variable were built for the SOLITAX instrument (referenced as Turbidity FBRU or Turb $\mathrm{FBRU}_{\mathrm{FB}}$ ) and the YSI 6136 instrument (referenced as Turbidity FNU or Turb ${ }_{\mathrm{FNU}}$ ) (figs. 4, 5, and 6; tables 2 and 3; and appendixes 1 and 2). For comparative purposes, a linear regression model for SSC and streamflow was built (fig. 6, tables 2 and 3, and appendix 3). Both turbidity models have coefficients of determination $\left(\mathrm{R}^{2}\right)$ of approximately 0.9 , which means that the turbidity measurements explain $90 \%$ of the variation of the logs of the SSC data. The Root Mean Square Error of both models are both between 0.12 and 0.15 . The slopes of the turbidity models are also similar-1.080 and 1.122. Full model statistics are included in appendix 1 and 2. The SSC values used in the linear models ranged from 15 to $1,970 \mathrm{mg} / \mathrm{L}$, which encompasses the ranges of conditions that occur on an annual basis at the site. The stream conditions did reach the upper range (1,000 to 2,000 FNUs) of the YSI 6136 (Rasmussen and others, 2009), but the data never appeared to truncate; this should be a consideration at other sites where higher turbidity values are expected. 


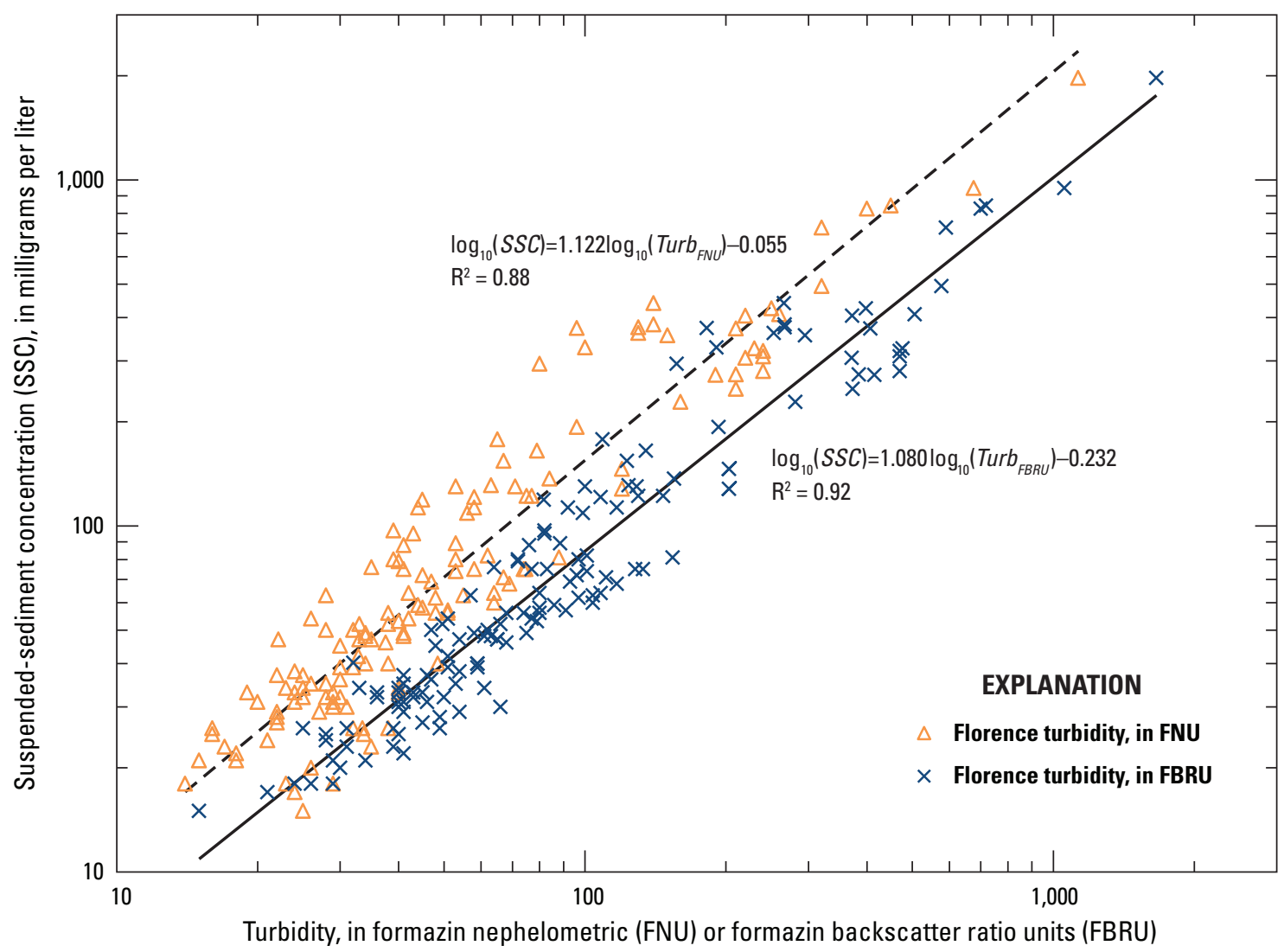

Figure 4. Suspended-sediment concentration and turbidity linear regression models using turbidity data from the Illinois River at Florence, Illinois (05586300), and samples collected at the Illinois River at Florence, III. (05586300) (125 samples) and the Illinois River at Valley City, III. (05586100) (15 samples). [R², coefficient of determination] 

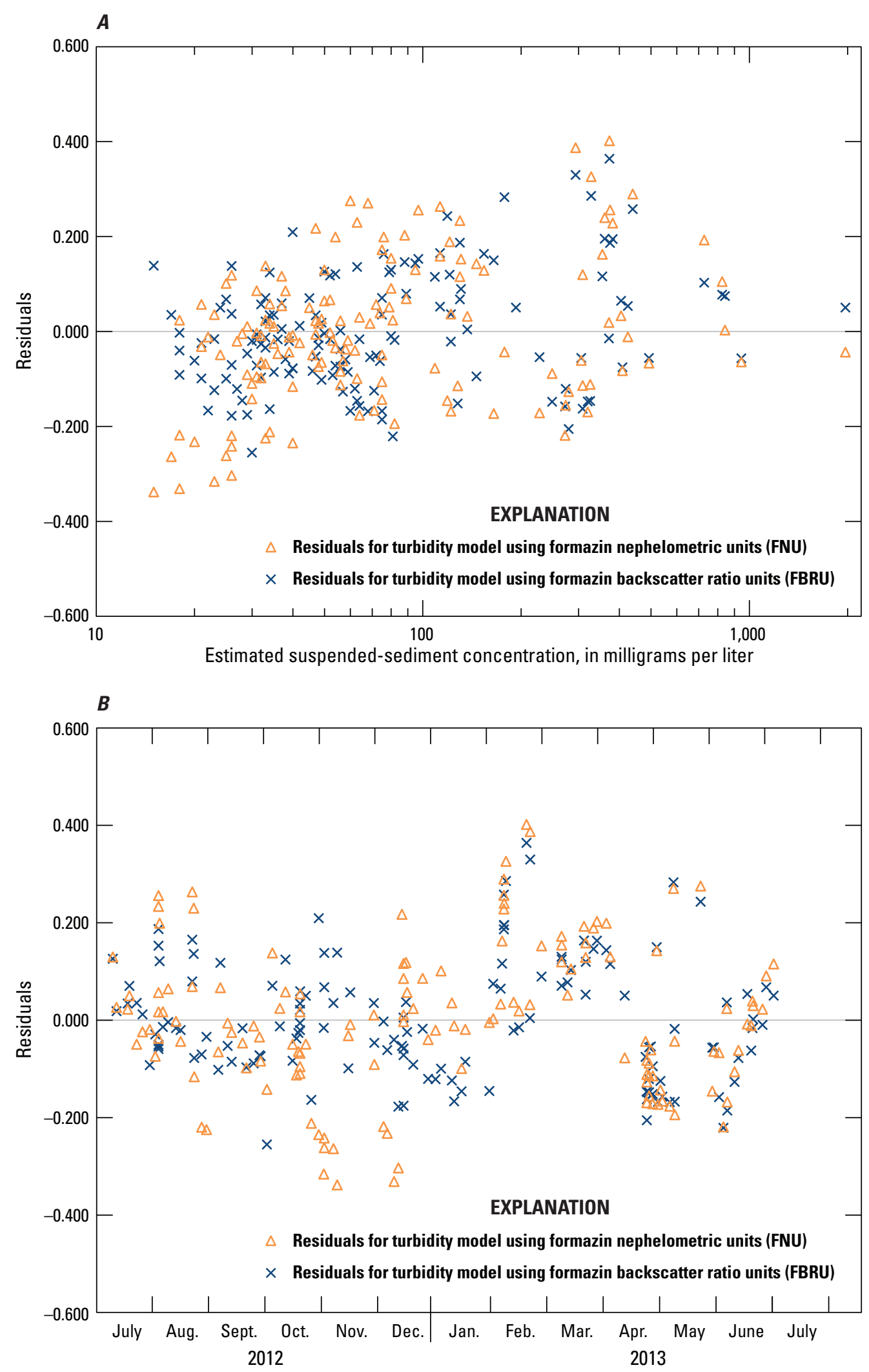

Figure 5. Relations between the regression residuals, estimated suspended-sediment concentrations, and dates for the linear regression models shown in figure 4. $A$, Residuals and estimated suspendedsediment concentration. $B$, Residuals and date. 


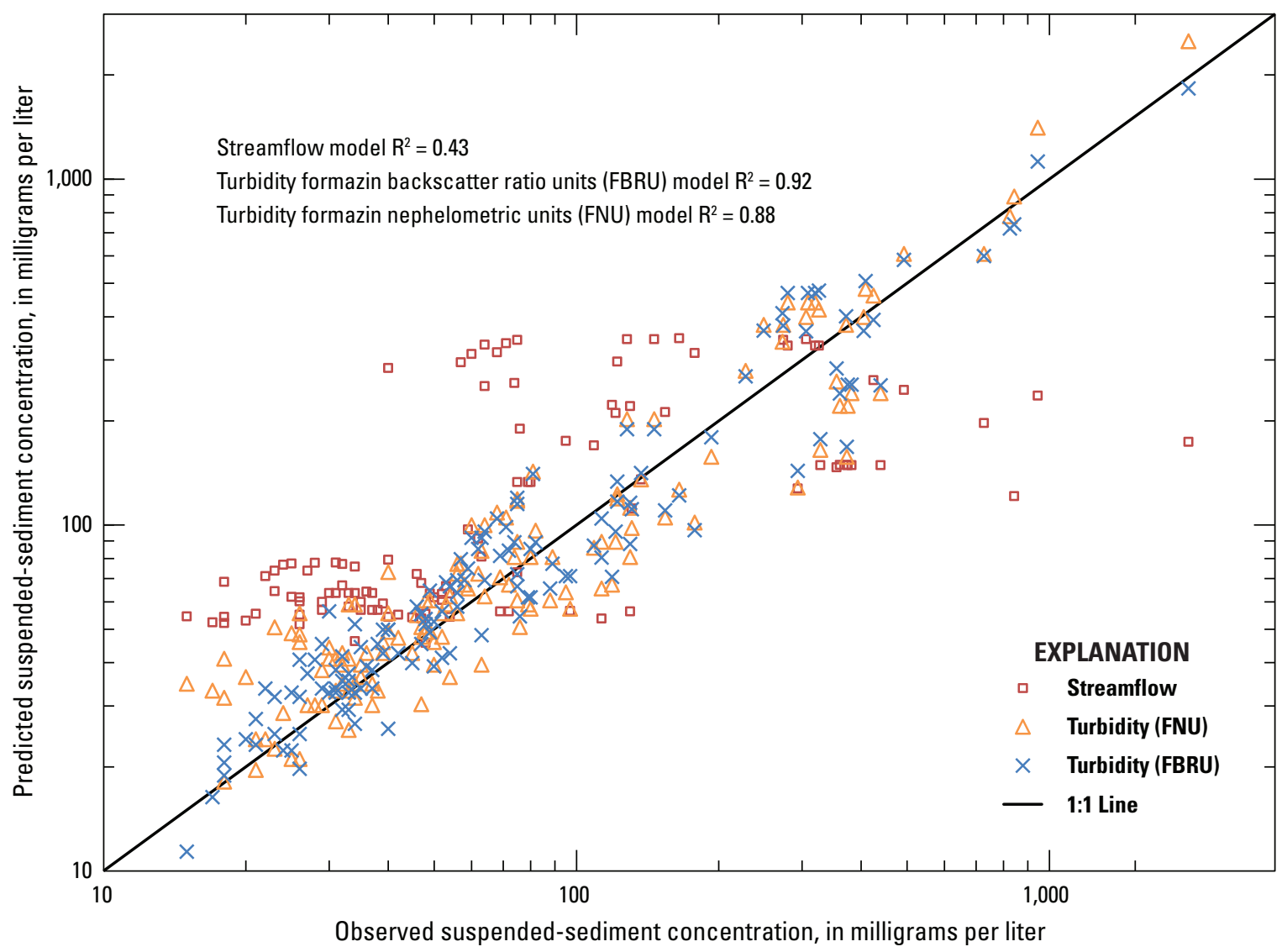

Figure 6. Predicted and observed suspended-sediment concentration using turbidity and streamflow re-transformed linear regression models presented in table 4 using turbidity data from the Illinois River at Florence, Illinois (05586300); samples collected at the Illinois River at Florence, III. (05586300) (125 samples), and the Illinois River at Valley City, III. (05586100) (15 samples); and streamflow data reported at the Illinois River at Valley City, III. (05586100). [R², coefficient of determination] 
Table 2. Predictor and response variable statistics for suspended-sediment concentration, turbidity, and streamflow linear regression models.

[FBRU, formazin backscatter ratio units; $\log _{10}$, base-10 logarithmic transform; Turb ${ }_{\mathrm{FBRU}}$, Solitax turbidity in formazin backscatter ratio units; SSC, suspended-sediment concentration; mg/L, milligrams per liter; FNU, formazin nephelometric units; Turb $b_{\mathrm{FNU}}$, YSI 6136 turbidity in formazin nephelometric units; $\mathrm{ft}^{3} / \mathrm{s}$, cubic feet per second]

\begin{tabular}{|c|c|c|c|c|}
\hline & \multicolumn{2}{|c|}{ Predictor variable } & \multicolumn{2}{|c|}{ Response variable } \\
\hline & Turbidity (FBRU) & $\log _{10}\left(\right.$Turb$\left._{\text {FвRu }}\right)$ & SSC (mg/L) & $\log _{10}(S S C)$ \\
\hline Minimum & 15 & 1.176 & 15 & 1.176 \\
\hline 1st Quartile & 47 & 1.667 & 34 & 1.532 \\
\hline Median & 77 & 1.884 & 59 & 1.767 \\
\hline Mean & 148 & 1.953 & 140 & 1.876 \\
\hline 3rd Quartile & 132 & 2.119 & 130 & 2.114 \\
\hline \multirow[t]{2}{*}{ Maximum } & 1,660 & 3.220 & 1,970 & 3.295 \\
\hline & Turbidity (FNU) & $\log _{10}\left(\right.$ Turb $\left._{\mathrm{FNu}}\right)$ & SSC (mg/L) & $\log _{10}(S S C)$ \\
\hline Minimum & 14 & 1.146 & 15 & 1.176 \\
\hline 1st Quartile & 29 & 1.462 & 34 & 1.532 \\
\hline Median & 41 & 1.613 & 59 & 1.767 \\
\hline Mean & 85 & 1.720 & 140 & 1.876 \\
\hline 3rd Quartile & 75 & 1.874 & 130 & 2.114 \\
\hline \multirow[t]{2}{*}{ Maximum } & 1,130 & 3.053 & 1,970 & 3.295 \\
\hline & Streamflow $\left(\mathrm{ft}^{3} / \mathrm{s}\right)$ & $\log _{10}($ Streamflow $)$ & SSC (mg/L) & $\log _{10}(S S C)$ \\
\hline Minimum & 3,370 & 3.528 & 15 & 1.176 \\
\hline 1st Quartile & 5,345 & 3.728 & 33 & 1.519 \\
\hline Median & 8,190 & 3.913 & 54 & 1.732 \\
\hline Mean & 28,890 & 4.154 & 139 & 1.852 \\
\hline 3rd Quartile & 40,950 & 4.612 & 129 & 2.111 \\
\hline Maximum & 112,000 & 5.049 & 1,970 & 3.295 \\
\hline
\end{tabular}

Table 3. Suspended-sediment concentration, turbidity, and streamflow linear regression models and coefficient of determinations using turbidity data from the Illinois River at Florence (05586300), and samples collected at the Illinois River at Florence (05586300) (125 samples) and the Illinois River at Valley City (05586100) (15 samples)

[ $\log _{10}$, base-10 logarithmic transform; SSC, suspended-sediment concentration; Turb ${ }_{\mathrm{FBRU}}$, Solitax turbidity in formazin backscatter ratio units; Turb $\mathrm{FNU}_{\text {, YSI }} 6136$ turbidity in formazin nephelometric units]

\begin{tabular}{lcc}
\hline \multicolumn{1}{c}{ Linear regression model } & $\begin{array}{c}\text { Coefficient of } \\
\text { determination }\left(\mathbf{R}^{2}\right)\end{array}$ & $\begin{array}{c}\text { Root Mean Square Error } \\
\text { (RMSE) }\end{array}$ \\
\hline $\log _{10}(\mathrm{SSC})=1.080 \log _{10}\left(\mathrm{Turb}_{\mathrm{FBRU}}\right)-0.232$ & 0.92 & 0.122 \\
$\log _{10}(\mathrm{SSC})=1.122 \log _{10}\left(\mathrm{Turb}_{\mathrm{FNU}}\right)-0.055$ & 0.88 & 0.151 \\
$\log _{10}(\mathrm{SSC})=0.578 \log _{10}($ Streamflow $)-0.551$ & 0.43 & 0.341 \\
\hline
\end{tabular}


The residuals of each turbidity model are shown in figure 5. A residual is the difference between the observed and estimated response variable. To meet the linear model assumptions, the residuals should have a constant variance (known as homoscedasticity), and this is the case for both models shown in figure $5 \mathrm{~A}$. Plotting the residuals versus time (fig. $5 \mathrm{~B}$ ) also can help reveal a trend in error, violating the linear model assumption of independence owing to one of the following or some combination of them (Helsel and Hirsch, 2002): seasonality, a long-term trend, dependence on some other serially correlated variable not used in the model, or serial dependence of residuals. Neither of the models shows a trend in time; therefore, the assumption independence is met.

Re-transformed linear regression models for SSC, turbidity, and streamflow are presented in table 4 . The predicted mean of the variable may be biased and needs to be multiplied by a non-parametric smearing bias correction factor (BCF) (Duan, 1983; Helsel and Hirsch, 2002) (table 4) because SSC was transformed for the regression model building. These equations can then be used to predict SSC and plot with observed SSC around a line of perfect agreement (fig. 6).

A time series of predicted SSC using the FBRU turbidity model is presented in figure 7 , along with the 90 -percent prediction intervals, which represent the range in which the predicted response will lie (Helsel and Hirsch, 2002). The streamflow time series also is plotted, which gives evidence of
Table 4. Suspended-sediment concentration, turbidity, and streamflow re-transformed linear regression models and non-parametric smearing bias correction factor using turbidity data from the Illinois River at Florence (05586300), and samples collected at the Illinois River at Florence (05586300) (125 samples) and the Illinois River at Valley City (05586100) (15 samples).

[BCF, non-parametric smearing bias correction factor; SSC, suspendedsediment concentration; TurbFBRU, Solitax turbidity in formazin backscatter ratio units; TurbFNU, YSI 6136 turbidity in formazin nephelometric units]

\begin{tabular}{ll}
\hline \multicolumn{1}{c}{ Linear regression model } & BCF \\
\hline$S S C=0.586$ Turb $_{F B R U}^{1.080} \times B C F$ & 1.04 \\
$S S C=0.881$ Turb $_{F N U^{1.122}} \times B C F$ & 1.06 \\
$S S C=0.281$ Streamflow $^{0.578} \times B C F$ & 1.48 \\
\hline
\end{tabular}

why simultaneous streamflow is a poor surrogate of SSC. The peak of the sediment is always occurring before the peak of the streamflow, which is not unusual in many natural streams. Lastly, the SSC samples and GCLAS estimated time series SSC are plotted. The GCLAS method starts with the SSC samples and then estimated values can be added manually by the use of a transport curve or by the use of time-series data, like turbidity. The resulting suspended-sediment loadings for each method will be compared in the Loadings section.

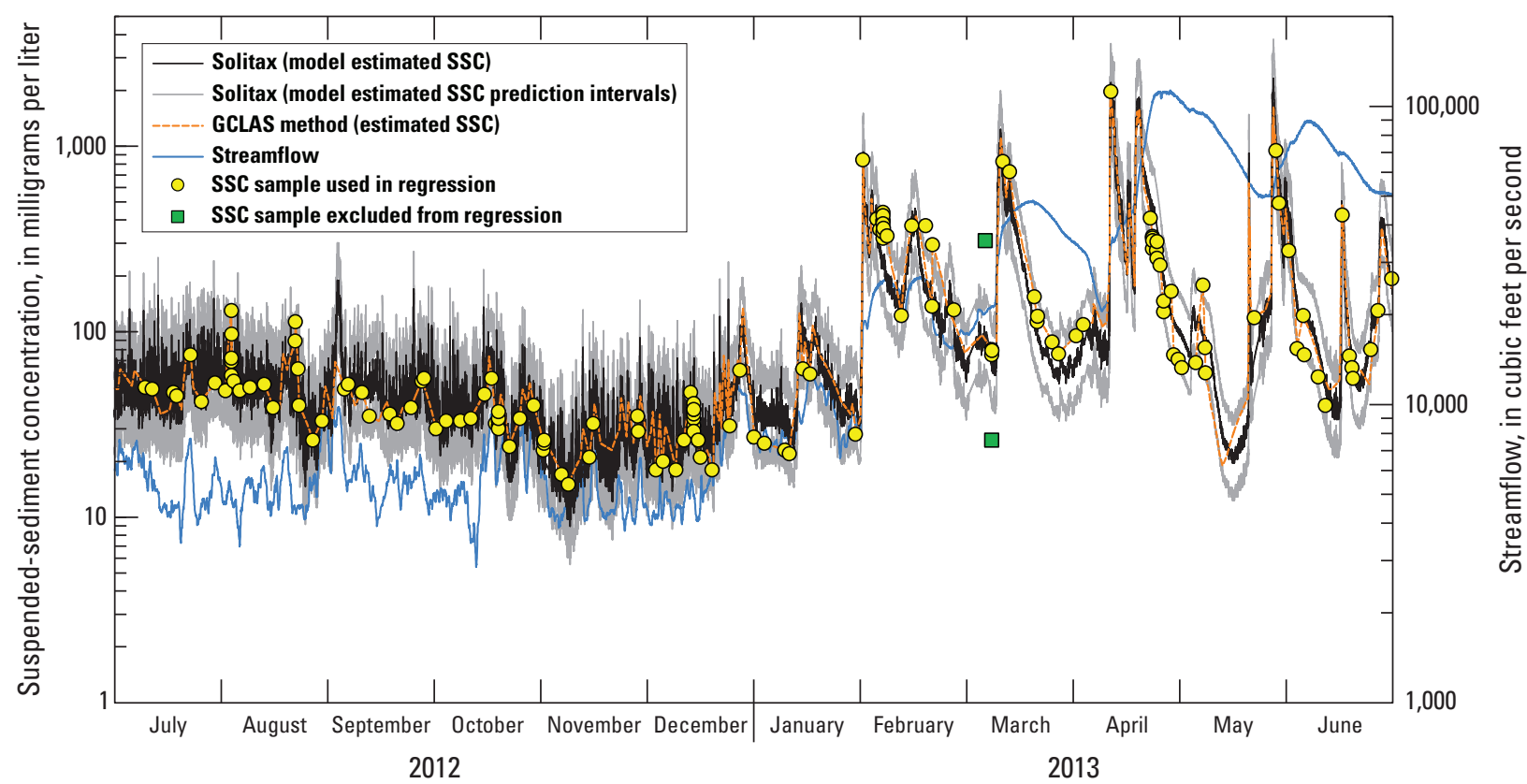

Figure 7. Time series streamflow and suspended-sediment concentration (SSC) for samples, modeled SSC (estimated) for SOLITAX, and Graphical Constituent Loading Analysis System (GCLAS) method. The results use turbidity data from the Illinois River at Florence, Illinois (05586300), and samples collected at the Illinois River at Florence, III. (05586300) (125 samples), and the Illinois River at Valley City, III. (05586100) (15 samples), and streamflow data reported at the Illinois River at Valley City, III. (05586100). 


\section{Acoustic Backscatter and Suspended-Sediment Concentration Regression Model}

As discussed in the Instrument Performance and Operational Considerations section, there appears to be some condition (environmental or anthropogenic) that affects the computed acoustic parameters used as a surrogate for SSC, and this problem is being further evaluated. The condition appears to be somewhat masked at SSC values above $155 \mathrm{mg} / \mathrm{L}$; a linear regression model was made with these values, and the predicted and observed values are presented in figure 8. Only the $\mathrm{R}^{2}$ for this model is given, and the model is not used to calculate a time-series dataset, because these issues are still being worked out. An additional ADVM was added to this site in a less turbulent area, and provisional results indicate that this may have fixed the issue. As additional concurrent acoustic and SSC data are collected at this site, it will be determined whether the data presented in this report can be used for SSC values greater than $155 \mathrm{mg} / \mathrm{L}$.

\section{Nitrate}

Nitrogen occurs in natural waters as the anions nitrite $\left(\mathrm{NO}^{-}\right)$and nitrate $\left(\mathrm{NO}^{-}\right)$, as the cation ammonium $\left(\mathrm{NH}^{+}\right)$, and in various transitional forms as well as incorporated into organic solutes. Ammonium ions are often adsorbed to mineral surfaces, while nitrate is soluble and stable in most natural waters. The nitrite and organic forms of nitrogen are generally considered to be intermediate forms of nitrogen, indicative of organic or wastewater contribution, and not stable in aerated water (Hem, 1985).

The in-situ NITRATAX and SUNA nitrate sensors were designed to provide concentration of nitrite plus nitrate nitrogen, as N. From June 1, 2012 to October 30, 2013, nitrate concentration was measured approximately 49,600 times by the in-situ nitrate sensors. These measurements consisted of readings every 15 minutes throughout this period. Water samples were collected at the sensor locations during maintenance and calibration visits and sent to the USGS NWQL to be analyzed for nitrite plus nitrate, as N. During the monitoring period, 20 discrete samples were analyzed by the NWQL. Table 5 presents the summary statistics of the NITRATAX

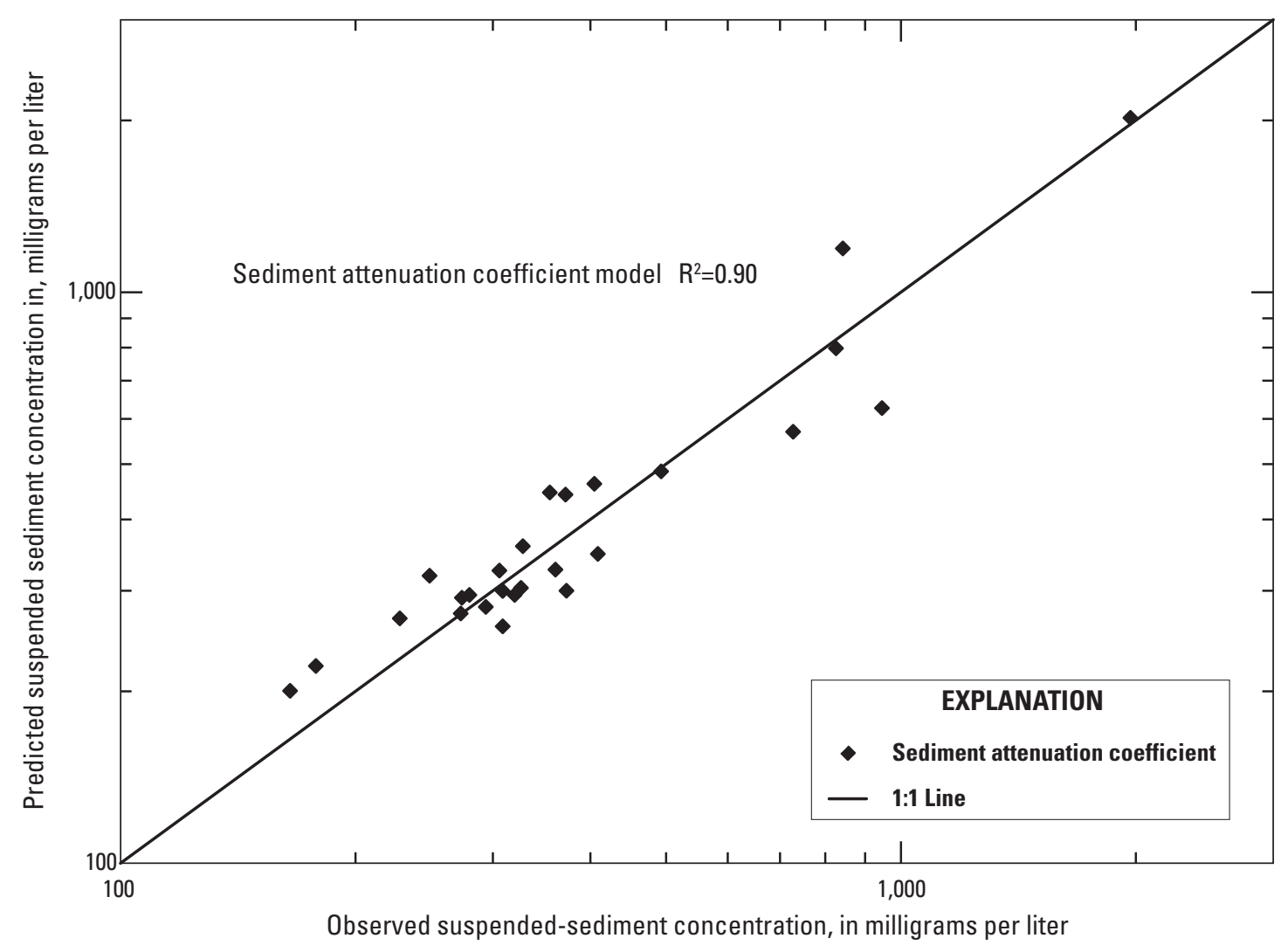

Figure 8. Observed and predicted suspended-sediment concentration using a linear regression model with an acoustic parameter, the sediment attenuation coefficient, using acoustic data from an ADVM in the Illinois River at Florence, Illinois (05586300), and samples collected at the Illinois River at Florence, III. (05586300) (23 samples), and the Illinois River at Valley City, III. (05586100) (3 samples). 
in-situ sensor and laboratory nitrate concentrations. The data record from the NITRATAX sensor is used as the primary data for analysis and discussion in this report because it is a more comprehensive and complete dataset than the dataset from the SUNA sensor. The continuous nitrate dataset includes flow periods and river conditions that were not represented by discrete samples sent to the laboratory, specifically periods of high and low streamflow.

Figure 9 presents a graph of continuous in-situ nitrate concentrations from the NITRATAX sensor, laboratory concentrations, and the relative percent difference between concurrent in-situ and laboratory samples. The continuous nitrate concentrations generally agreed well with laboratory concentrations, and relative percent differences between the two data values were always less than 5 percent. The manufacturer specifications for the NITRATAX sensor accuracy is 3 percent of the measured concentration plus or minus $0.5 \mathrm{mg} / \mathrm{L}$. The relative percent difference in concentrations was greater than the manufacturer's accuracy specifications in only two instances. One of these instances was during a high-flow event in February 2013, and the other instance was in May 2013 when the field technician noted that several of the optically based sensors were affected by high turbidity.
Table 5. Summary statistics for nitrite plus nitrate nitrogen, as N, measured by the NITRATAX in-situ sensor and point samples analyzed by the U.S. Geological Survey National Water-Quality Laboratory (NWOL) from the Illinois River at Florence, Illinois (05586300), 2012-13.

[Concentrations in milligrams per liter; see figure 9 for graphical comparison]

\begin{tabular}{lcc}
\hline & NITRATAX $^{1}$ & NWOL \\
\hline Mean & 3.58 & 4.09 \\
Median & 2.93 & 4.68 \\
Standard deviation & 2.13 & 2.03 \\
Sample variance & 4.54 & 4.11 \\
Range & 9.87 & 5.98 \\
Minimum & 0.88 & 1.23 \\
Maximum & 10.75 & 7.21 \\
Count & 12,253 & 22 \\
\hline
\end{tabular}

${ }^{1}$ Statistics based on 60-minute data values.

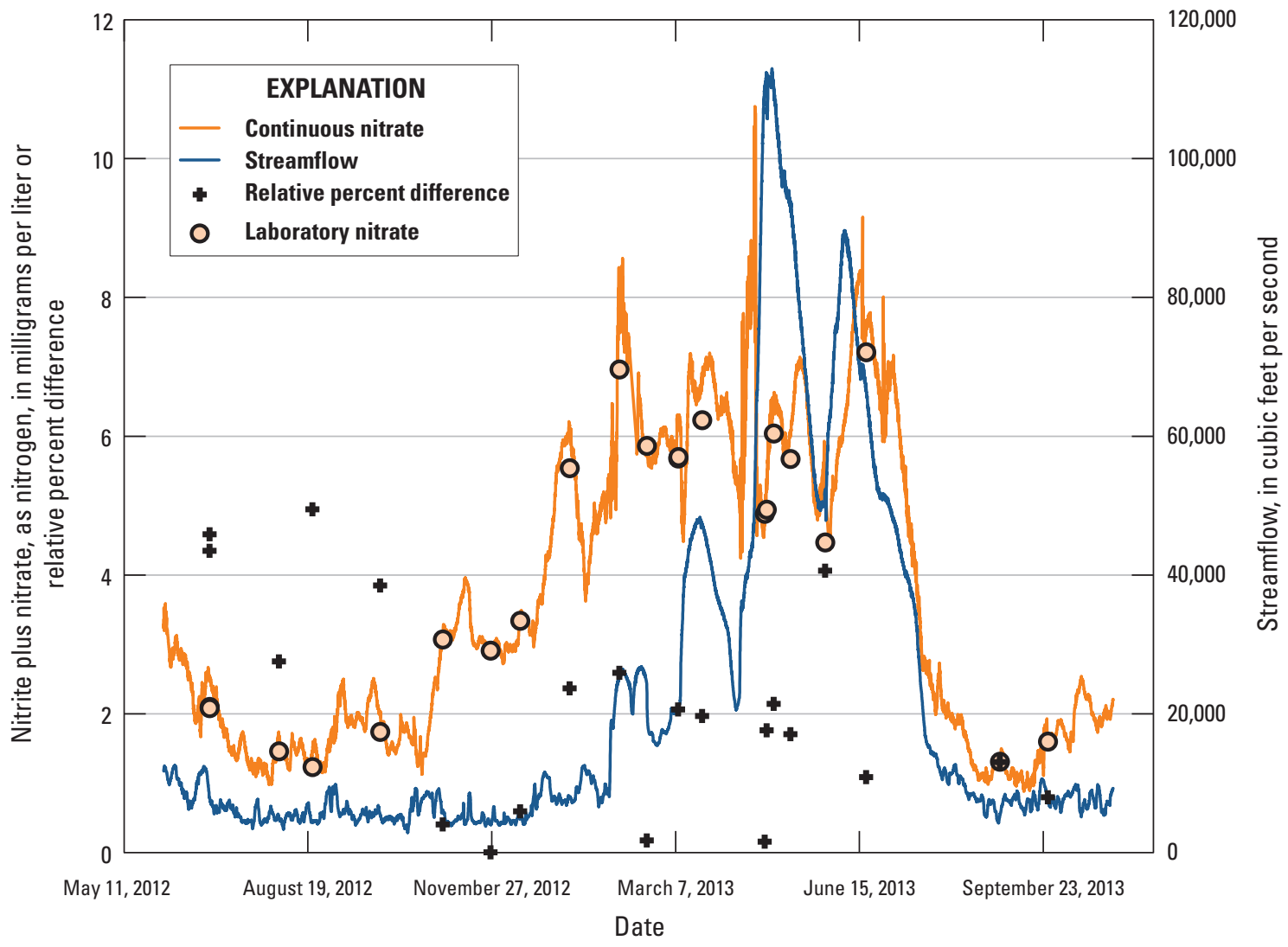

Figure 9. Concentrations of nitrite plus nitrate nitrogen as determined by the NITRATAX sensor and samples analyzed at the U.S. Geological Survey National Water Quality Laboratory, relative percent differences among concentrations, and streamflow for the period June 1, 2012-0ctober 30, 2013, at the Illinois River at Florence, Illinois (05586300). 
The largest relative percent difference values occurred when nitrate concentrations were at or below $2 \mathrm{mg} / \mathrm{L}$. The highest relative percent difference (4.94) was associated with concurrent in-situ and laboratory nitrate concentrations of 1.2 and $1.5 \mathrm{mg} / \mathrm{L}$. At low concentrations, small discrepancies between values can result in larger relative percent difference values, although the actual difference in concentration is small.

\section{Data Correspondence for Nitrate Sensors}

This continuous-monitoring effort presented the opportunity to deploy a Hach NITRATAX and Satlantic SUNA in-situ nitrate sensors side-by-side for a practical evaluation of suitability, reliability, and comparability in a large-river, multiple land-use watershed. Some issues and considerations regarding the physical deployment of each of the sensors were discussed previously.

Concentrations reported by the two sensors were typically within 10 percent of each other (fig.10); however, there were some periods when the two instruments measured substantially different concentrations: early January 2013, the second half of June 2013, and during October 2013. Concentrations reported by the NITRATAX were typically higher than concentrations reported by the SUNA (fig. 11), but there were exceptions to this generalization. At the lower concentrations (1.0 to around $2.7 \mathrm{mg} / \mathrm{L})$, the SUNA generally reported concentrations from $0.1-0.3 \mathrm{mg} / \mathrm{L}$ higher than the NITRATAX. For concentrations higher than about $3.3 \mathrm{mg} / \mathrm{L}$, the NITRATAX typically reported higher concentrations than the SUNA. For concentrations above $4.0 \mathrm{mg} / \mathrm{L}$, the NITRATAX concentrations were typically around $0.8 \mathrm{mg} / \mathrm{L}$ higher than concentrations reported by the SUNA. The January 2013 and June 2013 periods mentioned earlier are evident in figures 10 and 11 and show that the NITRATAX readings were substantially higher than the SUNA readings during these periods when concentrations ranged from 5.0 to $6.0 \mathrm{mg} / \mathrm{L}$. Other than the period of lower concentrations in fall 2013, the concentrations reported by the SUNA were higher than those reported by the NITRATAX only during a high-flow event in early February 2013, when in-stream concentrations were elevated and measured around 7.0 to $8.0 \mathrm{mg} / \mathrm{L}$.

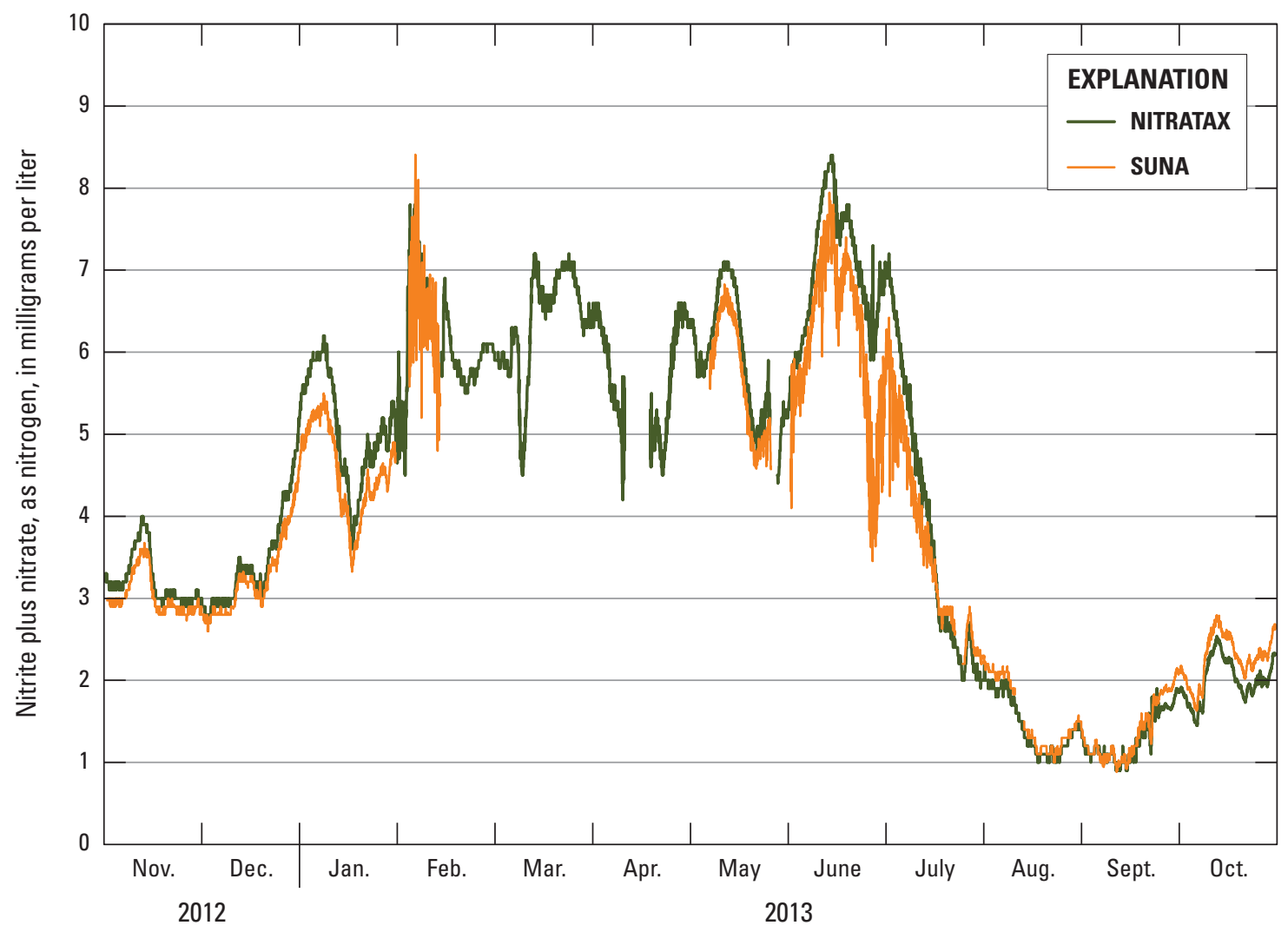

Figure 10. Continuous nitrate data from the NITRATAX and SUNA nitrate sensors at the Illinois River at Florence, Illinois (05586300), October 2012-0ctober 2013. 


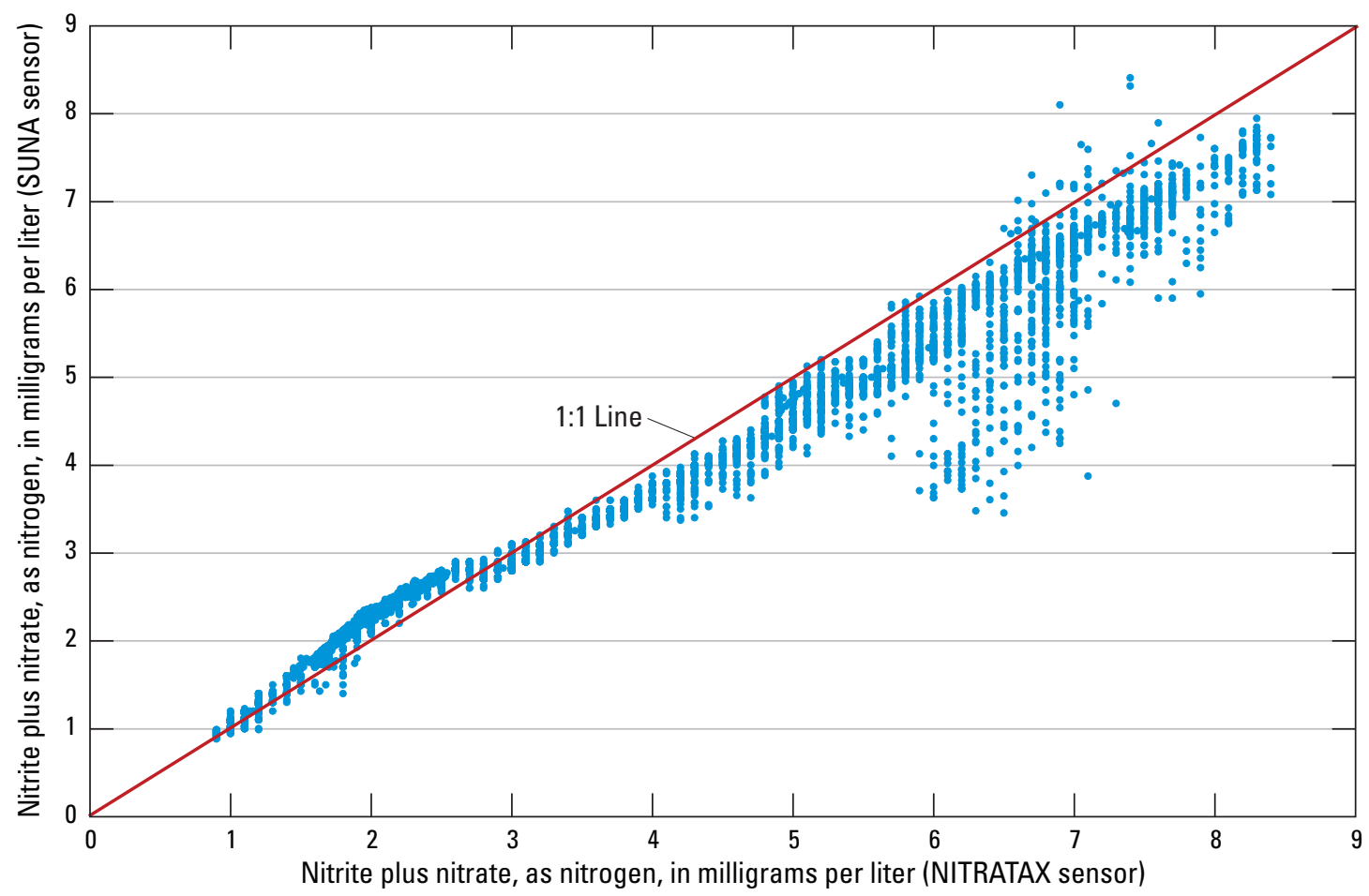

Figure 11. Comparison of continuous nitrate data collected by the NITRATAX and SUNA nitrate sensors at the Illinois River at Florence, Illinois (06686300), October 2012-October 2013.

The NITRATAX sensor deployed for most of the datacollection period had a measurement path length of $2 \mathrm{~mm}$. The SUNA sensor had a measurement path length of $10 \mathrm{~mm}$. The shorter path length of the NITRATAX sensor allows for measurement of nitrate at higher concentrations and in more turbid water. The longer path length of the SUNA might provide marginally more accurate measurement at lower concentrations, which often are concurrent with lower flow conditions and less turbid water. Figure 11 illustrates the differences in recorded values at various concentrations during the period of deployment.

For the remainder of this report, the continuous nitrate data record from the NITRATAX sensor will be used for discussion and analysis purposes because it provides a longer and more complete data record.

\section{Seasonality}

A comprehensive analysis of the seasonality of nitrate concentrations in the Illinois River at Florence is not possible with the limited period of data collected through this effort; however, some initial observations and inferences can be presented. It is important to be reminded that precipitation and streamflow were lower than normal in 2012, which has been identified as a year of drought in Illinois (http://www.isws. illinois.edu/hilites/drought/).
The following definitions of climatic season were used for this analysis:

Winter-January, February, and March

Spring-April, May, and June

Summer-July, August, and September

Fall-October, November, and December

Substantially different nitrate concentrations were present during the spring seasons of 2012 (represented only by June 2012) and 2013 as a result of different climatic and streamflow conditions. Continuous nitrate-data collection began in June 2012 during a period of declining streamflow and nitrate concentrations (fig. 9). Nitrate concentrations in June 2012 ranged from about 1.7 to $3.5 \mathrm{mg} / \mathrm{L}$. In 2013, discharge of the Illinois River was drastically higher and corresponding nitrate concentrations ranged from about 4.2 to greater than $10.0 \mathrm{mg} / \mathrm{L}$. Even though both streamflow and nitrate concentrations were substantially higher in 2013 than in 2012, nitrate concentrations were responsive to streamflow conditions in both years, increasing and decreasing in response to similar changes in streamflow. Nitrate concentrations typically lagged behind streamflow changes, but did so for both increases and decreases. This behavior likely reflects the general transport of nitrate from agricultural surfaces and soils through overland runoff or tile-drainage, as well as the transport of nitrate from residential lots and urban land surfaces. 
Both nitrate concentrations and streamflow conditions were generally similar during the summer months of 2012 and 2013. In these summer months, nitrate concentrations were typically less than $3 \mathrm{mg} / \mathrm{L}$ and often less than $2 \mathrm{mg} / \mathrm{L}$. An exception to this generalization was the first half of July 2013 when nitrate concentrations were decreasing rapidly, along with streamflow, from high levels present in June.

The data for fall 2013 is limited to data collected through October 2013, because the period of data for this effort continued only through October 2013. Nitrate concentrations began to increase throughout the fall months in both 2012 and 2013 even though streamflow remained stable. These increases in nitrate concentrations could have resulted in response to agricultural fertilizer applications or nitrogen from the release of decaying aquatic and other plant materials. Regardless of the cause, the data indicate increases in nitrate source loading and (or) increases of in-stream transport, since nitrate concentrations increased without corresponding increases in streamflow.

Data representing nitrate concentrations during the winter months (January-March) were available only for 2013. During these months, nitrate concentrations generally increased from around 4 to greater than $6 \mathrm{mg} / \mathrm{L}$. There was a correlation between nitrate concentrations and streamflow, but not as strong or consistent as during the spring months. These seasonal increases in nitrate concentrations might indicate reduced biological consumption of nitrate, continuing contribution of nitrate from organic and agricultural sources, and (or) reduced denitrification during colder periods.

\section{Phosphate}

The period of continuous phosphate data collected by the Cycle analyzer and used for this report was April 25, 2013October 21, 2013. As mentioned earlier, there were several issues with the Cycle analyzer deployment and performance that prevented reliable continuous phosphate-data collection and transmission prior to this period.

The data from the phosphate analyzer documented a substantial increase in phosphate concentrations during the deployment period (fig. 12). Phosphate concentrations from the initial deployment (April 25 through the end of June) were consistent and ranged from about 0.15 to $0.20 \mathrm{mg} / \mathrm{L}$, as $\mathrm{P}$. Phosphate concentrations began to increase steadily around July 1 and continued to increase through October, when they reached a high concentration of $0.53 \mathrm{mg} / \mathrm{L}$, as $\mathrm{P}$.

Nine discrete samples were collected from the river adjacent to the analyzer and were subsequently analyzed for dissolved orthophosphate at the USGS NWQL. These samples were collected during routine NAWQA sampling trips and equipment maintenance visits. The dates of the discrete samples collected in 2013 were April 25, April 29, May 8, May 29, June 18, July 22, August 14, August 30, and September 25.
Table 6 shows summary statistics for the continuous phosphate data collected by the Cycle analyzer and for samples analyzed at the NWQL. While the analytical results from these analyses can be compared and contrasted, the concentration values should not necessarily be identical because of a difference in filtration between the two methods. The Cycle analyzer incorporates a 10 micron filter, while the NWQL analysis is determined on a sample passed through a filter with 0.45 micron pore size, which is the standard operational pore size typically used to differentiate between total and dissolved constituent analyses. Regardless, some useful observations are readily made from comparison of these data, including the obvious difference in the number of concentration determinations acquired and the stream conditions represented by the data. The continuous dataset has higher mean, median, and maximum concentrations; includes a larger range of concentrations; and has a lower minimum concentration. These data characteristics indicate a more comprehensive description of stream concentrations throughout the monitored period. However, the standard deviations of the two datasets are not substantially different, indicating that both datasets capture the general tendencies and characteristics of the in-stream concentrations throughout the period sampled. The continuous dataset was able to capture periods of phosphate concentrations both lower and higher than those represented by the discrete samples data.

The Cycle analyzer cannot be calibrated by the user in the field, and standard solutions were not used in this study to check field readings of the analyzer. Future field maintenance of the analyzer will include a check with a standard phosphate solution in the range of expected environmental concentrations. Use of field checks with standard phosphate solutions will provide additional information regarding the analyzer values and will assist with adjustment of continuous data values for user-specific purposes.

Figure 13 shows a time-series plot of the continuous phosphate dataset, the orthophosphate concentrations determined from the discrete laboratory samples, and the relative percent differences in concentrations between the discrete sample concentrations and the Cycle analyzer readings at the time of discrete sample collection. Relative percent differences in concentrations were generally less than 25 percent. The Cycle analyzer concentrations were consistently higher than the laboratory concentrations except for the April 25 and May 29 samples. Results from the Cycle analyzer were not adjusted based upon laboratory analyses primarily because of the differences in filtration pore sizes and because the analyzer concentrations were consistently higher than the laboratory concentrations; a relation that arguably would be expected from the difference in filter pore size. The relation between analyzer phosphate concentrations and laboratory orthophosphate concentrations should be examined for each individual deployment location, and a determination should be made regarding the consistency or variability and the implications of the relation. 


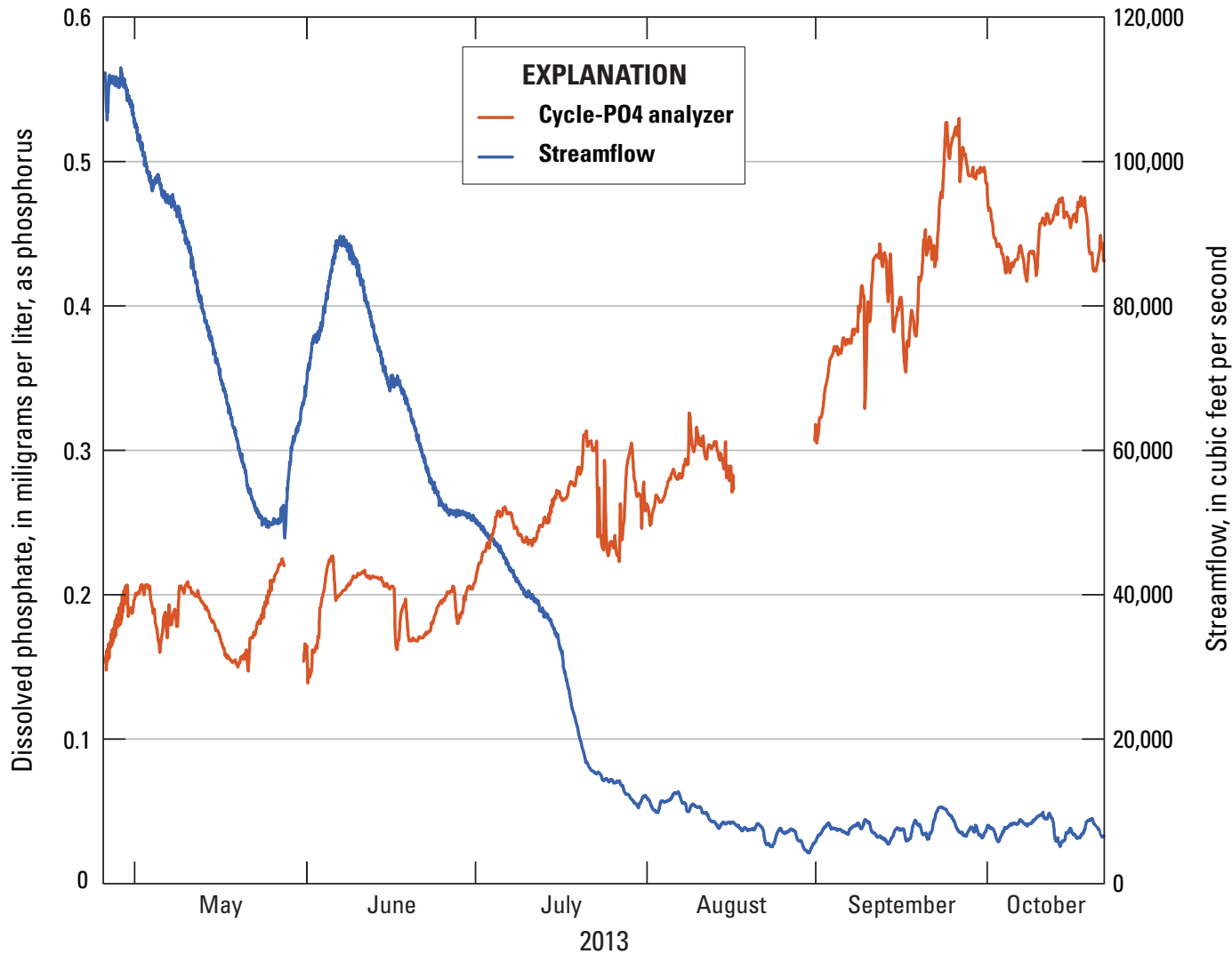

Figure 12. Concentrations of dissolved phosphate as determined by the Cycle-PO4 analyzer and streamflow for April 25, 2013-0ctober 30, 2013, at the Illinois River at Florence, Illinois (05586300).

Table 6. Summary statistics for phosphate data measured by the Cycle-PO4 analyzer and discrete samples analyzed by the U.S. Geological Survey National Water-Quality Laboratory (NWQL) for Illinois River at Florence, Illinois (05586300).

\begin{tabular}{lcc}
\hline & $\begin{array}{c}\text { 'Cycle PO4 } \\
\text { phosphate }\end{array}$ & $\begin{array}{c}\text { NWOL } \\
\text { orthophosphate }\end{array}$ \\
\hline Mean & 0.286 & 0.213 \\
Median & 0.255 & 0.172 \\
Standard deviation & 0.110 & 0.086 \\
Range & 0.473 & 0.276 \\
Minimum & 0.057 & 0.142 \\
Maximum & 0.53 & 0.418 \\
Count & 3,950 & 9 \\
\hline
\end{tabular}

${ }^{1}$ Based on 60 -minute interpolation of 240 - to 360 -minute data values. 
Figure 13. Concentrations of phosphate measured by the Cycle-P04 analyzer and dissolved orthophosphate analyzed by the U.S. Geological Survey National Water Quality Laboratory for April 25-0ctober 30, 2013.

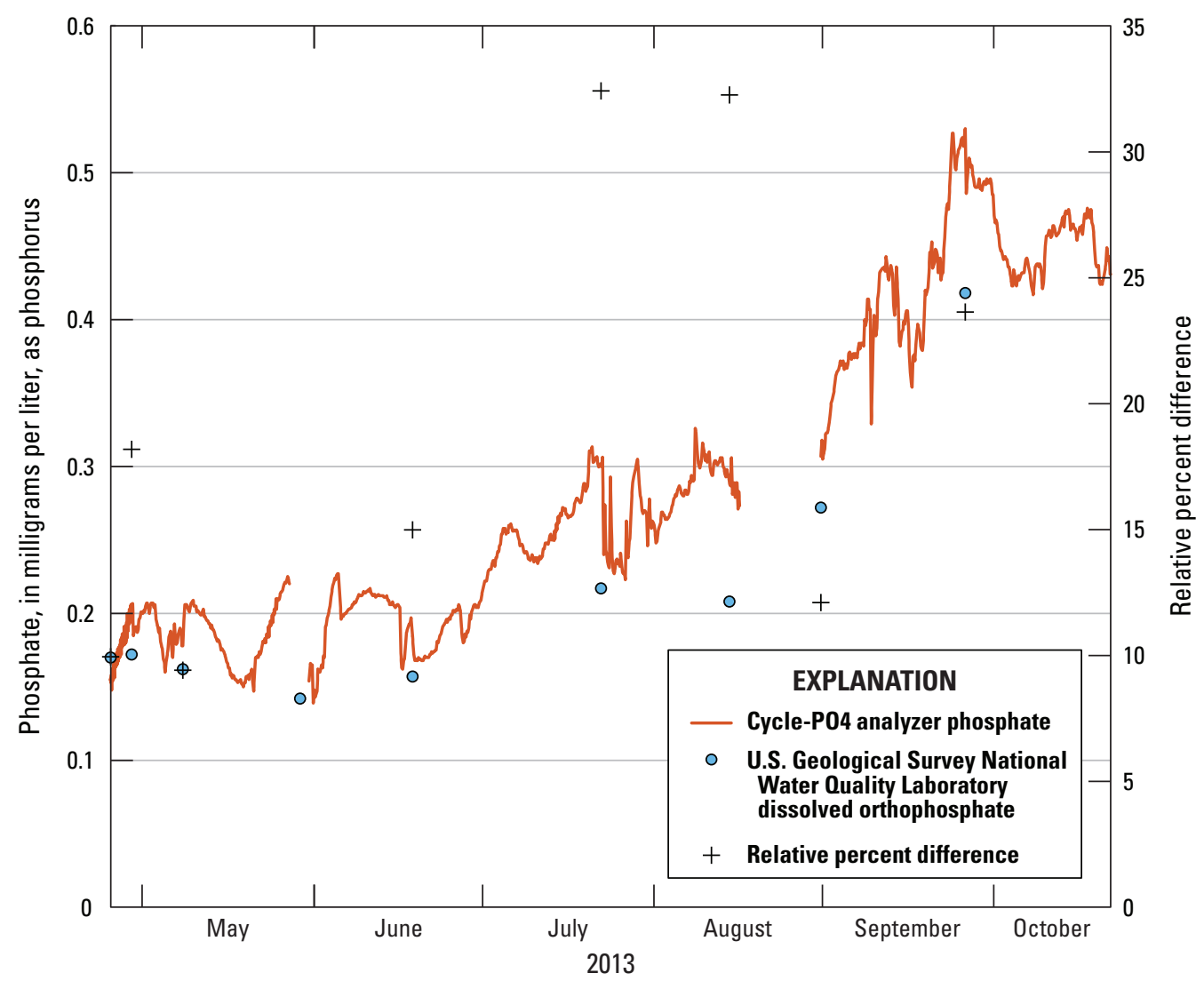

When a consistent relation among continuous data values and laboratory values is determined, the continuous data record could be adjusted through the use of algorithms to more closely agree with the laboratory values and adjust for consistent bias in the continuous dataset. Other constituent data, such as discharge and turbidity, and the determination of interferences from other constituents in the water matrix might prove valuable in deriving an algorithm for adjusting continuous phosphate concentrations after a more comprehensive dataset is acquired.

\section{Comparison of Continuously Monitored Phosphate to other Forms of Phosphate}

Total phosphorus (TP) includes all phosphorus present in a water sample, including that which is incorporated in biological organisms and absorbed to particulate matter. A 0.45 -micron membrane filter is generally used as the standard operational pore size for filtration of water samples (American Public Health Association, 1998). The Cycle analyzer utilizes two coarse-material screens and a $10-\mu \mathrm{m}$ pore size filter. The phosphate results reported by the Cycle analyzer are therefore considered, through this operational definition, to be unfiltered phosphate concentrations.

Most water-quality standardsare developed for TP in order to account for phosphorus that is bound to particulate matter or organic material, but has the potential of being released and converted to a biologically available form. The
State of Illinois water-quality standard for TP in general-use waters is $0.05 \mathrm{mg} / \mathrm{L}$ in any reservoir or lake with a surface area of 8.1 hectares ( 20 acres) or more, or in any stream at the point where it enters any such reservoir or lake (Illinois Pollution Control Board, 2013).

As previously discussed, discrete water samples were collected during April 25-October 30, 2013, from the Illinois River at Florence near the in-situ Cycle analyzer and were analyzed at the NWQL for dissolved orthophosphate (DOP) concentration (table 6). In addition, seven cross-sectional composite samples were collected for the NAWQA program during this time period at the Illinois River at Valley City, Ill. (05586100), and analyzed for TP, dissolved phosphorus, and DOP. Figure 14 depicts the concentrations of the different phosphorus forms from these cross-sectional composite samples as well as the concurrent Cycle analyzer phosphate concentrations at the Illinois River at Florence, Ill. (05586300).

In addition, four composite cross-sectional samples were collected using the EWI method during the initial months of the Cycle analyzer deployment and compared to point samples collected at the Cycle analyzer location to determine whether or not the location of the Cycle analyzer was representative of the entire stream. The results of these comparison samples are shown in table 7.

There was good correlation $\left(\mathrm{R}^{2}=0.8687\right)$ between DOP and TP concentrations in the samples analyzed at the NWQL. However, the limited number of samples in this comparative dataset was insufficient to determine relations between the two forms of phosphorus, especially when these samples 


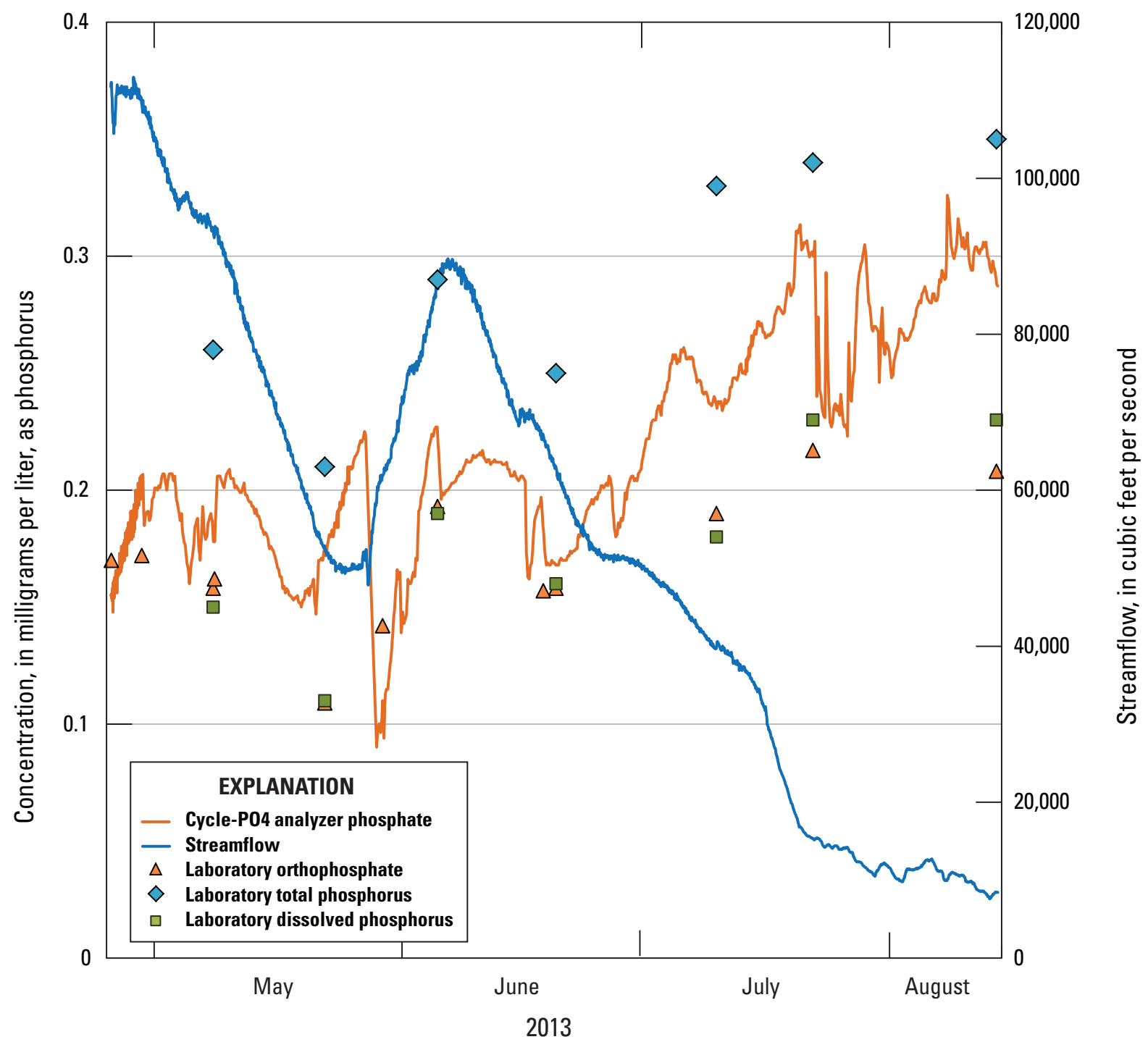

Figure 14. Concentrations of various forms of phosphorus in the Illinois River at Valley City, Illinois (05586100), and concurrent continuous phosphate concentrations at the Illinois River at Florence, III. (05586300), April 25-0ctober 30, 2013.

Table 7. Concentrations of nitrate plus nitrite and phosphate in samples collected using the equal-width-increment method and in point samples at the location of the in situ instruments at Illinois River at Florence, Illinois (05586300).

$[\mathrm{N}$, nitrogen; $\mathrm{P}$, phosphorus $]$

\begin{tabular}{lccccc}
\hline \multirow{2}{*}{ Date } & \multicolumn{2}{c}{$\begin{array}{c}\text { Nitrate plus nitrate, as N, } \\
\text { in milligrams per liter }\end{array}$} & & \multicolumn{2}{c}{$\begin{array}{c}\text { Orthophosphate, as } \mathbf{P} \text {, } \\
\text { in milligrams per liter }\end{array}$} \\
\cline { 2 - 3 } \cline { 5 - 6 } & $\begin{array}{c}\text { Equal width } \\
\text { increment sample }\end{array}$ & Point sample & & $\begin{array}{c}\text { Equal width } \\
\text { increment sample }\end{array}$ & Point sample \\
\hline August 3, 2012 & 1.49 & 1.46 & & 0.577 & 0.574 \\
August 21, 2012 & 1.23 & 1.23 & & 0.570 & 0.559 \\
March 8, 2013 & 5.70 & 5.68 & & 0.169 & 0.170 \\
April 24-25, 2013 & 4.88 & 4.94 & & 0.164 & 0.170 \\
\hline
\end{tabular}


represent a limited range of environmental and streamflow conditions. Therefore, an analysis was performed using results from water samples collected for the NAWQA program from 1991 through April 2013 at the Illinois River at Valley City (05586100) to determine relations between DOP and TP in this reach of the Illinois River and to determine whether continuous phosphate concentrations from the Cycle analyzer can be used to infer concentrations or characteristics of TP.

Samples were collected at the Illinois River at Valley City (05586100) for the NAWQA program at various times and frequencies since 1991. From 1991 to 2013, 246 samples were analyzed for TP and DOP. Table 8 provides the summary statistics from these samples. As mentioned in the Study Area section of this report, the nutrient concentrations in the Illinois River were determined to be similar at the Valley City and Florence locations; therefore, use of the long-term dataset at the Valley City station is appropriate for determination of relations among various forms of phosphorus and chemical constituents at the Florence station.

A linear regression model was developed relating TP and DOP concentrations using the 246 data pairs from the samples collected during 1991-2013. The $\mathrm{R}^{2}$ of the regression model was 0.24 . There were obvious outliers in the dataset that exert strong influence on this model, excluding them from the model could not be justified. The primary three outliers had concentrations of TP greater than $1.30 \mathrm{mg} / \mathrm{L}$ with corresponding DOP concentrations less than $0.15 \mathrm{mg} / \mathrm{L}$. There also were six TP concentrations above $0.6 \mathrm{mg} / \mathrm{L}$ that corresponded to DOP concentrations at or below about $0.2 \mathrm{mg} / \mathrm{L}$. This regression model did not provide a good relation between the variables when TP concentration was higher than about $0.6 \mathrm{mg} / \mathrm{L}$ and DOP was less than about $0.3 \mathrm{mg} / \mathrm{L}$.

A linear regression model also was developed relating TP and SSC using the 246 data pairs for 1991-2013. This model had a slightly better $\mathrm{R}^{2}$ of 0.43 than the previous model and more effectively accommodated the high TP concentrations, although it was not as accurate for the low TP concentrations. It was presumed that this model reflects the association of phosphorus with particulate material and the occasional high and co-occurring concentrations of both constituents.

The initial linear regression models using DOP or SSC to predict TP indicated that each of these independent variables was better for predicting TP at different turbidity and

Table 8. Summary statistics for dissolved orthophosphate and total phosphorus concentrations from samples collected at Illinois River at Valley City, Illinois (05586100), 1991-2013.

\begin{tabular}{lcc}
\hline & $\begin{array}{c}\text { Dissolved } \\
\text { orthophosphorus }\end{array}$ & Total phosphorus \\
\hline Minimum & 0.051 & 0.11 \\
Mean & 0.201 & 0.415 \\
Median & 0.176 & 0.390 \\
Maximum & 0.600 & 1.380 \\
Range & 0.549 & 1.27 \\
Count & 246 & 246 \\
\hline
\end{tabular}

TP concentration levels. That is, DOP was a better predictor variable at low TP concentrations, which typically coincide with lower turbidity levels, while SSC was a better prediction variable at higher concentrations of TP, which typically coincide with elevated turbidity levels. To take advantage of these characteristics, a multivariate linear regression model using both of these predictor variables was developed with a resulting $R^{2}$ of 0.802 . The multivariate regression model equation follows.

$$
T P=0.0816+1.10(D O P)+0.00063(S S C)
$$

Table 9 presents the three TP-prediction model summaries, and figure 15 depicts the observed-to-predicted correspondence from the final multivariate linear regression model using both DOP and SSC (units for TP, DOP, and SSC are all $\mathrm{mg} / \mathrm{L}$ ). The multiple-linear-regression model had an $\mathrm{R}^{2}$ of $0.8(\mathrm{RMSE}=$ 0.079), which was much higher than the single variable models and indicates a very good prediction model of TP in this reach of the Illinois River.

These initial analyses of the relations between DOP and TP concentrations indicate there is good potential for developing reasonable algorithms to calculate TP concentrations from continuous phosphate and turbidity data. However, these predictive algorithms will likely have greater uncertainty at higher phosphorus concentrations and during periods of increased streamflow and will likely need a seasonal component built in to account for point-source inputs in watersheds with point-source contributions. Algorithms will need to be developed for each water body independently owing to differences in watershed hydrologic factors, phosphorus inputs, and landscape and stream-sediment and other particulate-matter composition.

\section{Seasonality and Flow-Related Differences}

Streamflow in the Illinois River generally decreased during April-October 2013, the period during which the phosphate analyzer was deployed (fig. 12). During this period, streamflow decreased from nearly 110,000 to about 7,000 cubic feet per second $\left(\mathrm{ft}^{3} / \mathrm{s}\right)$. A significant flow event occurred near the end of May and lasted through June during which time streamflow increased from around 50,000 to about $90,000 \mathrm{ft}^{3} / \mathrm{s}$ and subsequently returned to $50,000 \mathrm{ft}^{3} / \mathrm{s}$ by the end of June. Streamflow decreased to about $10,000 \mathrm{ft}^{3} / \mathrm{s}$ by August 1 and generally ranged from 4,000 to $10,000 \mathrm{ft}^{3} / \mathrm{s}$ through October.

During this time period, phosphate concentrations ranged from about 0.22 to $0.53 \mathrm{mg} / \mathrm{L}$, as $\mathrm{P}$, and generally increased consistently during the relatively stable low-flow period from mid-July through October 2013 when streamflow was less than $20,000 \mathrm{ft}^{3} / \mathrm{s}$. The reasons for the increasing concentrations of phosphate during this period are not known, but could include increased or accumulating phosphate contributions from upstream wastewater-treatment facilities, release and oxidation of particulate-bound phosphorus in stream and bank sediments, and releases of phosphorus from dying and decomposing aquatic plants and algae. The high-flow period of June 2013 was an exception to this relation. As discussed previously, there was a 
Table 9. Final model equation and predictor and response variable statistics for total phosphorus (TP) concentration multivariate linear regression models developed using data from the Illinois River at Valley City, Illinois (05586100), 1991-2013.

[R2, coefficient of determination; TP, total phosphorus; mg/L, milligrams per liter; $\mathrm{P}$, phosphorus $]$

\begin{tabular}{|c|c|c|c|c|}
\hline \multicolumn{3}{|c|}{ Predictor variable(s) } & $\mathbf{R}^{2}$ & $\begin{array}{l}\text { Root mean } \\
\text { square error }\end{array}$ \\
\hline \multicolumn{5}{|c|}{ Dissolved orthophosphorus (DOP) } \\
\hline \multicolumn{5}{|c|}{ Suspended-sediment concentration (SSC) } \\
\hline \multicolumn{5}{|c|}{ DOP and SSC } \\
\hline \multicolumn{3}{|c|}{ TP and DOP model: $\mathrm{TP}=0.237+0.873(\mathrm{DOP})$} & 0.238 & 0.154 \\
\hline \multicolumn{3}{|c|}{$\mathrm{TP}$ and SSC model: $\mathrm{TP}=0.318+0.000541(\mathrm{SSC})$} & 0.432 & 0.134 \\
\hline \multicolumn{3}{|c|}{ Final Model (TP, DOP, and SSC): TP $=0.0816+1.10(\mathrm{DOP})+0.00063(\mathrm{SSC})$} & 0.802 & 0.079 \\
\hline & \multicolumn{2}{|c|}{ Predictor variable } & \multicolumn{2}{|c|}{ Response variable } \\
\hline & $\begin{array}{l}\text { Orthophosphorus } \\
\text { (mg/L, as P) }\end{array}$ & $\begin{array}{c}\text { Suspended sediment } \\
(\mathrm{mg} / \mathrm{L})\end{array}$ & \multicolumn{2}{|c|}{$\begin{array}{l}\text { Total phosphorus } \\
\text { (mg/L, as P }\end{array}$} \\
\hline Minimum & 0.051 & 29 & \multicolumn{2}{|c|}{0.11} \\
\hline 1st Quartile & 0.139 & 78 & \multicolumn{2}{|c|}{0.30} \\
\hline Median & 0.176 & 116 & \multicolumn{2}{|c|}{0.39} \\
\hline Mean & 0.201 & 178 & \multicolumn{2}{|c|}{0.41} \\
\hline 3rd Quartile & 0.241 & 200 & \multicolumn{2}{|c|}{0.48} \\
\hline Maximum & 0.600 & 1,970 & \multicolumn{2}{|c|}{1.38} \\
\hline
\end{tabular}

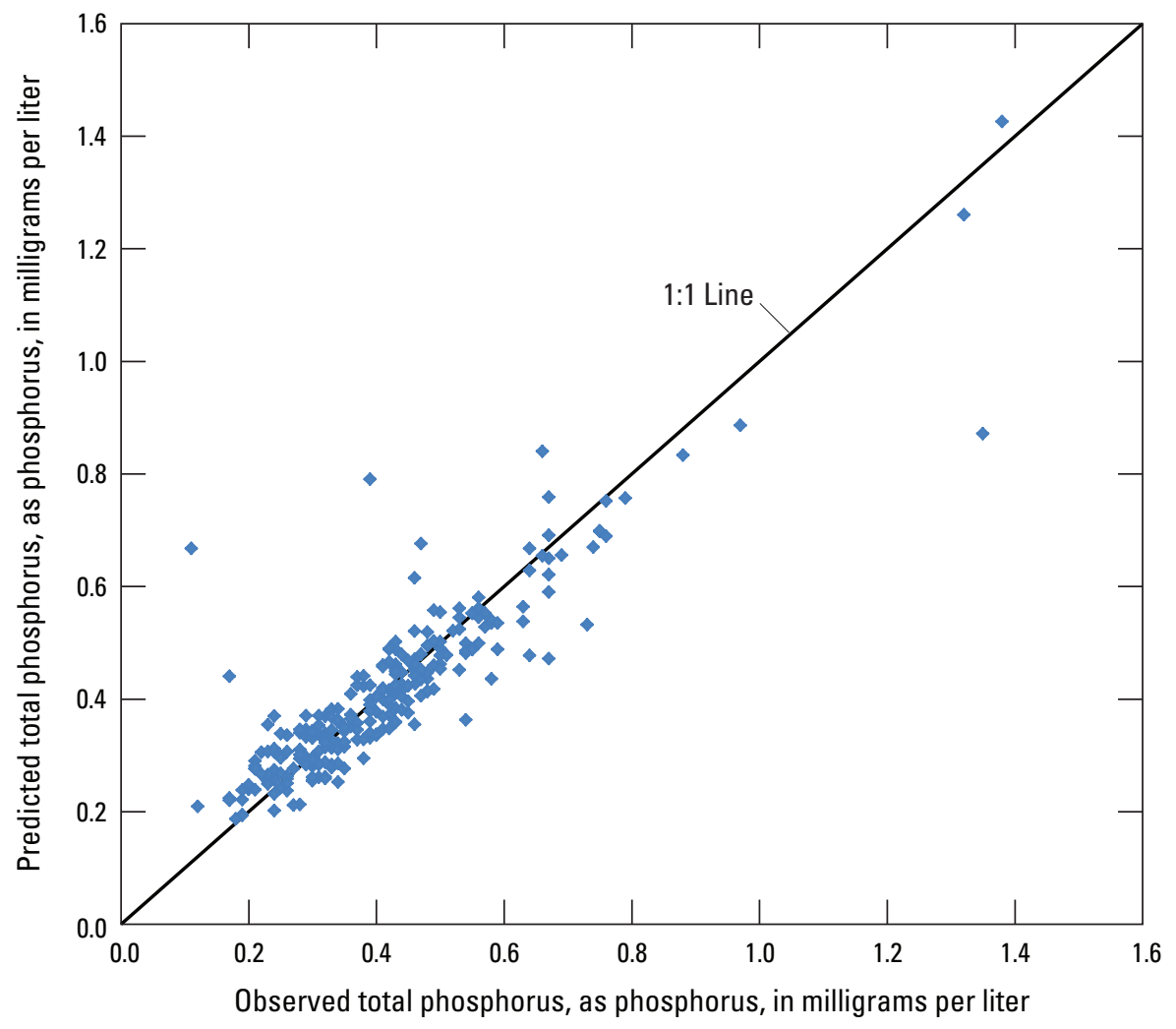

Figure 15. Observed and predicted total phosphorus concentrations using a linear regression model with orthophosphate and suspended sediment prediction variables. 
substantial increase and subsequent decrease in streamflow during June. phosphate concentrations, however, remained consistent for most of this period and did not demonstrate a dilution effect, except during the early period of the hydrograph (May 26 to June 3). There is some uncertainty in the accuracy of the Cycle analyzer data during this initial period of increased discharge and decreased phosphate concentration because turbidity concentrations were high and turbidity is known to interfere with the performance of the Cycle analyzer. The laboratory-analyzed sample from May 29 had a concentration of $0.142 \mathrm{mg} / \mathrm{L}$, which would indicate that phosphate concentrations might not have been diluted as much as indicated by the analyzer data and that turbidity might have been interfering with the accuracy of readings by the analyzer. These data, however, represent the only substantial flow event of the analyzer deployment period and could be an appropriate representation of phosphate concentration changes during high-flow events.

With the exception of the June period, only minor increases in streamflow occurred during the analyzer deployment, and it is not possible to determine a consistent response in phosphate concentrations to changes in streamflow from the available dataset. The data indicate both increases and decreases of phosphate concentrations in response to relatively small increases in streamflow. These different responses likely result from various contributing factors including environmental conditions, biological activity, and runoff contributions from different parts of the watershed (particularly urban and agricultural areas).

The continuous data collected during April-October 2013 indicated a general inverse relation between phosphate concentrations and discharge. This relation is not unexpected based upon the simple process of phosphate point-source dilution during periods of increased streamflow; however, this is a generalized relation from a limited dataset with demonstrated periods of exception.

Figure 16 depicts continuous phosphate concentration data versus streamflow, plotted as individual points for AprilOctober 2013. It is almost possible to trace the progression of phosphate data through the period of deployment because of the limited period of data and the nature of the continuous data record. A basic power-function regression equation provides the best single-line fit to the data with an $\mathrm{R}^{2}$ value of 0.8094 . The data for May 26-June 3 (indicated in red) deviate somewhat from the general trend of the data, but if this period of data is removed from the dataset, the best-fit equation and $\mathrm{R}^{2}$ value improve only slightly. This relation indicates that there is a significant inverse correspondence between phosphate concentration and streamflow at medium to high streamflows.

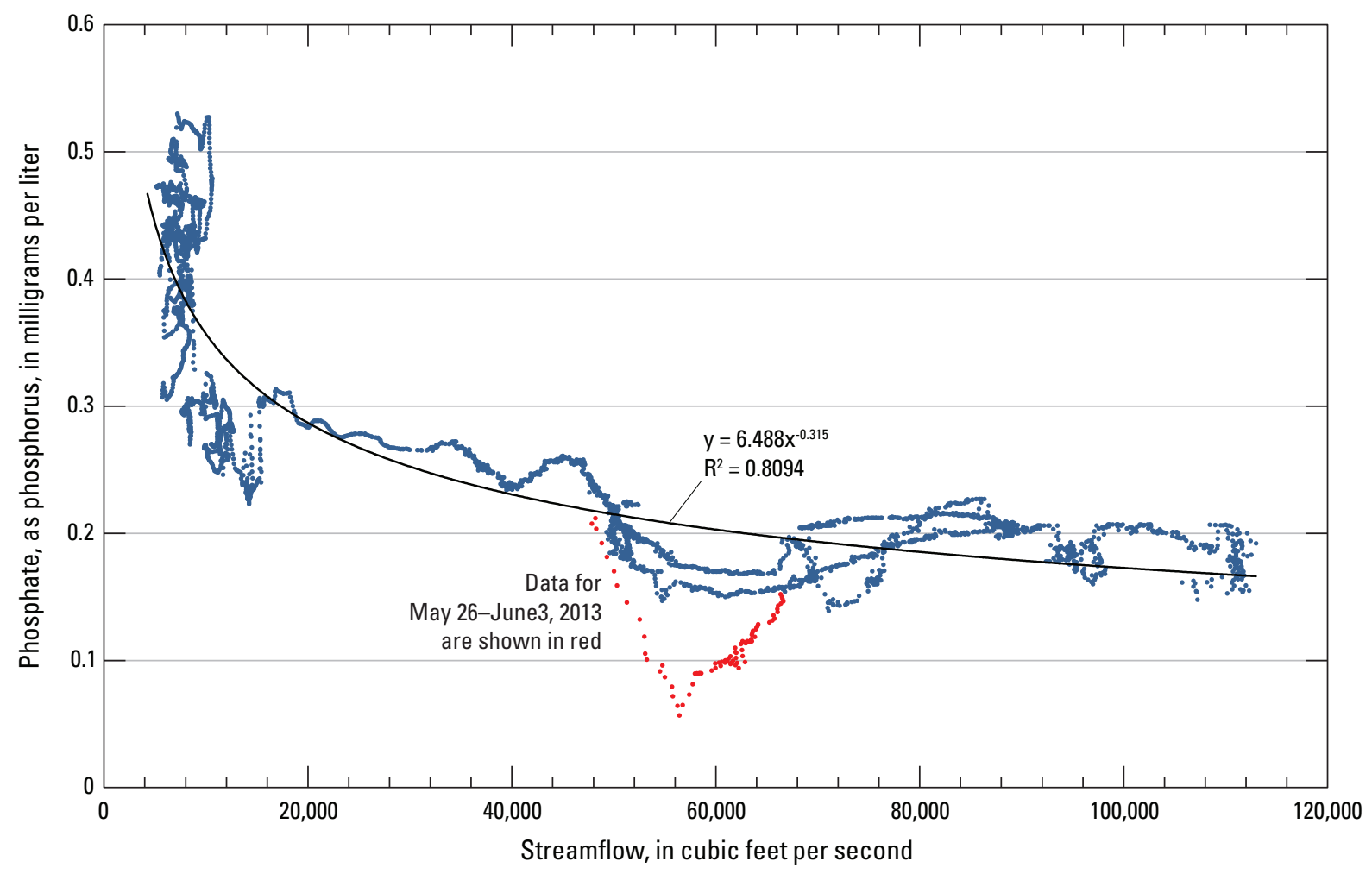

Figure 16. Continuous phosphate concentrations versus streamflow for April-0ctober 2013 at the Illinois River at Florence, Illinois (05586300). [ $\mathrm{R}^{2}$, coefficient of determination] 


\section{Loadings}

\section{Suspended Sediment}

Utilizing the time series SSC and streamflow data, the SSL was calculated for each instrument and method as outlined in the Methods section (table 9, fig. 17). The variation in the load is apparent from the first 6 months of drought followed by flooding and gives further evidence of the broad range of conditions in which the instruments were tested. The annual SSL was calculated for July 1, 2012-June 30, 2013. The annual SSLs calculated from the two turbidity sensors are within 5 percent of each other. The annual SSL calculated from the GCLAS method is within 7 percent of both turbidity loads. The historical annual SSLs (July 1-June 30) are plotted in figure 18 with the data from this study (July 1, 2012-June 30, 2013). The average annual SSL for 1981-2012 was approximately 5.2 million tons. The SSL for July 1, 2012June 30, 2013, was within 10 percent of the average historical annual SSL.
Table 10. Calculated suspended-sediment load for each instrumentand method used in the study.

[GCLAS, Graphical Constituent Loading Analysis System]

\begin{tabular}{lrrr}
\hline \multirow{2}{*}{\multicolumn{1}{c}{ Time period }} & \multicolumn{3}{c}{ Suspended-sediment load (tons) } \\
\cline { 2 - 4 } & \multicolumn{1}{c}{ Solitax } & \multicolumn{1}{c}{ YSI 6136 } & \multicolumn{1}{c}{ GCLAS } \\
\hline July 2012 & 24,830 & 25,107 & 23,818 \\
August 2012 & 20,862 & 20,303 & 22,719 \\
September 2012 & 26,409 & 25,588 & 20,397 \\
October 2012 & 19,743 & 25,530 & 19,902 \\
November 2012 & 9,176 & 12,012 & 10,387 \\
December 2012 & 23,123 & 21,698 & 24,047 \\
January 2013 & 74,697 & 77,187 & 73,508 \\
February 2013 & 346,352 & 341,861 & 423,800 \\
March 2013 & 611,024 & 612,353 & 716,800 \\
April 2013 & $1,843,570$ & $1,987,953$ & $1,671,010$ \\
May 2013 & 987,609 & $1,083,143$ & 909,350 \\
June 2013 & 720,164 & 701,822 & 699,790 \\
Annual total & $4,707,559$ & $4,934,557$ & $4,615,528$ \\
\hline
\end{tabular}

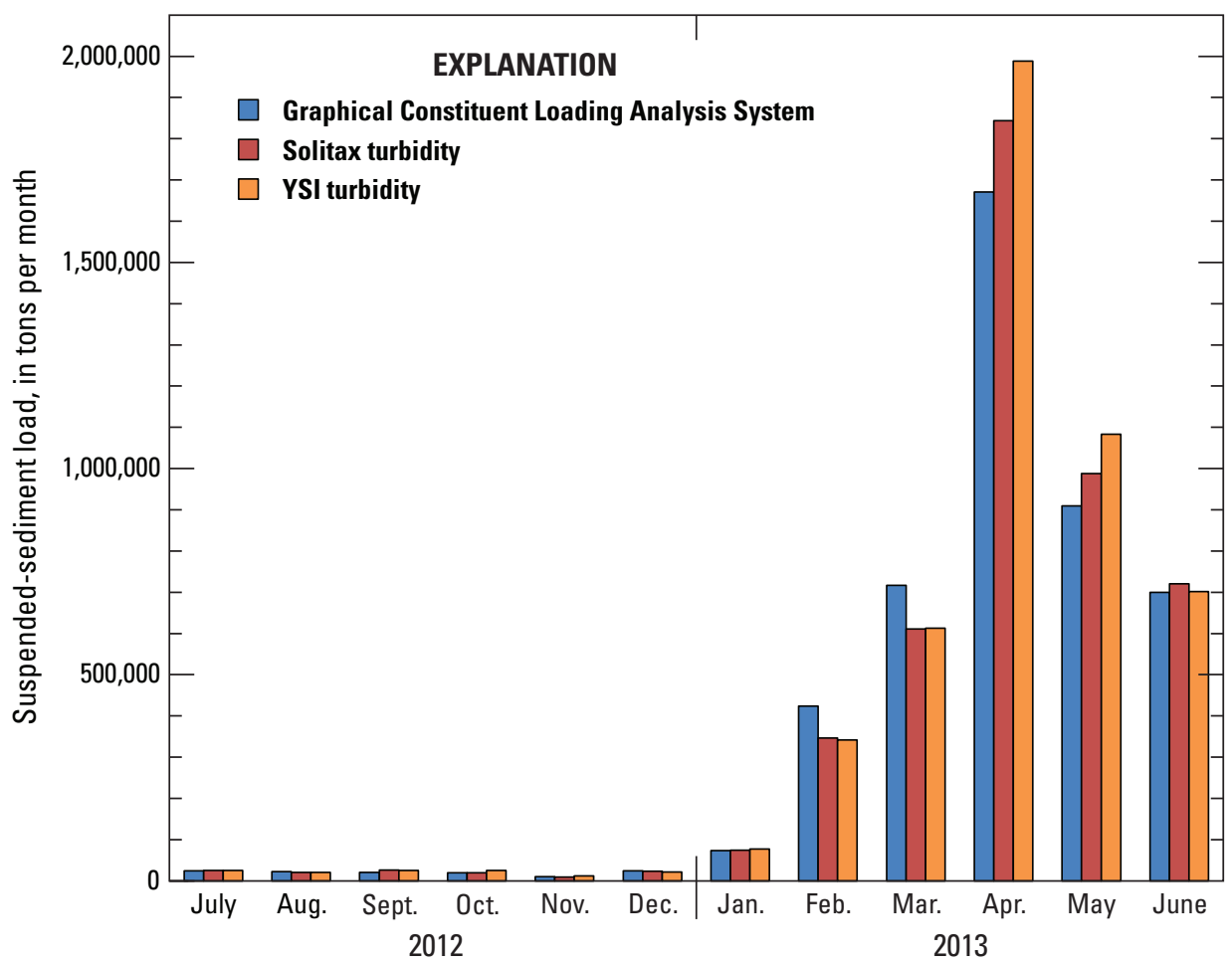

Figure 17. Monthly suspended-sediment load for each instrument and method used in the study at the Illinois River at Florence, Illinois (0558630). 


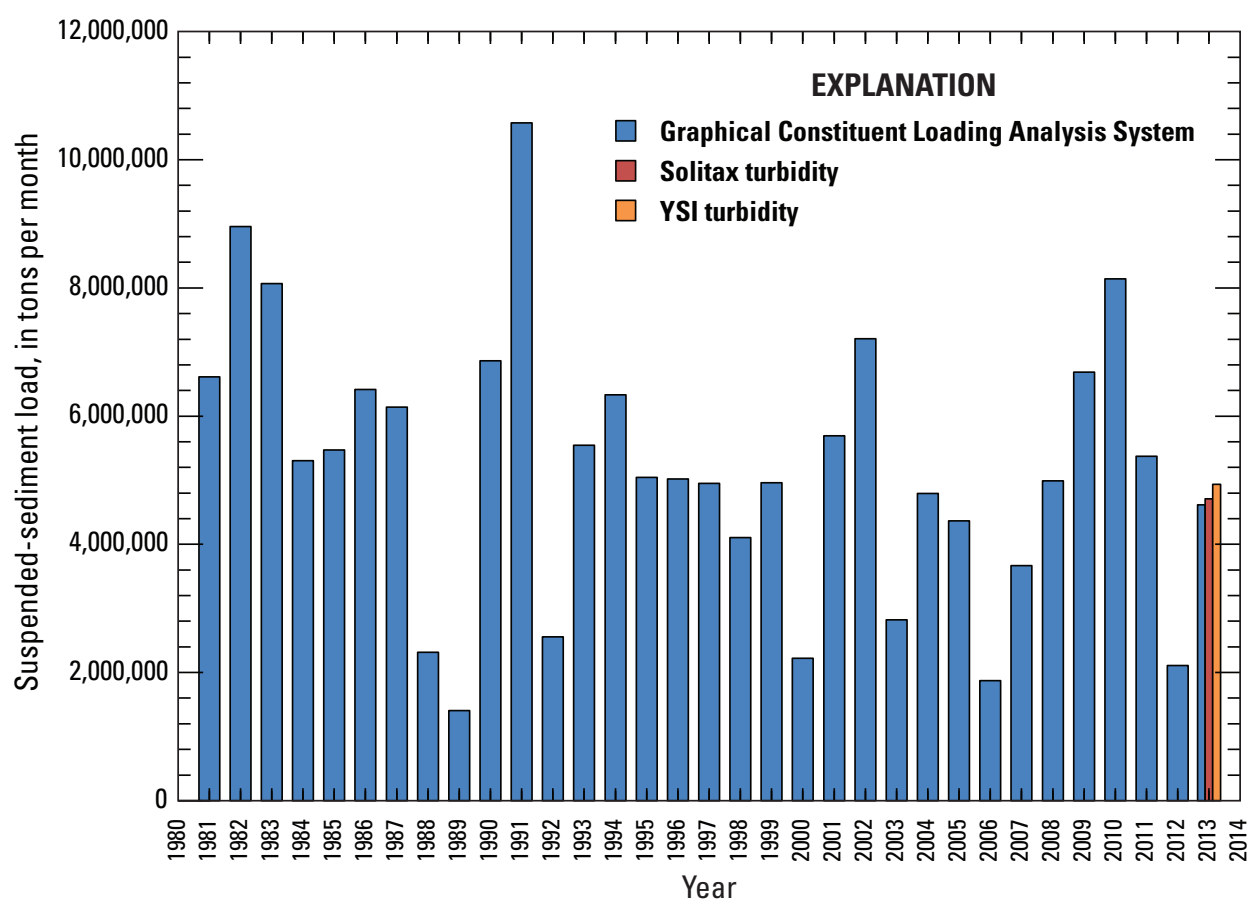

Figure 18. Annual suspendedsediment loads for the study period and historical data. Annual loads were calculated for July 1-June 30 and are labeled as the ending year at the Illinois River at Valley City, Illinois (05586100), prior to 2013 and the Illinois River at Florence, III. (05586300), in 2013.

\section{Nitrate}

Nitrate loads were computed for June 1, 2012October 31,2013, the period of continuous nitrate data collection. Streamflow values used for the load computations were from the USGS streamgaging station at Illinois River at Valley City, Ill. (05586100). The time required for water to travel from the streamgaging station at Valley City to the continuous monitoring station at Illinois River at Florence, Ill. (05586300), varies with the stage of the river and corresponding flow velocity. A travel time of 5 hours between the two locations was used in this analysis to pair a nitrate sensor concentration to a corresponding streamflow value in the calculation of continuous nitrate loads.

Nitrate loads were computed in two ways for comparative purposes. The calculation of instantaneous loads from continuous data was done by simply multiplying the reported nitrate concentration by the corresponding streamflow value and applying a unit-conversion factor. For this analysis, the following equation was used to compute an instantaneous nitrate load value for each continuous nitrate concentration value:

$\operatorname{Load}_{N 03}(\mathrm{lb} / \mathrm{d})=$ Concentration $(\mathrm{mg} / \mathrm{L}) \times \operatorname{Streamflow}\left(\mathrm{ft}^{3} / \mathrm{s}\right) \times 5.393$

Nitrate loads also were computed by traditional regressionmodel technique using 22 discrete nitrate samples collected at the Florence station during maintenance and service visits of the continuous-monitoring equipment. The USGS Load Estimator (LOADEST) program (Runkel and others, 2004) was used to compute a regression equation relating nitrate concentrations to corresponding streamflow values and incorporating a seasonal time component. The regression equation selected by the LOADEST program was

$$
\begin{aligned}
& \operatorname{Load}_{N 03}(l b / d)=12.5820+1.5963(\operatorname{Ln} Q)-0.2612\left(\operatorname{Ln} Q^{2}\right)- \\
& 0.2904 \operatorname{Sin}(2 p i \text { dtime })-0.0294 \operatorname{Cos}(2 p i \text { dtime })-0.4237(\text { dtime })
\end{aligned}
$$

Figure 19 depicts the time-series loads calculated by the two different methods, as well as the instantaneous load values associated with the discrete samples. The plot shows that loads calculated by the two methods are in general agreement, and the calculated loads change similarly in magnitude and direction in response to streamflow. There are, however, substantial differences in load quantities determined by the two methods at various times during both low- and high-flow periods. At times, the load computed from continuous data is larger, while at other times the load computed by the LOADEST program is larger. The load computed from the continuous data is in good agreement with the instantaneous loads associated with the discrete samples, whereas there can be substantial differences between the loads computed by the LOADEST program and the instantaneous loads associated with the discrete samples.

It is particularly important to assess differences between the load values computed by the two methods during periods of increased streamflow, when the majority of in-stream nitrate transport occurs. The target period in this case was February-June 2013. Separation of the two time-series plots for the load-computation methods is evident during this time even though the $y$-axis is presented with a logarithmic scale. 


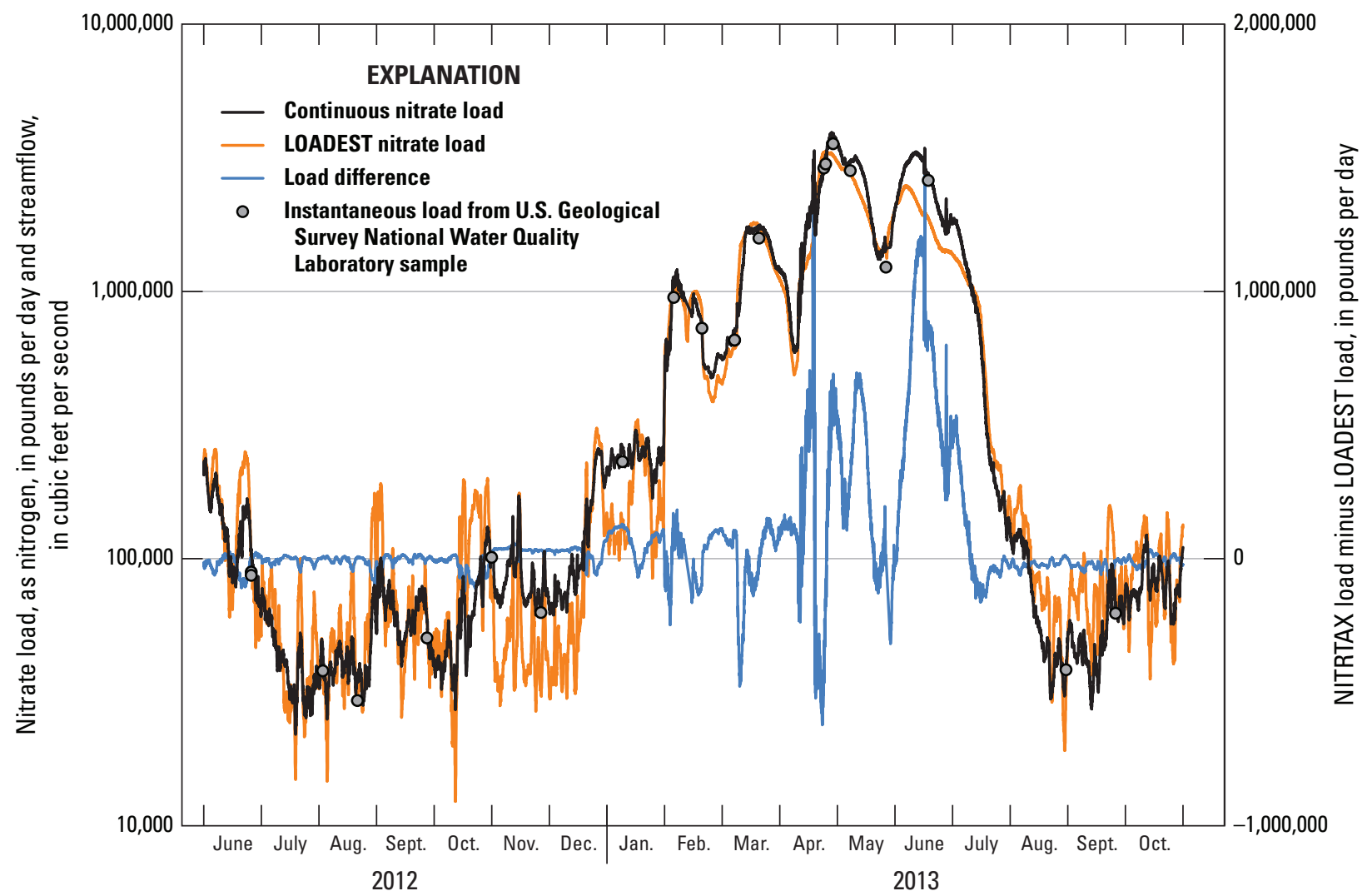

Figure 19. Instantaneous nitrate loads computed using data and the LOADEST program for the Illinois River at Florence, Illinois (05586300).

The continuous data load values are in reasonable agreement with the instantaneous discrete load values during a couple of important peaks on the plot, whereas the loads computed using the LOADEST program appear to underestimate and overestimate loads during some peaks and valleys on the plot. Also shown in figure 19 is a line showing the difference in instantaneous load quantities between the two computational methods (blue line). The difference in computed load was calculated as the NITRATAX load minus the LOADEST load. These differences are greatest during periods of increased loading and streamflow with differences of up to $1,500,000$ pounds per day (lb/d). The differences in loads during periods of stable and lower streamflow are minor in comparison.

Figure 20 shows time-series plots of $(A)$ streamflow, $(B)$ nitrate load computed from the continuous data, $(C)$ the relative percent difference between the loads computed by the two methods, and $(D)$ the absolute values of the differences in actual nitrate loads between the two load-computation methods. These plots show several important observations and illustrate the advantages of a continuous data record. First, the majority of the nitrate loading occurs during periods of increased streamflow. Second, the relative percent differences between the two methods of load computations typically ranges from 10 to 20 percent and is somewhat lower during periods of high streamflow owing to the order of magnitude of the load values. Third, the quantitative differences in load values are substantial and range greatly, and it is during the critical high-flow periods that the continuous-data based load calculations show distinct advantage and an increase in accuracy.

Figure 21 depicts total monthly nitrate loads for June 2012-October 2013, as computed from the continuous data and by the LOADEST program. This figure illustrates how the LOADEST program might overestimate loads during stable and low-flow periods (fall months), but underestimate loads during high-flow and storm-event periods (spring months). The uncertainty and modeling capability of the LOADEST program is of course dependent upon the number of sample values available to input into the program, and the uncertainty can be reduced with more frequent sampling and a longer period of data record. Throughout the entire period of June 2012-October 2013, the continuous data indicated that approximately 25.2 million pounds of additional nitrate were transported past the Florence station above what the traditional LOADEST program estimated using laboratory results from 22 samples collected during the 17-month period. Many routine ambient-monitoring programs collect samples no greater than monthly and without additional high-flow samples. Consequently, they might not provide sample data that include many of the high-load events or periods. There also was a low-to-normal flow period, November 2012 and January 2013, during which the continuous data showed nitrate concentrations, and associated loads, to be substantially higher than accounted for in the LOADEST program. 

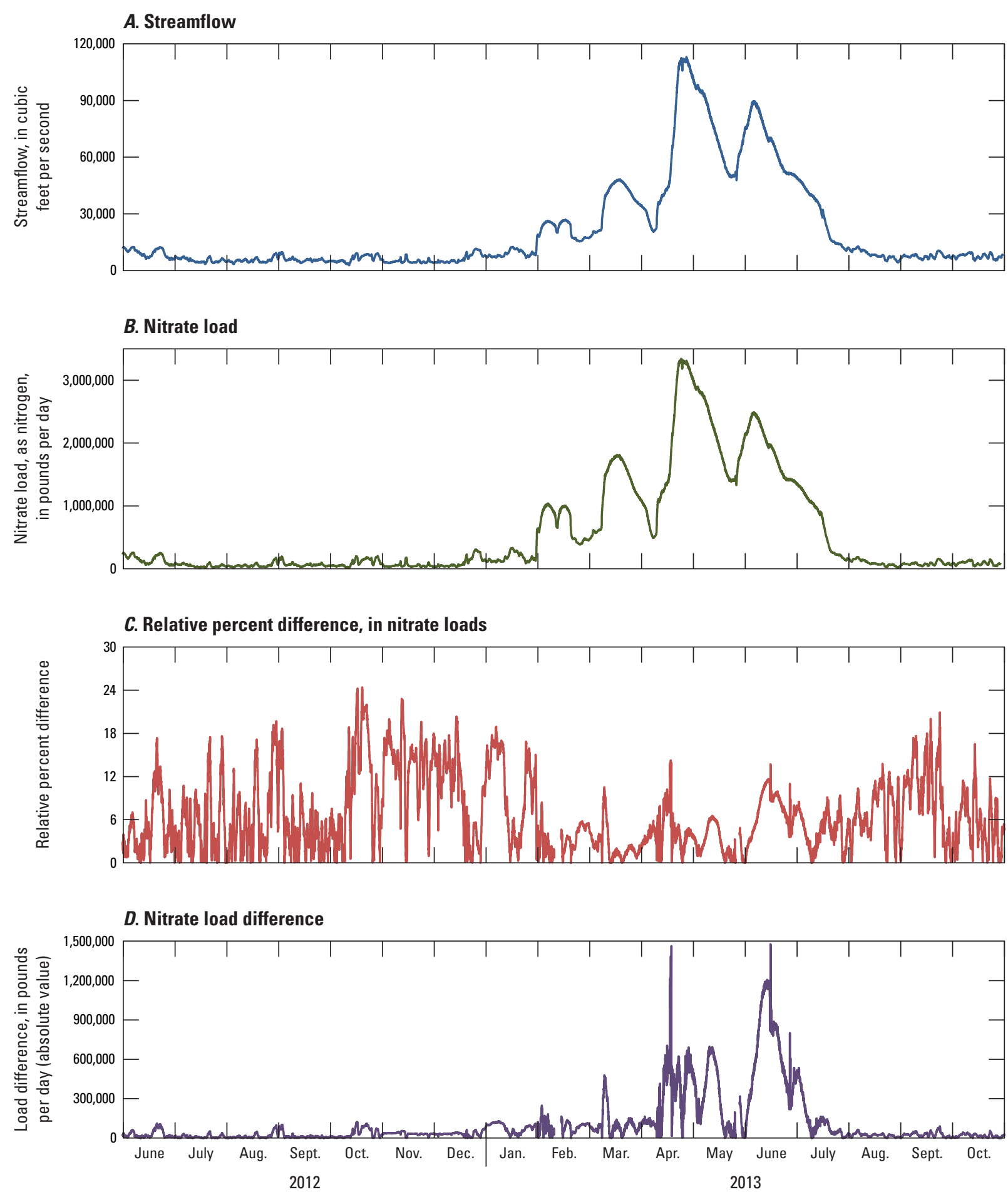

Figure 20. Instantaneous nitrate loads and the differences in loads computed using continuous data and the LOADEST program for June 2012-0ctober 2013 at the Illinois River at Florence, Illinois (05586300). A, Streamflow, in cubic feet per second. $B$, Nitrate load. $C$, Relative percent difference in nitrate loads. $D$, Nitrate load difference, in pounds per day (absolute value). 


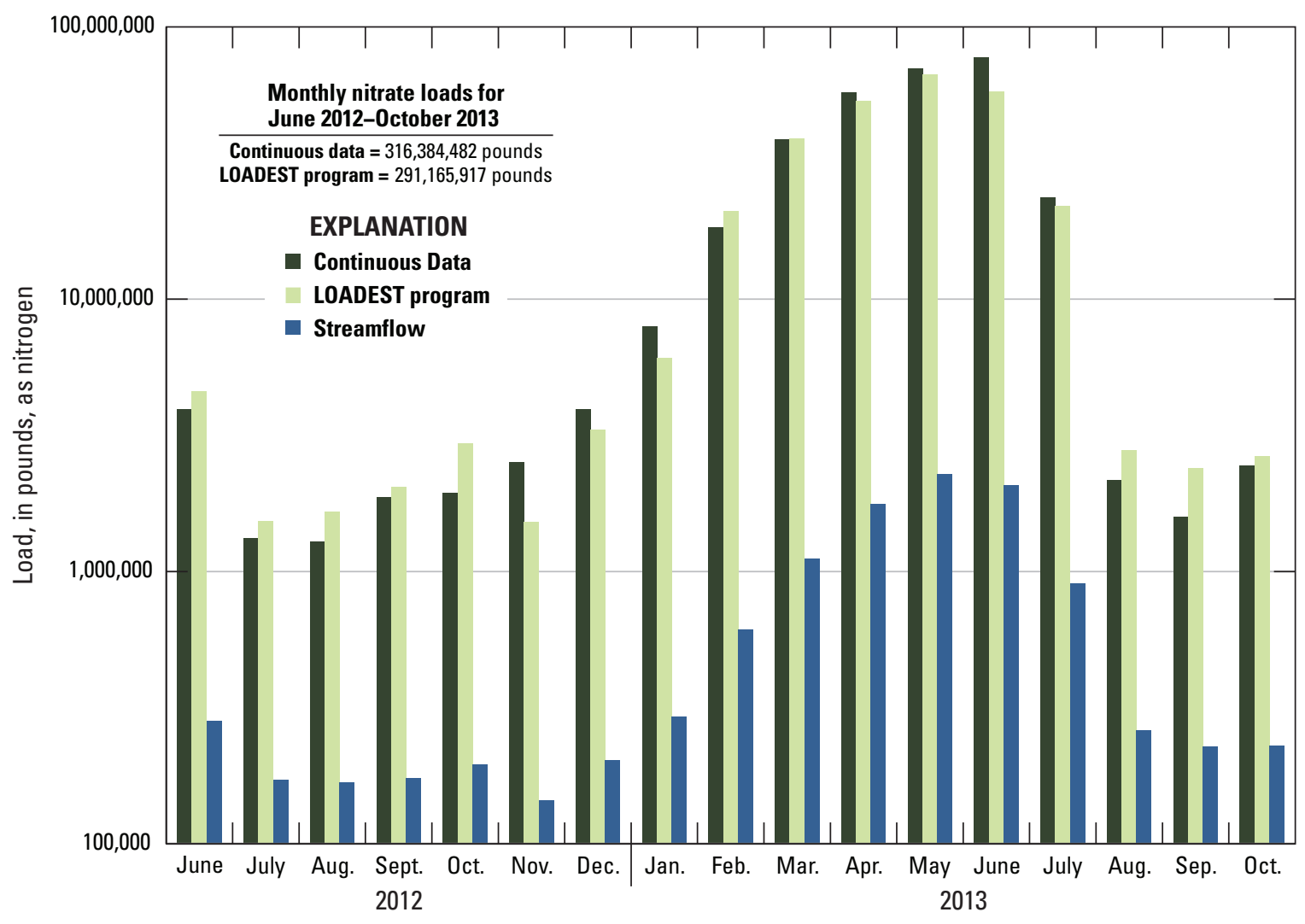

Figure 21. Monthly nitrate loads in the Illinois River at Florence, Illinois (05586300), June 2012-0ctober 2013.

\section{Phosphate}

Calculation of phosphate loads at the Illinois River at Florence, Ill. (05586300), was done in the same manner as for nitrate loads using both continuous- and discrete-sample based calculations. Data used for the LOADEST program included DOP and streamflow data for August 2012-November 2013. This period of record included data from before the Cycle analyzer was installed, but provided a more comprehensive set of data from which to calculate an appropriate regression equation for the station. The equation selected by LOADEST for DOP load calculation was

$$
\begin{aligned}
& \operatorname{Load}_{P 04}(\mathrm{lb} / \mathrm{d})=9.4695+1.0475(\operatorname{LnQ})+0.0209\left(\operatorname{Ln} Q^{2}\right)- \\
& 0.3629 \operatorname{Sin}(2 \text { pi dtime })-0.3054 \operatorname{Cos}(2 \text { pi dtime })- \\
& 0.6554(\text { dtime })+1.0466\left(\mathrm{dtime}^{2}\right)
\end{aligned}
$$

Figure 22 shows time-series plots of the loads calculated by the two methods, as well as instantaneous load values associated with each of the discrete samples for AprilOctober 2013. The Cycle analyzer was deployed only during April-October 2013, and figure 23 depicts only this period. The plot indicates substantial differences, at times, between the load values computed by the two methods. The load values computed using the continuous data are virtually always greater than the load values computed by the LOADEST program. As with nitrate, the loads calculated from the continuous data also show a greater response to changes in streamflow than the LOADEST computed values. Instantaneous loads computed from discrete samples generally are closer to the LOADEST loads than to the continuous-data based loads, although they commonly are somewhere in between the LOADEST and continuous load values. Quantitative differences between the two load estimates are greatest during periods of higher streamflow.

In the discussion regarding the continuous phosphate data, it was noted that the continuous Cycle analyzer data had a positive bias when compared to discrete laboratory data (fig. 13). This bias would carry through in the calculation of continuous-data based load values and warrants further evaluation.

The quantitative differences and the relative percent differences between the two methods of calculating phosphate loads are shown in figure 23. Relative percent differences in the load values were generally less than 10 percent, with the primary exception of the high-flow period in early June 2013 when loads computed from the continuous data were substantially larger than the loads computed by the LOADEST program. 


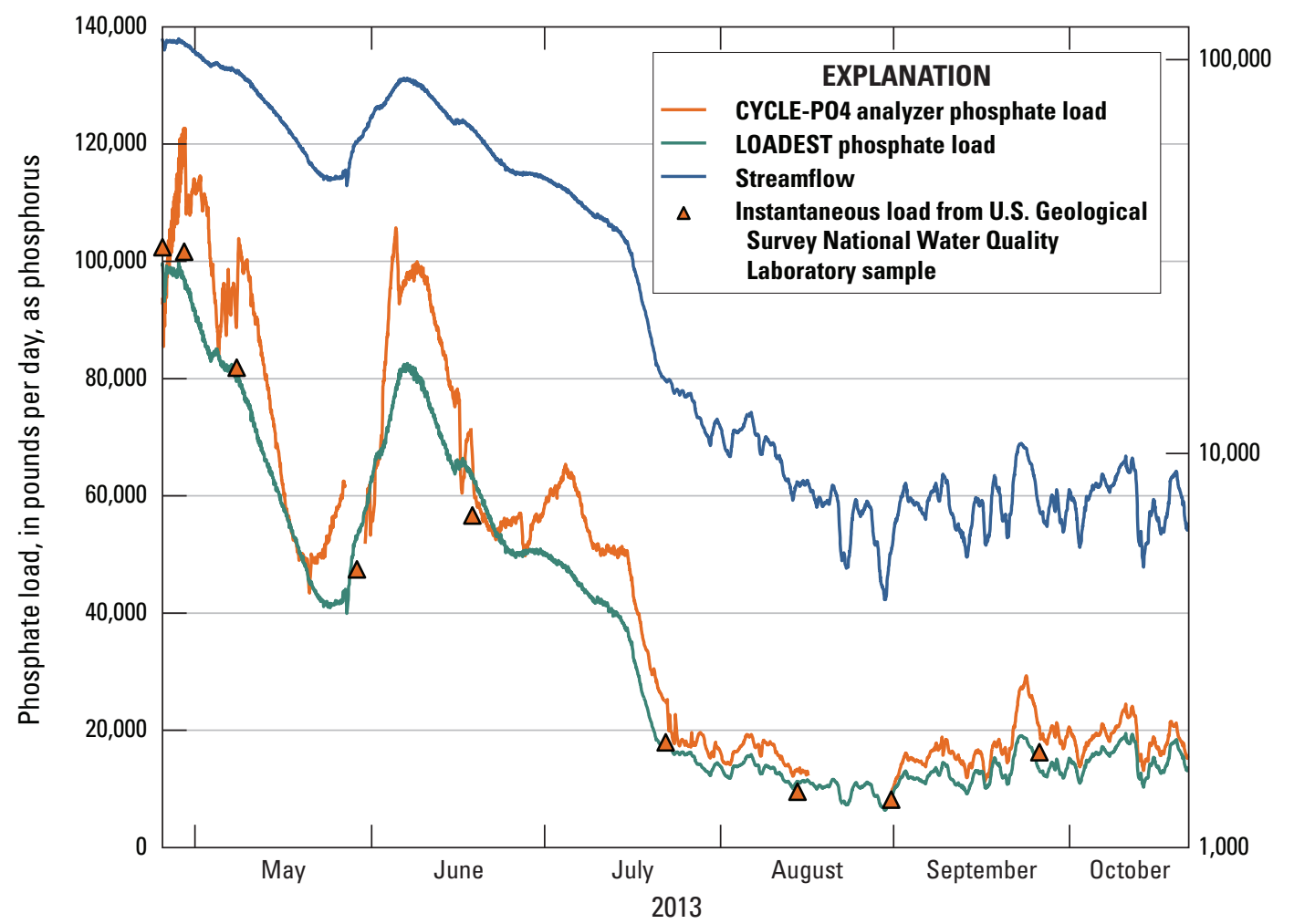

Figure 22. Phosphate loads at the Illinois River at Florence, Illinois (05586300), April-October 2013.

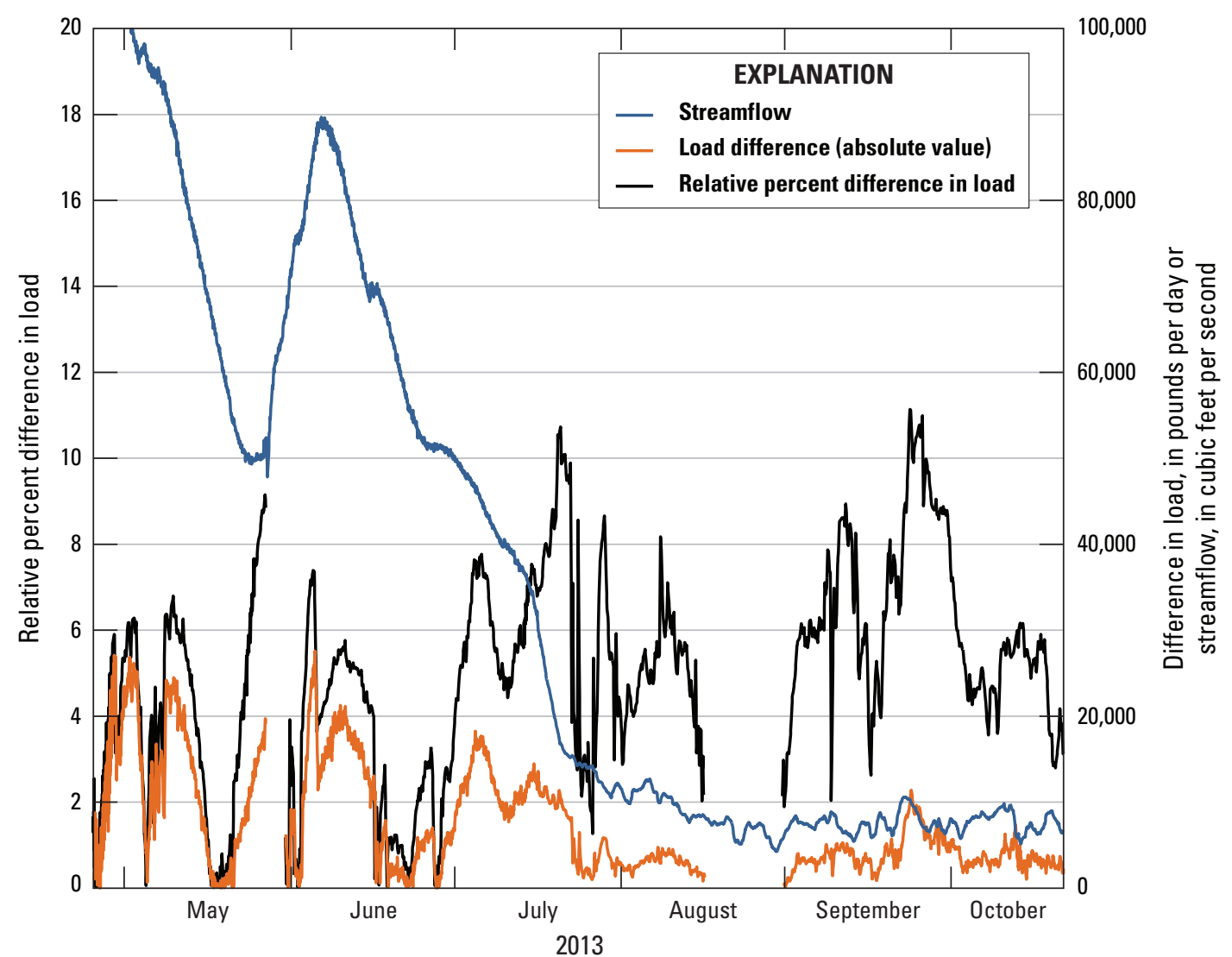

Figure 23. Relative percent differences and quantitative differences in computed phosphate loads for the Illinois River at Florence, Illinois (05586300), April-October 2013. 


\section{Discussion}

\section{Suspended Sediment}

The instruments and methods used in this study were tested for a wide range of conditions that occurred during the study period. The SSC values used in the linear models ranged from 15 to $1,970 \mathrm{mg} / \mathrm{L}$, which encompasses the ranges of conditions that occur at the site on an annual basis.

The techniques and methods for using turbidity as a surrogate for SSC are well documented in Rasmussen and others (2009). These methods were followed in this study, and two different turbidity linear regression models had great $\mathrm{R}^{2}$, near 0.9 . The SOLITAX $\mathrm{R}^{2}(0.92)$ was slightly better than the YSI $6136 \mathrm{R}^{2}(0.88)$. SSC samples are still needed on an annual basis to verify whether or not the linear regression models still apply, but sampling could be cut to 6 to 12 samples per year for a variety of turbidity and SSC conditions. The following factors may cause a deviation from the existing model, and shifts or new models may need to be created depending upon the severity of the problems.

- Changes in sediment source and type

- Changes in longitudinal or vertical location of the instrument

- Changes in channel configuration (meandering, aggradation, degradation)

- Changes to sensor setup, model, or type

The stream conditions did reach the upper range $(1,000$ to 2,000 FNUs) of the YSI 6136 (Rasmussen and others, 2009), but the data never appeared to truncate. This should be a consideration at other sites where higher turbidity values are expected. For the SOLITAX, the manufacturer denotes an upper range of $50,000 \mathrm{mg} / \mathrm{L}$ for total-suspended solids (Hach Company, 2014). The SSLs calculated from the two turbidity sensors were within 5 percent of each other and within 7 percent of loads calculated by traditional methods using discrete storm and routine samples.

For sediment acoustics at this site, there appears to be some condition (environmental or anthropogenic) that has an effect on the backscatter data. Even with the issues, the linear regression model for SSC values greater than $155 \mathrm{mg} / \mathrm{L}$ had great $\mathrm{R}^{2}$, near 0.9 . Utilizing acoustics as a surrogate for SSC is advantageous because of the dual use of one instrument, velocity and SSC. Testing that uses acoustics as a surrogate for SSC is ongoing at the Spoon River near Seville, Ill., and the Kickapoo Creek near Bloomington, Ill.; provisional results are pending. These results, along with provisional results of a second ADVM installed at Florence (in a less turbulent area), are promising for the future of using acoustic parameters as a surrogate for SSC, and a USGS techniques and methods report is currently being drafted.

\section{Nitrate}

In-situ nitrite plus nitrate concentrations were measured on a continuous basis using two ultraviolet absorption sensors with slightly different characteristics;a Hach NITRATAX and a Satlantic SUNA. There are some physical differences between these two instruments that require consideration when deploying the instruments in the field. Each instrument provided a reliable data record once some initial deployment issues were addressed. The measurement path lengths of the instruments differ, and it has been found that a shorter path length is advantageous because it is less affected by sediment and turbidity and typically provides a broader range of concentration measurement.

Reliable data can be provided by in-situ nitrate sensors, and the temporal completeness of the data record is greatly increased with continuous monitoring of nitrate. The in-situ sensors, when adequately maintained and calibrated, provided concentration values that were reasonably similar to concentrations determined by the laboratory. Some of the advantages of a continuous and near-real-time record of nitrate concentration data include

- ability to adjust sampling or operational procedures in response to changing conditions

- more complete coverage of nitrate concentration over extreme (low- or high-flow) hydrologic events

- ability to calculate more comprehensive and accurate nitrate loading quantities and subsequent determination of riverine transport

- increased ability to assess seasonal and flow-related changes

- ability to identify and respond to developing or occurring high-nitrate events

Perhaps the most advantageous and compelling use of continuous nitrate data is the determination of nitrate loading. This study determined that while the general nitrate loading in the Illinois River can be determined by interpretive modeling using periodic sample collection and a continuous record of streamflow, there are some periods and flow conditions that are mischaracterized with respect to potential or actual nitrate loading. Typically, these are low- and high-flow periods that are critically important with respect to the total amount of nitrate transported or the potential effects on the stream ecosystem. The greatest differences in computed nitrate loadings based upon periodic or continuous nitrate-concentration data records were during periods of increased streamflow and greatest nitrate transport. However, while the quantitative differences were small in comparison to high-flow periods, there also were several periods in the data record of this study that identified substantial differences in loadings during low-flow periods using the two different approaches. For the 
June 2012-October 2013 period, the continuous data record yielded a cumulative nitrate load approximately 8.3 percent larger than the LOADEST-derived load.

\section{Phosphate}

Continuous in-situ phosphate data were measured using a WET Labs Cycle-PO4 phosphate analyzer. The analyzer installation and operation presented some difficulties and complications with respect to physical configuration, data communications, and performance. However, these issues were overcome and consistent and reliable phosphate data were provided by the analyzer from April through October 2013. In comparison to laboratory-analyzed samples, the phosphate concentrations provided by the analyzer were generally around 10 to 15 percent higher than laboratory orthophosphate concentrations. This difference appears to be fairly uniform and can therefore be determined for each deployment location or instrument, and a correction can be applied to the data.

The in-situ phosphate analyzer determines only phosphate concentration. Relations between phosphate and total phosphorus appear to be determinable and practical with correlation coefficients greater than 0.8 when suspended sediment or turbidity variables are included in linear regression models to account for phosphorus associated with particulate matter.

\section{Conclusion}

The results from this study indicate that in-situ instruments can provide reliable, real-time continuous nutrient data that can greatly increase the understanding of nitrogen and phosphorus in Illinois water bodies, improve comprehensive data collection during extreme hydrologic events, and reduce uncertainties in nutrient-loading computations. The increased data record achievable with continuous monitoring allows for improved and more comprehensive regression algorithms for modeling nutrient loading. For nitrate, the continuous data record yielded a cumulative nitrate load approximately 8.3 percent larger than the LOADEST-derived load. Results indicate that suspended sediment and orthophosphate can be used to predict total phosphorus. Regression equations incorporating phosphate and suspended sediment improved the prediction of total phosphorus (correlation coefficients greater than 0.8 ) because phosphate is associated with particulate matter. In-situ instruments like continuous turbidity provide a surrogate to determine suspended-sediment concentrations and loads.

\section{References Cited}

Alexander, R.B., Smith, R.A., Schwarz, G.E., Boyer, E.W., Nolan, J.V, and Brakebill, J.W., 2008, Differences in phosphorus and nitrogen delivery to the Gulf of Mexico from the Mississippi River Basin: Environmental Science and Technology, v. 42, no. 3, p. 822-830.

Anderson, C.W., 2005, Turbidity: U.S. Geological Survey Techniques of Water-Resources Investigations, book 9, chap. A6, sec. $6.7,55$ p.

American Public Health Association, 1998, Standard methods for the examination of water and wastewater (20th ed.): Washington D.C., American Public Health Association, American Water Works Association, and Water Environment Federation publication [variously paged].

Duan, Naihua, 1983, Smearing estimate-A nonparametric retransformation method: Journal of the American Statistical Association, v. 78, no. 383, p. 605-610.

Edwards, T.K., and Glysson, G.D., 1999, Field methods for measurement of fluvial sediment-Applications of hydraulics: U.S. Geological Survey Techniques of WaterResources Investigations, book 3, chap. C2, 89 p., available at http://pubs.usgs.gov/twri/twri3-c2/.

Fishman, M.J., ed., 1993, Methods of analysis by the U.S. Geological Survey National Water Quality Laboratory-Determination of inorganic and organic constituents in water and fluvial sediments: U.S. Geological Survey Open-File Report 93-125, 217 p.

Gray, J.R., and Gartner, J.W., 2006, Overview of selected surrogate technologies for continuous suspended-sediment monitoring, in Proceedings of the 8th Federal Interagency Sedimentation Conference, April 2-6, 2006, Reno, Nev., p. 337-344, accessed March 2008 at http://pubs.usgs. gov/misc_reports/FISC_1947-2006/pdf/1st-7thFISCsCD/8thFISC/Session\%204C-1_Gray.pdf.

Guy, H.P., 1970, Fluvial sediment concepts-Applications of hydraulics: U.S. Geological Survey Techniques of WaterResources Investigations, book 3, chap. C1, 55 p., available at http://pubs.usgs.gov/twri/twri3-c1/.

Hach Company, 2012, NITRATAX sc User manual (5th ed.) DOC023.54.03211, accessed September 2014 at http:// www.hach.com/nitratax-plus-sc-sensor-2-mm-path-length/ product-downloads?id=7640095062. 
Hach Company, 2014, SOLITAX sc description page, accessed March 2014 at http://www.hach.com/SOLITAXsc-ss-wiper-with-sc200-controller/product?id=7640286605.

Heimann, D.C., Cline, T.L., and Glaspie, L.M., 2011, Suspended-sediment and suspended-sand concentrations and loads for selected streams in the Mississippi River Basin, 1940-2009: U.S. Geological Survey Data Series 593, 6 p.

Helsel, D.R., and Hirsch, R.M., 2002, Statistical methods in water resources-Hydrologic analysis and interpretation: U.S. Geological Survey Techniques of Water-Resources Investigations, book 4, chap. A3, 522 p., available at http:// pubs.usgs.gov/twri/twri4a3/.

Hem, J.D., 1985, Study and interpretation of the chemical characteristics of natural water ( $3 \mathrm{~d}$ ed.): U.S. Geological Survey Water-Supply Paper 2254, 263 p.

Illinois Pollution Control Board, 2013, Environmental Regulations for the State of Illinois, Title 35 of the Illinois Administrative Code, Subtitle C, Chapter I, Part 302, accessed January 2014 at http://www.ipcb.state.il.us/SLR/ IPCBandIEPAEnvironmentalRegulations-Title35.aspx.

Koltun, G.F., Eberle, Michael, Gray, J.R., and Glysson, G.D., 2006, User's manual for the Graphical Constituent Loading Analysis System (GCLAS): U.S. Geological Survey Techniques and Methods, 4-C1, 51 p., available at http://pubs. usgs.gov/tm/2006/tm4C1/.

Pellerin, B.A., Bergamaschi, B.A., Downing, B.D., Saraceno, J.F., Garrett, J.A., and Olsen, L.D., 2013, Optical techniques for the determination of nitrate in environmental watersGuidelines for instrument selection, operation, deployment, maintenance, quality assurance, and data reporting: U.S. Geological Survey Techniques and Methods 1-D5, 37 p., available at http://pubs.usgs.gov/tm/01/d5/.

Porterfield, George, 1972, Computation of fluvial-sediment discharge-Applications of hydraulics: U.S. Geological Survey Techniques of Water-Resources Investigations Report, book 3, chap. C3, 66 p., available at http://pubs. usgs.gov/twri/twri3-c3/pdf/TWRI_3-C3.pdf.

Rasmussen, P.P., Gray, J.R., Glysson, G.D., and Ziegler, A.C., 2009, Guidelines and procedures for computing time-series suspended-sediment concentrations and loads from instream turbidity-sensor and streamflow data: U.S. Geological Survey Techniques and Methods, book 3, chap. C4, 53 p., available at http://pubs.usgs.gov/tm/tm $3 \mathrm{c} 4 /$.

Rubin, D.M., Topping, D.J., Wright, S.A., and Melis, T.S., 2007, High-resolution measurements of suspended-sediment concentration and grain size in the Colorado River in Grand Canyon using a multi-frequency acoustic system, in Proceedings of the 10th International Symposium on River Sedimentation, Moscow, Russia, August 1-4, 2007: p. 330-339.
Runkel, R.L., Crawford, C.G., and Cohn, T.A., 2004, Load Estimator (LOADEST) —A FORTRAN program for estimating constituent loads in streams and rivers: U.S. Geological Survey Techniques and Methods book 4, chap. A5, 69 p., available at http://pubs.usgs.gov/tm/2005/tm4A5/.

Satlantic Incorporated, 2011, SUNA user manual, SUNACom 2.2.0, Document SAT-DN-00498, accessed September 2014 at http://satlantic.com/manuals.

Sholar, C.J., and Shreve, E.A., 1998, Quality-assurance plan for the analysis of fluvial sediment by the Northeastern Region, Kentucky District Sediment Laboratory: U.S. Geological Survey Open-File Report 98-384, 20 p., available at http://pubs.usgs.gov/of/1998/0384/report.pdf.

Sontek, 2009, Argonaut-SL system manual firmware (ver. 12.0): San Diego, CA, 316 p.

Sprague, L.A., Hirsch, R.M., and Aulenbach, B.T, 2011, Nitrate in the Mississippi River and its tributaries, 1980 to 2008-Are we making progress?: Environmental Science and Technology, v. 45, no. 17, p. 7209-7216.

Topping, D.J., Melis, T.S., Rubin, D.M., and Wright, S.A., 2004, High-resolution monitoring of suspended-sediment concentration and grain size in the Colorado River in Grand Canyon using a laser acoustic system, in Proceedings of the 9th International Symposium on River Sedimentation, Yichang, China, October 18-21, 2004: Tsinghua University Press, p. 2507-2514.

Topping, D.J., Melis, T.S., Wright, S.A., and Rubin, D.M., 2006, High-resolution monitoring of suspended-sediment concentration and grain size in the Colorado River in Grand Canyon using laser-diffraction instruments and a three-frequency acoustic system, in Proceedings of the 8th Federal Interagency Sedimentation Conference, Reno, Nev., April 2-6, 2006: p. 555-559.

U.S. Environmental Protection Agency, 1999, Guidance manual for compliance with the interim enhanced surface water treatment rule-Turbidity provisions: Washington, D.C., Office of Water, EPA 815-R-99-010 [variously paged].

WET Labs, Inc., 2011, Cycle (PO4) hardware user's guide (rev. 1.1): Philomath, Ore., 44 p.

YSI Incorporated, 2014, 6136 turbidity sensor (6 series) description page, accessed March 2014 at http://www.ysi. com/accessoriesdetail.php?6136-Turbidity-Sensor-6-Series-94. 



\section{Appendix 1. Estimating Suspended Sediment Concentration from In-situ Turbidity Measurements in Formazin Backscatter Ratio Units (FBRU) - Model Information and Data (Hach Solitax Instrument to Measure Turbidity)}

\section{Model form}

$\log _{10} \mathrm{SSC}=-0.232+1.080 \log _{10}$ TurbFBRU

\begin{tabular}{lcccc}
\cline { 2 - 5 } & \multicolumn{2}{c}{ Predictor variable summary statistics } & \multicolumn{2}{c}{ Response variable summary statistics } \\
\cline { 2 - 5 } & Turbidity (FBRU) & $\log _{10}\left(\right.$ Turb $\left._{\text {FBRu }}\right)$ & SSC (mg/L) & log $_{10}$ (SSC) \\
\hline Minimum & 15 & 1.176 & 15 & 1.176 \\
1st Quartile & 47 & 1.667 & 34 & 1.532 \\
Median & 77 & 1.884 & 59 & 1.767 \\
Mean & 148 & 1.953 & 140 & 1.876 \\
3rd Quartile & 132 & 2.119 & 130 & 2.114 \\
Maximum & 1,660 & 3.220 & 1,970 & 3.295 \\
\hline
\end{tabular}

\section{Model calibration}

\begin{tabular}{lc}
\hline \multicolumn{2}{c}{ Basic data } \\
\hline Number of observations & 140 \\
Error degrees of freedom & 138 \\
$\begin{array}{l}\text { Root mean squared error (Standard error of } \\
\text { regression) }\end{array}$ & 0.12169 \\
R-squared & 0.924 \\
Adjusted R-squared & 0.924 \\
F-statistic versus constant model & 1,680 \\
p-value & $3.35 \mathrm{E}-79$ \\
Non-parametric smearing bias correction factor & 1.0413 \\
Probability plot correlation coefficient & 0.98985 \\
\hline
\end{tabular}

Estimated coefficients

\begin{tabular}{lcccccc}
\hline & Estimate & SE & tStat & pValue & Lower 90 percent & Upper 90 percent \\
\hline (Intercept) & -0.23211 & 0.052391 & -4.4303 & $1.9 \mathrm{E}-05$ & -0.318867 & -0.145352 \\
$\log _{10}$ TurbFBRU & 1.0796 & 0.02631 & 41.034 & $3.35 \mathrm{E}-79$ & 1.03605 & 1.12319 \\
\hline
\end{tabular}


Appendix 1. Estimating Suspended Sediment Concentration from In-situ Turbidity Measurements in Formazin Backscatter Ratio Units (FBRU)—Model Information and Data(Hach Solitax Instrument to Measure Turbidity):

[CST, central standard time; SSC, suspended-sediment concentration; $\mathrm{mg} / \mathrm{L}$, milligrams per liter; $\log _{10}$, base-10 logarithmic transform; mm, millimeter; FBRU, formazin backscatter ratio units]

\begin{tabular}{|c|c|c|c|c|c|c|c|c|c|c|}
\hline \multicolumn{6}{|c|}{ Suspended sediment } & \multicolumn{5}{|c|}{ Solitax } \\
\hline \multirow{2}{*}{$\begin{array}{l}\text { Date and time } \\
\text { (CST) }\end{array}$} & \multirow{2}{*}{$\begin{array}{l}\text { Station } \\
\text { number }\end{array}$} & \multirow{2}{*}{$\begin{array}{c}\text { Method } \\
\text { code }^{1}\end{array}$} & \multicolumn{2}{|c|}{ Concentration (SSC) } & \multirow{2}{*}{$\begin{array}{l}\text { Percent finer } \\
\text { than } 0.0625 \mathrm{~mm}\end{array}$} & \multirow{2}{*}{$\begin{array}{l}\text { Date and time } \\
\text { (CST) }\end{array}$} & \multicolumn{2}{|c|}{ Turbidity } & \multirow{2}{*}{$\begin{array}{l}\text { Regression estimate } \\
\text { SSC (mg/L) }\end{array}$} & \multirow{2}{*}{$\begin{array}{r}\text { Regression } \\
\text { residual } \log _{1}\end{array}$} \\
\hline & & & (mg/L) & $\log _{10}(\mathrm{mg} / \mathrm{L})$ & & & (FBRU) & $\log _{10}(\mathrm{FBRU})$ & & \\
\hline $07 / 09 / 2012 \quad 17: 20$ & 05586300 & 920 & 50 & 1.699 & & 07/09/2012 17:15 & 47 & 1.672 & 39 & 0.126 \\
\hline 07/11/2012 17:30 & 05586300 & 920 & 49 & 1.690 & & 07/11/2012 17:30 & 58 & 1.763 & 49 & 0.018 \\
\hline 07/17/2012 19:00 & 05586300 & 920 & 47 & 1.672 & & 07/17/2012 19:00 & 54 & 1.732 & 45 & 0.034 \\
\hline 07/18/2012 18:00 & 05586300 & 920 & 45 & 1.653 & & 07/18/2012 18:00 & 48 & 1.681 & 40 & 0.070 \\
\hline 07/22/2012 16:00 & 05586300 & 920 & 75 & 1.875 & & 07/22/2012 16:00 & 83 & 1.919 & 72 & 0.035 \\
\hline 07/25/2012 19:00 & 05586300 & 920 & 42 & 1.623 & & 07/25/2012 19:00 & 51 & 1.708 & 43 & 0.012 \\
\hline 07/29/2012 16:00 & 05586300 & 920 & 53 & 1.724 & & 07/29/2012 16:00 & 79 & 1.898 & 68 & -0.092 \\
\hline 08/01/2012 16:00 & 05586300 & 920 & 48 & 1.681 & & 08/01/2012 16:00 & 63 & 1.799 & 53 & -0.029 \\
\hline 08/03/2012 08:44 & 05586300 & 30 & 130 & 2.114 & & 08/03/2012 08:45 & 100 & 2.000 & 88 & 0.187 \\
\hline 08/03/2012 08:53 & 05586300 & 20 & 69 & 1.839 & & 08/03/2012 09:00 & 93 & 1.968 & 81 & -0.054 \\
\hline 08/03/2012 09:20 & 05586300 & 30 & 72 & 1.857 & 99 & 08/03/2012 09:15 & 96 & 1.982 & 84 & -0.051 \\
\hline 08/03/2012 09:26 & 05586300 & 30 & 58 & 1.763 & & 08/03/2012 09:30 & 80 & 1.903 & 69 & -0.059 \\
\hline 08/03/2012 09:55 & 05586300 & 10 & 97 & 1.987 & 62 & 08/03/2012 10:00 & 82 & 1.914 & 71 & 0.153 \\
\hline 08/04/2012 00:44 & 05586100 & 10 & 54 & 1.732 & 87 & 08/04/2012 00:45 & 51 & 1.708 & 43 & 0.121 \\
\hline 08/05/2012 18:00 & 05586300 & 920 & 48 & 1.681 & & 08/05/2012 18:00 & 61 & 1.785 & 52 & -0.014 \\
\hline 08/08/2012 15:30 & 05586300 & 920 & 50 & 1.699 & & 08/08/2012 15:30 & 62 & 1.792 & 53 & -0.004 \\
\hline 08/12/2012 18:00 & 05586300 & 920 & 52 & 1.716 & & 08/12/2012 18:00 & 66 & 1.820 & 56 & -0.016 \\
\hline 08/15/2012 06:30 & 05586300 & 920 & 39 & 1.591 & & 08/15/2012 06:30 & 51 & 1.708 & 43 & -0.020 \\
\hline 08/21/2012 14:27 & 05586300 & 30 & 89 & 1.949 & 97 & 08/21/2012 14:30 & 89 & 1.947 & 77 & 0.080 \\
\hline 08/21/2012 14:45 & 05586300 & 10 & 113 & 2.053 & 97 & 08/21/2012 14:45 & 92 & 1.964 & 80 & 0.165 \\
\hline 08/22/2012 09:28 & 05586100 & 10 & 63 & 1.799 & 93 & 08/22/2012 09:30 & 57 & 1.756 & 48 & 0.136 \\
\hline 08/22/2012 16:00 & 05586300 & 920 & 40 & 1.602 & & 08/22/2012 16:00 & 59 & 1.771 & 50 & -0.078 \\
\hline 08/26/2012 15:00 & 05586300 & 920 & 26 & 1.415 & & 08/26/2012 15:00 & 39 & 1.591 & 32 & -0.071 \\
\hline 08/29/2012 06:30 & 05586300 & 920 & 33 & 1.519 & & 08/29/2012 06:30 & 45 & 1.653 & 37 & -0.034 \\
\hline 09/04/2012 15:00 & 05586300 & 920 & 49 & 1.690 & & 09/04/2012 15:00 & 75 & 1.875 & 65 & -0.102 \\
\hline 09/05/2012 17:00 & 05586300 & 920 & 52 & 1.716 & & 09/05/2012 17:00 & 50 & 1.696 & 41 & 0.117 \\
\hline 09/09/2012 16:00 & 05586300 & 920 & 47 & 1.672 & & 09/09/2012 16:00 & 65 & 1.813 & 55 & -0.053 \\
\hline 09/11/2012 19:00 & 05586300 & 920 & 35 & 1.544 & & 09/11/2012 19:00 & 53 & 1.724 & 44 & -0.085 \\
\hline 09/17/2012 15:00 & 05586300 & 920 & 36 & 1.556 & & 09/17/2012 15:00 & 47 & 1.672 & 39 & -0.017 \\
\hline
\end{tabular}


Appendix 1. Estimating Suspended Sediment Concentration from In-situ Turbidity Measurements in Formazin Backscatter Ratio Units (FBRU)—Model Information and Data(Hach Solitax Instrument to Measure Turbidity)._-Continued

[CST, central standard time; SSC, suspended-sediment concentration; mg/L, milligrams per liter; $\log _{10}$, base-10 logarithmic transform; mm, millimeter; FBRU, formazin backscatter ratio units]

\begin{tabular}{|c|c|c|c|c|c|c|c|c|c|c|}
\hline \multicolumn{6}{|c|}{ Suspended sediment } & \multicolumn{5}{|c|}{ Solitax } \\
\hline \multirow{2}{*}{$\begin{array}{l}\text { Date and time } \\
\text { (CST) }\end{array}$} & \multirow{2}{*}{$\begin{array}{l}\text { Station } \\
\text { number }\end{array}$} & \multirow{2}{*}{$\begin{array}{c}\text { Method } \\
\text { code }^{1}\end{array}$} & \multicolumn{2}{|c|}{ Concentration (SSC) } & \multirow{2}{*}{$\begin{array}{l}\text { Percent finer } \\
\text { than } 0.0625 \mathrm{~mm}\end{array}$} & \multirow{2}{*}{$\begin{array}{l}\text { Date and time } \\
\text { (CST) }\end{array}$} & \multicolumn{2}{|c|}{ Turbidity } & \multirow{2}{*}{$\begin{array}{l}\text { Regression estimate } \\
\text { SSC (mg/L) }\end{array}$} & \multirow{2}{*}{$\begin{array}{r}\text { Regression } \\
\text { residual } \log _{1}\end{array}$} \\
\hline & & & (mg/L) & $\log _{10}(\mathrm{mg} / \mathrm{L})$ & & & (FBRU) & $\log _{10}(\mathrm{FBRU})$ & & \\
\hline 09/19/2012 17:00 & 05586300 & 920 & 32 & 1.505 & & 09/19/2012 17:00 & 50 & 1.699 & 42 & -0.097 \\
\hline 09/23/2012 16:00 & 05586300 & 920 & 39 & 1.591 & & 09/23/2012 16:00 & 59 & 1.771 & 50 & -0.089 \\
\hline 09/26/2012 19:00 & 05586300 & 920 & 54 & 1.732 & & 09/26/2012 19:00 & 77 & 1.886 & 66 & -0.072 \\
\hline 09/27/2012 09:30 & 05586300 & 30 & 56 & 1.748 & & 09/27/2012 09:30 & 80 & 1.903 & 69 & -0.074 \\
\hline 09/30/2012 18:30 & 05586300 & 920 & 30 & 1.477 & & 09/30/2012 18:30 & 66 & 1.820 & 56 & -0.255 \\
\hline 10/03/2012 17:30 & 05586300 & 920 & 33 & 1.519 & & $10 / 03 / 201217: 30$ & 36 & 1.556 & 29 & 0.070 \\
\hline 10/07/2012 18:00 & 05586300 & 920 & 33 & 1.519 & & 10/07/2012 18:00 & 43 & 1.633 & 35 & -0.013 \\
\hline 10/10/2012 19:00 & 05586300 & 920 & 34 & 1.531 & & 10/10/2012 19:00 & 33 & 1.519 & 27 & 0.124 \\
\hline 10/14/2012 15:00 & 05586300 & 920 & 46 & 1.663 & & $10 / 14 / 2012 \quad 15: 00$ & 68 & 1.833 & 58 & -0.084 \\
\hline $10 / 16 / 201216: 30$ & 05586300 & 920 & 56 & 1.748 & & 10/16/2012 16:30 & 74 & 1.869 & 64 & -0.038 \\
\hline 10/17/2012 18:30 & 05586300 & 920 & 32 & 1.505 & & 10/17/2012 18:30 & 43 & 1.633 & 35 & -0.026 \\
\hline $10 / 18 / 2012$ 15:55 & 05586300 & 30 & 31 & 1.491 & & 10/18/2012 16:00 & 40 & 1.602 & 33 & -0.006 \\
\hline $10 / 18 / 201215: 58$ & 05586300 & 30 & 33 & 1.519 & & 10/18/2012 16:00 & 40 & 1.602 & 33 & 0.021 \\
\hline 10/18/2012 16:01 & 05586300 & 30 & 30 & 1.477 & & 10/18/2012 16:00 & 40 & 1.602 & 33 & -0.020 \\
\hline 10/18/2012 16:06 & 05586300 & 20 & 34 & 1.531 & 98 & 10/18/2012 16:00 & 40 & 1.602 & 33 & 0.034 \\
\hline 10/18/2012 16:18 & 05586300 & 30 & 37 & 1.568 & & 10/18/2012 16:15 & 41 & 1.613 & 34 & 0.059 \\
\hline 10/21/2012 18:00 & 05586300 & 920 & 24 & 1.380 & & 10/21/2012 18:00 & 28 & 1.447 & 22 & 0.050 \\
\hline 10/24/2012 18:00 & 05586300 & 920 & 34 & 1.531 & & 10/24/2012 18:00 & 61 & 1.785 & 52 & -0.164 \\
\hline 10/28/2012 17:00 & 05586300 & 920 & 40 & 1.602 & & 10/28/2012 17:00 & 32 & 1.505 & 26 & 0.209 \\
\hline 10/31/2012 10:00 & 05586300 & 30 & 23 & 1.362 & & 10/31/2012 10:00 & 31 & 1.491 & 25 & -0.016 \\
\hline $10 / 31 / 201215: 53$ & 05586100 & 15 & 25 & 1.398 & 98 & 10/31/2012 16:00 & 28 & 1.447 & 22 & 0.068 \\
\hline 10/31/2012 17:00 & 05586300 & 920 & 26 & 1.415 & & 10/31/2012 17:00 & 25 & 1.398 & 20 & 0.138 \\
\hline $11 / 05 / 201215: 00$ & 05586300 & 920 & 17 & 1.230 & & $11 / 05 / 2012$ 15:00 & 21 & 1.322 & 16 & 0.035 \\
\hline 11/07/2012 15:00 & 05586300 & 920 & 15 & 1.176 & & 11/07/2012 15:00 & 15 & 1.176 & 11 & 0.138 \\
\hline $11 / 13 / 201215: 00$ & 05586300 & 920 & 21 & 1.322 & & $11 / 13 / 2012$ 15:00 & 34 & 1.531 & 27 & -0.099 \\
\hline 11/14/2012 17:00 & 05586300 & 920 & 32 & 1.505 & & 11/14/2012 17:00 & 36 & 1.556 & 29 & 0.057 \\
\hline $11 / 27 / 201209: 40$ & 05586300 & 30 & 35 & 1.544 & & 11/27/2012 09:45 & 41 & 1.613 & 34 & 0.035 \\
\hline 11/27/2012 15:00 & 05586300 & 920 & 29 & 1.462 & & 11/27/2012 15:00 & 41 & 1.613 & 34 & -0.047 \\
\hline $12 / 02 / 2012$ 15:00 & 05586300 & 920 & 18 & 1.255 & & $12 / 02 / 201215: 00$ & 24 & 1.380 & 19 & -0.003 \\
\hline
\end{tabular}


Appendix 1. Estimating Suspended Sediment Concentration from In-situ Turbidity Measurements in Formazin Backscatter Ratio Units (FBRU)—Model Information and

[CST, central standard time; SSC, suspended-sediment concentration; $\mathrm{mg} / \mathrm{L}$, milligrams per liter; $\log _{10}$, base-10 logarithmic transform; mm, millimeter; FBRU, formazin backscatter ratio units]

\begin{tabular}{|c|c|c|c|c|c|c|c|c|c|c|}
\hline \multicolumn{6}{|c|}{ Suspended sediment } & \multicolumn{5}{|c|}{ Solitax } \\
\hline \multirow{2}{*}{$\begin{array}{l}\text { Date and time } \\
\text { (CST) }\end{array}$} & \multirow{2}{*}{$\begin{array}{l}\text { Station } \\
\text { number }\end{array}$} & \multirow{2}{*}{$\begin{array}{c}\text { Method } \\
\text { code }^{1}\end{array}$} & \multicolumn{2}{|c|}{ Concentration (SSC) } & \multirow{2}{*}{$\begin{array}{l}\text { Percent finer } \\
\text { than } 0.0625 \mathrm{~mm}\end{array}$} & \multirow{2}{*}{$\begin{array}{l}\text { Date and time } \\
\text { (CST) }\end{array}$} & \multicolumn{2}{|c|}{ Turbidity } & \multirow{2}{*}{$\begin{array}{l}\text { Regression estimate } \\
\text { SSC (mg/L) }\end{array}$} & \multirow{2}{*}{$\begin{array}{r}\text { Regression } \\
\text { residual } \log _{10}\end{array}$} \\
\hline & & & (mg/L) & $\log _{10}(\mathrm{mg} / \mathrm{L})$ & & & (FBRU) & $\log _{10}(\mathrm{FBRU})$ & & \\
\hline $12 / 04 / 201215: 00$ & 05586300 & 920 & 20 & 1.301 & & 12/04/2012 15:00 & 30 & 1.477 & 24 & -0.062 \\
\hline 12/08/2012 07:00 & 05586300 & 920 & 18 & 1.255 & & 12/08/2012 07:00 & 26 & 1.415 & 21 & -0.040 \\
\hline $12 / 10 / 201215: 00$ & 05586300 & 920 & 26 & 1.415 & & 12/10/2012 15:00 & 49 & 1.690 & 41 & -0.178 \\
\hline $12 / 12 / 201212: 30$ & 05586300 & 70 & 47 & 1.672 & & $12 / 12 / 201212: 30$ & 65 & 1.813 & 55 & -0.053 \\
\hline $12 / 13 / 201209: 30$ & 05586300 & 920 & 31 & 1.491 & & $12 / 13 / 201209: 30$ & 46 & 1.663 & 38 & -0.072 \\
\hline 12/13/2012 09:37 & 05586300 & 20 & 37 & 1.568 & & $12 / 13 / 201209: 30$ & 46 & 1.663 & 38 & 0.005 \\
\hline $12 / 13 / 201209: 45$ & 05586300 & 920 & 29 & 1.462 & & $12 / 13 / 201209: 45$ & 54 & 1.732 & 45 & -0.176 \\
\hline 12/13/2012 09:50 & 05586300 & 920 & 38 & 1.580 & & $12 / 13 / 201209: 45$ & 54 & 1.732 & 45 & -0.058 \\
\hline $12 / 14 / 201216: 47$ & 05586100 & 10 & 26 & 1.415 & 99 & $12 / 14 / 201216: 45$ & 31 & 1.491 & 25 & 0.037 \\
\hline $12 / 15 / 201207: 30$ & 05586300 & 920 & 21 & 1.322 & & $12 / 15 / 201207: 30$ & 29 & 1.462 & 23 & -0.025 \\
\hline $12 / 18 / 201215: 10$ & 05586300 & 920 & 18 & 1.255 & & $12 / 18 / 201215: 15$ & 29 & 1.462 & 23 & -0.091 \\
\hline $12 / 23 / 201216: 00$ & 05586300 & 920 & 31 & 1.491 & & $12 / 23 / 201216: 00$ & 41 & 1.613 & 34 & -0.018 \\
\hline $12 / 26 / 201215: 00$ & 05586300 & 920 & 62 & 1.792 & & $12 / 26 / 201215: 00$ & 97 & 1.987 & 85 & -0.120 \\
\hline $12 / 30 / 201215: 00$ & 05586300 & 920 & 27 & 1.431 & & $12 / 30 / 2012$ 15:00 & 45 & 1.653 & 37 & -0.121 \\
\hline 01/02/2013 15:00 & 05586300 & 920 & 25 & 1.398 & & 01/02/2013 15:00 & 40 & 1.602 & 33 & -0.100 \\
\hline 01/08/2013 09:45 & 05586300 & 70 & 23 & 1.362 & & 01/08/2013 09:45 & 39 & 1.591 & 32 & -0.124 \\
\hline 01/09/2013 16:50 & 05586300 & 920 & 22 & 1.342 & & 01/09/2013 16:45 & 41 & 1.613 & 34 & -0.167 \\
\hline 01/13/2013 15:00 & 05586300 & 920 & 63 & 1.799 & & 01/13/2013 15:00 & 104 & 2.017 & 92 & -0.146 \\
\hline 01/15/2013 15:00 & 05586300 & 920 & 59 & 1.771 & & 01/15/2013 15:00 & 86 & 1.935 & 75 & -0.086 \\
\hline 01/28/2013 15:00 & 05586300 & 920 & 28 & 1.447 & & 01/28/2013 15:00 & 49 & 1.690 & 41 & -0.145 \\
\hline 01/30/2013 17:45 & 05586300 & 920 & 843 & 2.926 & & 01/30/2013 17:45 & 718 & 2.856 & 740 & 0.074 \\
\hline 02/03/2013 16:30 & 05586300 & 920 & 405 & 2.607 & & 02/03/2013 16:30 & 372 & 2.571 & 364 & 0.064 \\
\hline 02/04/2013 12:40 & 05586300 & 70 & 355 & 2.550 & 89 & 02/04/2013 12:45 & 295 & 2.470 & 283 & 0.116 \\
\hline 02/05/2013 10:55 & 05586300 & 920 & 440 & 2.643 & & 02/05/2013 11:00 & 266 & 2.425 & 253 & 0.258 \\
\hline 02/05/2013 11:09 & 05586300 & 20 & 375 & 2.574 & & $02 / 05 / 201311: 15$ & 267 & 2.427 & 254 & 0.186 \\
\hline 02/05/2013 11:22 & 05586300 & 920 & 382 & 2.582 & & 02/05/2013 11:15 & 267 & 2.427 & 254 & 0.194 \\
\hline 02/05/2013 15:00 & 05586300 & 920 & 361 & 2.558 & & 02/05/2013 15:00 & 253 & 2.403 & 240 & 0.195 \\
\hline 02/06/2013 15:00 & 05586300 & 920 & 328 & 2.516 & & 02/06/2013 15:00 & 191 & 2.281 & 177 & 0.285 \\
\hline $02 / 10 / 201316: 30$ & 05586300 & 920 & 122 & 2.086 & & $02 / 10 / 201316: 30$ & 147 & 2.167 & 133 & -0.021 \\
\hline
\end{tabular}


Appendix 1. Estimating Suspended Sediment Concentration from In-situ Turbidity Measurements in Formazin Backscatter Ratio Units (FBRU)—Model Information and Data(Hach Solitax Instrument to Measure Turbidity).-Continued

[CST, central standard time; SSC, suspended-sediment concentration; $\mathrm{mg} / \mathrm{L}$, milligrams per liter; $\log _{10}$, base-10 logarithmic transform; mm, millimeter; FBRU, formazin backscatter ratio units]

\begin{tabular}{|c|c|c|c|c|c|c|c|c|c|c|}
\hline \multicolumn{6}{|c|}{ Suspended sediment } & \multicolumn{5}{|c|}{ Solitax } \\
\hline \multirow{2}{*}{$\begin{array}{l}\text { Date and time } \\
\text { (CST) }\end{array}$} & \multirow{2}{*}{$\begin{array}{l}\text { Station } \\
\text { number }\end{array}$} & \multirow{2}{*}{$\begin{array}{l}\text { Method } \\
\text { code }^{1}\end{array}$} & \multicolumn{2}{|c|}{ Concentration (SSC) } & \multirow{2}{*}{$\begin{array}{l}\text { Percent finer } \\
\text { than } 0.0625 \mathrm{~mm}\end{array}$} & \multirow{2}{*}{$\begin{array}{l}\text { Date and time } \\
\text { (CST) }\end{array}$} & \multicolumn{2}{|c|}{ Turbidity } & \multirow{2}{*}{$\begin{array}{l}\text { Regression estimate } \\
\text { SSC (mg/L) }\end{array}$} & \multirow{2}{*}{$\begin{array}{r}\text { Regression } \\
\text { residual } \log _{10}\end{array}$} \\
\hline & & & (mg/L) & $\log _{10}(\mathrm{mg} / \mathrm{L})$ & & & (FBRU) & $\log _{10}$ (FBRU) & & \\
\hline 02/13/2013 16:31 & 05586100 & 10 & 372 & 2.571 & 98 & 02/13/2013 16:30 & 407 & 2.610 & 401 & -0.015 \\
\hline 02/17/2013 15:00 & 05586300 & 920 & 373 & 2.572 & & 02/17/2013 15:00 & 182 & 2.260 & 168 & 0.364 \\
\hline 02/19/2013 11:00 & 05586300 & 70 & 137 & 2.137 & 98 & 02/19/2013 11:00 & 155 & 2.190 & 141 & 0.004 \\
\hline 02/19/2013 15:00 & 05586300 & 920 & 294 & 2.468 & & 02/19/2013 15:00 & 157 & 2.196 & 143 & 0.330 \\
\hline 02/25/2013 17:00 & 05586300 & 920 & 131 & 2.117 & & 02/25/2013 17:00 & 124 & 2.093 & 111 & 0.089 \\
\hline 03/06/2013 16:00 & 05586300 & 920 & 309 & 2.490 & & \multicolumn{5}{|c|}{ outlier not used in regression model } \\
\hline 03/08/2013 12:30 & 05586300 & 15 & 26 & 1.415 & & \multicolumn{5}{|c|}{ outlier not used in regression model } \\
\hline 03/08/2013 13:00 & 05586300 & 70 & 75 & 1.875 & & 03/08/2013 13:00 & 77 & 1.886 & 66 & 0.070 \\
\hline 03/08/2013 13:20 & 05586300 & 10 & 80 & 1.903 & & 03/08/2013 13:15 & 72 & 1.857 & 62 & 0.130 \\
\hline $03 / 08 / 201314: 52$ & 05586100 & 10 & 79 & 1.898 & 95 & 03/08/2013 14:45 & 72 & 1.857 & 62 & 0.125 \\
\hline 03/11/2013 17:30 & 05586300 & 920 & 826 & 2.917 & & 03/11/2013 17:30 & 700 & 2.845 & 720 & 0.077 \\
\hline 03/13/2013 15:00 & 05586300 & 920 & 728 & 2.862 & & 03/13/2013 15:00 & 590 & 2.771 & 598 & 0.103 \\
\hline 03/20/2013 16:00 & 05586300 & 920 & 154 & 2.188 & & 03/20/2013 16:00 & 123 & 2.090 & 110 & 0.163 \\
\hline 03/21/2013 11:30 & 05586300 & 50 & 113 & 2.053 & & 03/21/2013 11:30 & 117 & 2.068 & 104 & 0.052 \\
\hline $03 / 21 / 201314: 47$ & 05586100 & 10 & 121 & 2.083 & 75 & 03/21/2013 14:45 & 108 & 2.033 & 96 & 0.120 \\
\hline 03/25/2013 18:30 & 05586300 & 920 & 88 & 1.944 & & 03/25/2013 18:30 & 76 & 1.881 & 65 & 0.146 \\
\hline 03/27/2013 15:00 & 05586300 & 920 & 76 & 1.881 & & 03/27/2013 15:00 & 64 & 1.806 & 54 & 0.163 \\
\hline 04/01/2013 16:00 & 05586300 & 920 & 95 & 1.978 & & 04/01/2013 16:00 & 82 & 1.914 & 71 & 0.144 \\
\hline 04/03/2013 17:00 & 05586300 & 920 & 109 & 2.037 & & 04/03/2013 17:00 & 99 & 1.996 & 87 & 0.115 \\
\hline $04 / 11 / 2013$ 12:56 & 05586100 & 10 & 1,970 & 3.294 & 100 & 04/11/2013 13:00 & 1,660 & 3.220 & 1,828 & 0.050 \\
\hline 04/15/2013 18:00 & 05586300 & 920 & & & & bottle broken at lab & & & & \\
\hline $04 / 17 / 2013$ 17:30 & 05586300 & 920 & & & & bottle broken at lab & & & & \\
\hline $04 / 21 / 2013 \quad 15: 30$ & 05586300 & 920 & & & & bottle broken at lab & & & & \\
\hline $04 / 22 / 201319: 30$ & 05586300 & 920 & 409 & 2.612 & & $04 / 22 / 201319: 30$ & 506 & 2.704 & 507 & -0.076 \\
\hline $04 / 23 / 201310: 53$ & 05586300 & 920 & 326 & 2.513 & 91 & 04/23/2013 11:00 & 477 & 2.679 & 476 & -0.146 \\
\hline 04/23/2013 11:19 & 05586300 & 10 & 320 & 2.505 & 89 & 04/23/2013 11:15 & 470 & 2.672 & 468 & -0.148 \\
\hline 04/23/2013 11:23 & 05586300 & 10 & 280 & 2.447 & 87 & $04 / 23 / 201311: 30$ & 470 & 2.672 & 468 & -0.206 \\
\hline 04/23/2013 11:33 & 05586300 & 920 & 309 & 2.490 & & 04/23/2013 11:30 & 470 & 2.672 & 468 & -0.163 \\
\hline $04 / 24 / 201314: 50$ & 05586300 & 10 & 274 & 2.438 & & $04 / 24 / 201314: 45$ & 385 & 2.585 & 377 & -0.121 \\
\hline
\end{tabular}


Appendix 1. Estimating Suspended Sediment Concentration from In-situ Turbidity Measurements in Formazin Backscatter Ratio Units (FBRU)—Model Information and Data(Hach Solitax Instrument to Measure Turbidity).-Continued

[CST, central standard time; SSC, suspended-sediment concentration; $\mathrm{mg} / \mathrm{L}$, milligrams per liter; $\log _{10}$, base-10 logarithmic transform; mm, millimeter; FBRU, formazin backscatter ratio units]

\begin{tabular}{|c|c|c|c|c|c|c|c|c|c|c|}
\hline \multicolumn{6}{|c|}{ Suspended sediment } & \multicolumn{5}{|c|}{ Solitax } \\
\hline \multirow{2}{*}{$\begin{array}{l}\text { Date and time } \\
\text { (CST) }\end{array}$} & \multirow{2}{*}{$\begin{array}{l}\text { Station } \\
\text { number }\end{array}$} & \multirow{2}{*}{$\begin{array}{l}\text { Method } \\
\text { code }^{1}\end{array}$} & \multicolumn{2}{|c|}{ Concentration (SSC) } & \multirow{2}{*}{$\begin{array}{l}\text { Percent finer } \\
\text { than } 0.0625 \mathrm{~mm}\end{array}$} & \multirow{2}{*}{$\begin{array}{l}\text { Date and time } \\
\text { (CST) }\end{array}$} & \multicolumn{2}{|c|}{ Turbidity } & \multirow{2}{*}{$\begin{array}{l}\text { Regression estimate } \\
\text { SSC (mg/L) }\end{array}$} & \multirow{2}{*}{$\begin{array}{c}\text { Regression } \\
\text { residual } \log _{10}\end{array}$} \\
\hline & & & (mg/L) & $\log _{10}(\mathrm{mg} / \mathrm{L})$ & & & (FBRU) & $\log _{10}($ FBRU) & & \\
\hline $04 / 24 / 2013$ 17:33 & 05586100 & 10 & 249 & 2.396 & 89 & $04 / 24 / 2013 \quad 17: 30$ & 373 & 2.572 & 365 & -0.148 \\
\hline 04/24/2013 18:00 & 05586300 & 920 & 306 & 2.486 & & 04/24/2013 18:00 & 371 & 2.569 & 363 & -0.056 \\
\hline 04/25/2013 15:30 & 05586300 & 50 & 228 & 2.358 & & 04/25/2013 15:30 & 281 & 2.449 & 269 & -0.054 \\
\hline $04 / 26 / 2013$ 15:57 & 05586100 & 20 & 128 & 2.107 & 88 & 04/26/2013 16:00 & 203 & 2.308 & 189 & -0.152 \\
\hline 04/26/2013 16:06 & 05586100 & 20 & 146 & 2.164 & & 04/26/2013 16:00 & 203 & 2.308 & 189 & -0.095 \\
\hline 04/28/2013 19:00 & 05586300 & 920 & 165 & 2.217 & & 04/28/2013 19:00 & 135 & 2.130 & 122 & 0.150 \\
\hline 04/29/2013 11:20 & 05586300 & 50 & 75 & 1.875 & & 04/29/2013 11:15 & 128 & 2.107 & 115 & -0.168 \\
\hline 04/30/2013 19:00 & 05586300 & 920 & 71 & 1.851 & & 04/30/2013 19:00 & 111 & 2.045 & 99 & -0.125 \\
\hline 05/01/2013 20:00 & 05586300 & 920 & 64 & 1.806 & & 05/01/2013 20:00 & 108 & 2.033 & 96 & -0.157 \\
\hline 05/05/2013 20:00 & 05586300 & 920 & 68 & 1.833 & & 05/05/2013 20:00 & 117 & 2.068 & 104 & -0.168 \\
\hline 05/07/2013 20:00 & 05586300 & 920 & 178 & 2.250 & & 05/07/2013 20:00 & 109 & 2.037 & 97 & 0.283 \\
\hline 05/08/2013 11:26 & 05586100 & 10 & 82 & 1.914 & 95 & 05/08/2013 11:30 & 101 & 2.004 & 89 & -0.018 \\
\hline 05/08/2013 14:00 & 05586300 & 50 & 60 & 1.778 & & 05/08/2013 14:00 & 104 & 2.017 & 92 & -0.167 \\
\hline $05 / 22 / 201311: 43$ & 05586100 & 10 & 119 & 2.076 & 97 & $05 / 22 / 201311: 45$ & 82 & 1.912 & 71 & 0.243 \\
\hline 05/28/2013 17:00 & 05586300 & 920 & 946 & 2.976 & 97 & 05/28/2013 17:00 & 1,057 & 3.024 & 1,122 & -0.057 \\
\hline 05/29/2013 13:40 & 05586300 & 50 & 493 & 2.693 & & 05/29/2013 13:45 & 577 & 2.761 & 584 & -0.056 \\
\hline 06/01/2013 09:30 & 05586300 & 920 & 273 & 2.436 & 98 & 06/01/2013 09:30 & 415 & 2.618 & 409 & -0.158 \\
\hline 06/03/2013 17:30 & 05586300 & 920 & 81 & 1.908 & & 06/03/2013 17:30 & 154 & 2.188 & 140 & -0.221 \\
\hline 06/05/2013 13:01 & 05586100 & 10 & 122 & 2.086 & 96 & 06/05/2013 13:00 & 130 & 2.114 & 117 & 0.036 \\
\hline 06/05/2013 19:30 & 05586300 & 920 & 75 & 1.875 & & 06/05/2013 19:30 & 133 & 2.124 & 120 & -0.186 \\
\hline 06/09/2013 19:00 & 05586300 & 920 & 57 & 1.756 & & 06/09/2013 19:00 & 91 & 1.959 & 80 & -0.127 \\
\hline 06/11/2013 20:00 & 05586300 & 920 & 40 & 1.602 & & 06/11/2013 20:00 & 59 & 1.771 & 50 & -0.078 \\
\hline 06/16/2013 15:00 & 05586300 & 920 & 425 & 2.628 & & 06/16/2013 15:00 & 398 & 2.600 & 391 & 0.054 \\
\hline 06/18/2013 17:20 & 05586300 & 50 & 74 & 1.869 & 99 & $06 / 18 / 201317: 15$ & 101 & 2.004 & 89 & -0.063 \\
\hline 06/19/2013 09:44 & 05586100 & 10 & 64 & 1.806 & 94 & 06/19/2013 09:45 & 80 & 1.903 & 69 & -0.016 \\
\hline 06/19/2013 17:30 & 05586300 & 920 & 56 & 1.748 & & 06/19/2013 17:30 & 68 & 1.833 & 58 & 0.002 \\
\hline $06 / 24 / 201318: 30$ & 05586300 & 920 & 80 & 1.903 & & $06 / 24 / 201318: 30$ & 97 & 1.987 & 85 & -0.010 \\
\hline 06/26/2013 20:00 & 05586300 & 920 & 130 & 2.114 & & 06/26/2013 20:00 & 129 & 2.111 & 116 & 0.067 \\
\hline 06/30/2013 18:30 & 05586300 & 920 & 193 & 2.286 & & 06/30/2013 18:30 & 193 & 2.286 & 179 & 0.050 \\
\hline
\end{tabular}

${ }^{1}$ Method code for sampling methods: Equal Width Increment (EWI)-10, EWI non-isokinetic-15, Equal Discharge Increment (EDI)-20, Single-Vertical-30, Point-50, Fixed Single Vertical-BOX-920. 


\section{Appendix 2. Estimating Suspended Sediment Concentration from In-situ Turbidity Measurements in Formazin Nephelometric Units (FNU)_Model Information and Data (YSI 6136 Instrument to Measure Turbidity)}

\section{Model form}

$\log _{10} \mathrm{SSC}=1.122 \log _{10}$ TurbFNU-0.055

\begin{tabular}{lcccc}
\cline { 2 - 5 } & \multicolumn{2}{c}{ Predictor variable summary statistics } & \multicolumn{2}{c}{ Response variable summary statistics } \\
\cline { 2 - 5 } & Turbidity (FNU) & $\log _{10}\left(\right.$ Turb $\left._{\text {FNu }}\right)$ & SSC (mg/L) & $\log _{10}$ (SSC) \\
\hline Minimum & 14 & 1.146 & 15 & 1.176 \\
1st Quartile & 29 & 1.462 & 34 & 1.532 \\
Median & 41 & 1.613 & 59 & 1.767 \\
Mean & 85 & 1.720 & 140 & 1.876 \\
3rd Quartile & 75 & 1.874 & 130 & 2.114 \\
Maximum & 1,130 & 3.053 & 1,970 & 3.295 \\
\hline
\end{tabular}

\section{Model calibration}

\begin{tabular}{lc}
\hline \multicolumn{2}{c}{ Basic data } \\
\hline Number of observations & 140 \\
Error degrees of freedom & 138 \\
$\begin{array}{l}\text { Root mean squared error (Standard error of } \\
\quad \text { regression) }\end{array}$ & 0.1512 \\
R-squared & 0.883 \\
Adjusted R-squared & 0.882 \\
F-statistic versus constant model & 1,040 \\
p-value & $3.54 \mathrm{E}-66$ \\
Non-parametric smearing bias correction factor & 1.0627 \\
Probability plot correlation coefficient & 0.99657 \\
\hline
\end{tabular}

Estimated coefficients

\begin{tabular}{lcccccc}
\hline & Estimate & SE & tStat & pValue & Lower 90 percent & Upper 90 percent \\
\hline (Intercept) & -0.054624 & 0.061154 & -0.89323 & 0.37329 & -0.155893 & 0.0466442 \\
$\log _{10}$ TurbFNU & 1.1223 & 0.034768 & 32.28 & $3.54 \mathrm{E}-66$ & 1.06475 & 1.1799 \\
\hline
\end{tabular}


Appendix 2. Estimating Suspended Sediment Concentration from In-situ Turbidity Measurements in Formazin Nephelometric Units (FNU)—Model Information and Data (YSI 6136 Instrument to Measure Turbidity).

[CST, central standard time; SSC, suspended-sediment concentration; $\mathrm{mg} / \mathrm{L}$, milligrams per liter; $\log _{10}$, base-10 logarithmic transform; mm, millimeter; FNU, formazin nephelometric units]

\begin{tabular}{|c|c|c|c|c|c|c|c|c|c|c|}
\hline \multicolumn{6}{|c|}{ Suspended sediment } & \multicolumn{5}{|c|}{ YSI } \\
\hline \multirow{2}{*}{$\begin{array}{l}\text { Date and time } \\
\text { (CST) }\end{array}$} & \multirow{2}{*}{$\begin{array}{l}\text { Station } \\
\text { number }\end{array}$} & \multirow{2}{*}{$\begin{array}{c}\text { Method } \\
\text { code }^{1}\end{array}$} & \multicolumn{2}{|c|}{ Concentration (SSC) } & \multirow{2}{*}{$\begin{array}{l}\text { Percent finer } \\
\text { than } 0.0625 \mathrm{~mm}\end{array}$} & \multirow{2}{*}{$\begin{array}{l}\text { Date and time } \\
\text { (CST) }\end{array}$} & \multicolumn{2}{|c|}{ Turbidity } & \multirow{2}{*}{$\begin{array}{l}\text { Regression estimate } \\
\text { SSC (mg/L) }\end{array}$} & \multirow{2}{*}{$\begin{array}{l}\text { Regression } \\
\text { residual } \log _{10}\end{array}$} \\
\hline & & & (mg/L) & $\log _{10}(\mathrm{mg} / \mathrm{L})$ & & & (FNU) & $\log _{10}(\mathrm{FNU})$ & & \\
\hline 07/09/2012 17:20 & 05586300 & 920 & 50 & 1.699 & & 07/09/2012 17:26 & 28 & 1.447 & 39 & 0.129 \\
\hline 07/11/2012 17:30 & 05586300 & 920 & 49 & 1.690 & & 07/11/2012 17:26 & 34 & 1.531 & 49 & 0.026 \\
\hline 07/17/2012 19:00 & 05586300 & 920 & 47 & 1.672 & & 07/17/2012 18:56 & 33 & 1.519 & 47 & 0.022 \\
\hline 07/18/2012 18:00 & 05586300 & 920 & 45 & 1.653 & & 07/18/2012 17:56 & 30 & 1.477 & 43 & 0.050 \\
\hline 07/22/2012 16:00 & 05586300 & 920 & 75 & 1.875 & & 07/22/2012 15:56 & 58 & 1.763 & 89 & -0.049 \\
\hline 07/25/2012 19:00 & 05586300 & 920 & 42 & 1.623 & & 07/25/2012 18:56 & 33 & 1.516 & 47 & -0.024 \\
\hline 07/29/2012 16:00 & 05586300 & 920 & 53 & 1.724 & & 07/29/2012 15:56 & 40 & 1.602 & 59 & -0.019 \\
\hline 08/01/2012 16:00 & 05586300 & 920 & 48 & 1.681 & & 08/01/2012 15:56 & 41 & 1.613 & 61 & -0.074 \\
\hline 08/03/2012 08:44 & 05586300 & 30 & 130 & 2.114 & & 08/03/2012 08:41 & 53 & 1.724 & 81 & 0.233 \\
\hline 08/03/2012 08:53 & 05586300 & 20 & 69 & 1.839 & & 08/03/2012 08:56 & 47 & 1.672 & 71 & 0.017 \\
\hline 08/03/2012 09:20 & 05586300 & 30 & 72 & 1.857 & 99 & 08/03/2012 09:26 & 45 & 1.653 & 67 & 0.057 \\
\hline 08/03/2012 09:26 & 05586300 & 30 & 58 & 1.763 & & 08/03/2012 09:26 & 45 & 1.653 & 67 & -0.037 \\
\hline 08/03/2012 09:55 & 05586300 & 10 & 97 & 1.987 & 62 & 08/03/2012 09:56 & 39 & 1.591 & 57 & 0.256 \\
\hline 08/04/2012 00:44 & 05586100 & 10 & 54 & 1.732 & 87 & 08/04/2012 00:41 & 26 & 1.415 & 36 & 0.199 \\
\hline 08/05/2012 18:00 & 05586300 & 920 & 48 & 1.681 & & 08/05/2012 17:56 & 34 & 1.531 & 49 & 0.017 \\
\hline 08/08/2012 15:30 & 05586300 & 920 & 50 & 1.699 & & 08/08/2012 15:26 & 32 & 1.505 & 46 & 0.064 \\
\hline 08/12/2012 18:00 & 05586300 & 920 & 52 & 1.716 & & 08/12/2012 17:56 & 38 & 1.580 & 56 & -0.002 \\
\hline 08/15/2012 06:30 & 05586300 & 920 & 39 & 1.591 & & 08/15/2012 06:26 & 32 & 1.505 & 46 & -0.044 \\
\hline $08 / 21 / 201214: 27$ & 05586300 & 30 & 89 & 1.949 & 97 & $08 / 21 / 201214: 26$ & 53 & 1.724 & 81 & 0.069 \\
\hline 08/21/2012 14:45 & 05586300 & 10 & 113 & 2.053 & 97 & 08/21/2012 14:41 & 44 & 1.643 & 66 & 0.263 \\
\hline 08/22/2012 09:28 & 05586100 & 10 & 63 & 1.799 & 93 & 08/22/2012 09:26 & 28 & 1.447 & 39 & 0.230 \\
\hline 08/22/2012 16:00 & 05586300 & 920 & 40 & 1.602 & & $08 / 22 / 201215: 56$ & 38 & 1.580 & 56 & -0.116 \\
\hline 08/26/2012 15:00 & 05586300 & 920 & 26 & 1.415 & & 08/26/2012 14:56 & 32 & 1.505 & 46 & -0.220 \\
\hline 08/29/2012 06:30 & 05586300 & 920 & 33 & 1.519 & & 08/29/2012 06:26 & 40 & 1.602 & 59 & -0.225 \\
\hline 09/04/2012 15:00 & 05586300 & 920 & 49 & 1.690 & & 09/04/2012 14:56 & 41 & 1.613 & 61 & -0.065 \\
\hline 09/05/2012 17:00 & 05586300 & 920 & 52 & 1.716 & & 09/05/2012 16:56 & 33 & 1.519 & 47 & 0.066 \\
\hline 09/09/2012 16:00 & 05586300 & 920 & 47 & 1.672 & & 09/09/2012 15:56 & 35 & 1.544 & 51 & -0.006 \\
\hline 09/11/2012 19:00 & 05586300 & 920 & 35 & 1.544 & & 09/11/2012 18:56 & 28 & 1.447 & 39 & -0.025 \\
\hline 09/17/2012 15:00 & 05586300 & 920 & 36 & 1.556 & & 09/17/2012 14:56 & 30 & 1.477 & 43 & -0.047 \\
\hline
\end{tabular}


Appendix 2. Estimating Suspended Sediment Concentration from In-situ Turbidity Measurements in Formazin Nephelometric Units (FNU)—Model Information and Data (YSI 6136 Instrument to Measure Turbidity).-Continued

[CST, central standard time; SSC, suspended-sediment concentration; mg/L, milligrams per liter; $\log _{10}$, base-10 logarithmic transform; mm, millimeter; FNU, formazin nephelometric units]

\begin{tabular}{|c|c|c|c|c|c|c|c|c|c|c|}
\hline \multicolumn{6}{|c|}{ Suspended sediment } & \multicolumn{5}{|c|}{ YSI } \\
\hline \multirow{2}{*}{$\begin{array}{l}\text { Date and time } \\
\text { (CST) }\end{array}$} & \multirow{2}{*}{$\begin{array}{l}\text { Station } \\
\text { number }\end{array}$} & \multirow{2}{*}{$\begin{array}{l}\text { Method } \\
\text { code }^{1}\end{array}$} & \multicolumn{2}{|c|}{ Concentration (SSC) } & \multirow{2}{*}{$\begin{array}{l}\text { Percent finer } \\
\text { than } 0.0625 \mathrm{~mm}\end{array}$} & \multirow{2}{*}{$\begin{array}{l}\text { Date and time } \\
\text { (CST) }\end{array}$} & \multicolumn{2}{|c|}{ Turbidity } & \multirow{2}{*}{$\begin{array}{l}\text { Regression estimate } \\
\text { SSC (mg/L) }\end{array}$} & \multirow{2}{*}{$\begin{array}{r}\text { Regression } \\
\text { residual } \log _{1}\end{array}$} \\
\hline & & & (mg/L) & $\log _{10}(\mathrm{mg} / \mathrm{L})$ & & & (FNU) & $\log _{10}(\mathrm{FNU})$ & & \\
\hline 09/19/2012 17:00 & 05586300 & 920 & 32 & 1.505 & & 09/19/2012 16:56 & 30 & 1.477 & 43 & -0.098 \\
\hline 09/23/2012 16:00 & 05586300 & 920 & 39 & 1.591 & & 09/23/2012 15:56 & 30 & 1.477 & 43 & -0.012 \\
\hline 09/26/2012 19:00 & 05586300 & 920 & 54 & 1.732 & & 09/26/2012 18:56 & 42 & 1.623 & 62 & -0.035 \\
\hline 09/27/2012 09:30 & 05586300 & 30 & 56 & 1.748 & & 09/27/2012 09:26 & 48 & 1.681 & 72 & -0.084 \\
\hline 09/30/2012 18:30 & 05586300 & 920 & 30 & 1.477 & & 09/30/2012 18:26 & 31 & 1.491 & 44 & -0.142 \\
\hline $10 / 03 / 201217: 30$ & 05586300 & 920 & 33 & 1.519 & & $10 / 03 / 201217: 26$ & 19 & 1.279 & 26 & 0.138 \\
\hline 10/07/2012 18:00 & 05586300 & 920 & 33 & 1.519 & & $10 / 07 / 2012$ 17:56 & 24 & 1.380 & 33 & 0.024 \\
\hline 10/10/2012 19:00 & 05586300 & 920 & 34 & 1.531 & & $10 / 10 / 2012$ 18:56 & 23 & 1.362 & 32 & 0.058 \\
\hline $10 / 14 / 201215: 00$ & 05586300 & 920 & 46 & 1.663 & & $10 / 14 / 201214: 56$ & 38 & 1.574 & 55 & -0.049 \\
\hline $10 / 16 / 201216: 30$ & 05586300 & 920 & 56 & 1.748 & & $10 / 16 / 201216: 26$ & 51 & 1.707 & 77 & -0.113 \\
\hline $10 / 17 / 201218: 30$ & 05586300 & 920 & 32 & 1.505 & & $10 / 17 / 2012$ 18:26 & 28 & 1.447 & 39 & -0.064 \\
\hline $10 / 18 / 201215: 55$ & 05586300 & 30 & 31 & 1.491 & & $10 / 18 / 2012$ 15:56 & 29 & 1.462 & 41 & -0.095 \\
\hline $10 / 18 / 201215: 58$ & 05586300 & 30 & 33 & 1.519 & & $10 / 18 / 2012$ 15:56 & 29 & 1.462 & 41 & -0.068 \\
\hline 10/18/2012 16:01 & 05586300 & 30 & 30 & 1.477 & & $10 / 18 / 201215: 56$ & 29 & 1.462 & 41 & -0.110 \\
\hline $10 / 18 / 201216: 06$ & 05586300 & 20 & 34 & 1.531 & 98 & 10/18/2012 16:11 & 25 & 1.398 & 35 & 0.017 \\
\hline 10/18/2012 16:18 & 05586300 & 30 & 37 & 1.568 & & 10/18/2012 16:11 & 25 & 1.398 & 35 & 0.054 \\
\hline 10/21/2012 18:00 & 05586300 & 920 & 24 & 1.380 & & $10 / 21 / 201217: 56$ & 21 & 1.322 & 29 & -0.049 \\
\hline 10/24/2012 18:00 & 05586300 & 920 & 34 & 1.531 & & $10 / 24 / 201217: 56$ & 40 & 1.602 & 59 & -0.212 \\
\hline 10/28/2012 17:00 & 05586300 & 920 & 40 & 1.602 & & $10 / 28 / 201216: 56$ & 48 & 1.686 & 73 & -0.235 \\
\hline 10/31/2012 10:00 & 05586300 & 30 & 23 & 1.362 & & $10 / 31 / 201209: 56$ & 35 & 1.544 & 51 & -0.316 \\
\hline $10 / 31 / 201215: 53$ & 05586100 & 15 & 25 & 1.398 & 98 & $10 / 31 / 2012$ 15:56 & 34 & 1.528 & 49 & -0.262 \\
\hline $10 / 31 / 201217: 00$ & 05586300 & 920 & 26 & 1.415 & & $10 / 31 / 201216: 56$ & 34 & 1.525 & 48 & -0.242 \\
\hline $11 / 05 / 2012$ 15:00 & 05586300 & 920 & 17 & 1.230 & & $11 / 05 / 201214: 56$ & 24 & 1.380 & 33 & -0.264 \\
\hline 11/07/2012 15:00 & 05586300 & 920 & 15 & 1.176 & & $11 / 07 / 201214: 56$ & 25 & 1.398 & 35 & -0.338 \\
\hline $11 / 13 / 201215: 00$ & 05586300 & 920 & 21 & 1.322 & & $11 / 13 / 201214: 56$ & 18 & 1.255 & 24 & -0.032 \\
\hline $11 / 14 / 201217: 00$ & 05586300 & 920 & 32 & 1.505 & & $11 / 14 / 201216: 56$ & 25 & 1.398 & 35 & -0.009 \\
\hline $11 / 27 / 2012$ 09:40 & 05586300 & 30 & 35 & 1.544 & & 11/27/2012 09:41 & 26 & 1.415 & 36 & 0.010 \\
\hline $11 / 27 / 2012$ 15:00 & 05586300 & 920 & 29 & 1.462 & & $11 / 27 / 201214: 56$ & 27 & 1.433 & 38 & -0.091 \\
\hline $12 / 02 / 201215: 00$ & 05586300 & 920 & 18 & 1.255 & & $12 / 02 / 201214: 56$ & 23 & 1.362 & 32 & -0.218 \\
\hline
\end{tabular}


Appendix 2. Estimating Suspended Sediment Concentration from In-situ Turbidity Measurements in Formazin Nephelometric Units (FNU)—Model Information and Data (YSI 6136 Instrument to Measure Turbidity).-Continued

[CST, central standard time; SSC, suspended-sediment concentration; $\mathrm{mg} / \mathrm{L}$, milligrams per liter; $\log _{10}$, base-10 logarithmic transform; mm, millimeter; FNU, formazin nephelometric units]

\begin{tabular}{|c|c|c|c|c|c|c|c|c|c|c|}
\hline \multicolumn{6}{|c|}{ Suspended sediment } & \multicolumn{5}{|c|}{ YSI } \\
\hline \multirow{2}{*}{$\begin{array}{l}\text { Date and time } \\
\text { (CST) }\end{array}$} & \multirow{2}{*}{$\begin{array}{l}\text { Station } \\
\text { number }\end{array}$} & \multirow{2}{*}{$\begin{array}{l}\text { Method } \\
\text { code }^{1}\end{array}$} & \multicolumn{2}{|c|}{ Concentration (SSC) } & \multirow{2}{*}{$\begin{array}{l}\text { Percent finer } \\
\text { than } 0.0625 \mathrm{~mm}\end{array}$} & \multirow{2}{*}{$\begin{array}{l}\text { Date and time } \\
\text { (CST) }\end{array}$} & \multicolumn{2}{|c|}{ Turbidity } & \multirow{2}{*}{$\begin{array}{l}\text { Regression estimate } \\
\text { SSC (mg/L) }\end{array}$} & \multirow{2}{*}{$\begin{array}{c}\text { Regression } \\
\text { residual } \log _{10}\end{array}$} \\
\hline & & & (mg/L) & $\log _{10}(\mathrm{mg} / \mathrm{L})$ & & & (FNU) & $\log _{10}(\mathrm{FNU})$ & & \\
\hline $12 / 04 / 201215: 00$ & 05586300 & 920 & 20 & 1.301 & & $12 / 04 / 201214: 56$ & 26 & 1.415 & 36 & -0.232 \\
\hline 12/08/2012 07:00 & 05586300 & 920 & 18 & 1.255 & & $12 / 08 / 201206: 56$ & 29 & 1.462 & 41 & -0.331 \\
\hline $12 / 10 / 201215: 00$ & 05586300 & 920 & 26 & 1.415 & & $12 / 10 / 201214: 56$ & 38 & 1.580 & 56 & -0.303 \\
\hline $12 / 12 / 2012 \quad 12: 30$ & 05586300 & 70 & 47 & 1.672 & & $12 / 12 / 201212: 26$ & 22 & 1.345 & 30 & 0.217 \\
\hline $12 / 13 / 201209: 30$ & 05586300 & 920 & 31 & 1.491 & & $12 / 13 / 201209: 26$ & 24 & 1.380 & 33 & -0.003 \\
\hline 12/13/2012 09:37 & 05586300 & 20 & 37 & 1.568 & & 12/13/2012 09:41 & 22 & 1.342 & 30 & 0.116 \\
\hline $12 / 13 / 201209: 45$ & 05586300 & 920 & 29 & 1.462 & & $12 / 13 / 201209: 41$ & 22 & 1.342 & 30 & 0.010 \\
\hline 12/13/2012 09:50 & 05586300 & 920 & 38 & 1.580 & & $12 / 13 / 201209: 56$ & 24 & 1.380 & 33 & 0.085 \\
\hline $12 / 14 / 201216: 47$ & 05586100 & 10 & 26 & 1.415 & 99 & $12 / 14 / 201216: 41$ & 16 & 1.204 & 21 & 0.118 \\
\hline $12 / 15 / 201207: 30$ & 05586300 & 920 & 21 & 1.322 & & 12/15/2012 07:26 & 15 & 1.176 & 20 & 0.057 \\
\hline $12 / 18 / 2012 \quad 15: 10$ & 05586300 & 920 & 18 & 1.255 & & $12 / 18 / 2012$ 15:11 & 14 & 1.146 & 18 & 0.024 \\
\hline $12 / 23 / 2012$ 16:00 & 05586300 & 920 & 31 & 1.491 & & $12 / 23 / 201215: 56$ & 20 & 1.301 & 27 & 0.086 \\
\hline $12 / 26 / 201215: 00$ & 05586300 & 920 & 62 & 1.792 & & $12 / 26 / 201214: 56$ & 48 & 1.681 & 72 & -0.040 \\
\hline 12/30/2012 15:00 & 05586300 & 920 & 27 & 1.431 & & $12 / 30 / 201214: 56$ & 22 & 1.342 & 30 & -0.021 \\
\hline 01/02/2013 15:00 & 05586300 & 920 & 25 & 1.398 & & $01 / 02 / 201314: 56$ & 16 & 1.204 & 21 & 0.101 \\
\hline 01/08/2013 09:45 & 05586300 & 70 & 23 & 1.362 & & 01/08/2013 09:41 & 17 & 1.230 & 23 & 0.035 \\
\hline 01/09/2013 16:50 & 05586300 & 920 & 22 & 1.342 & & 01/09/2013 16:56 & 18 & 1.255 & 24 & -0.012 \\
\hline 01/13/2013 15:00 & 05586300 & 920 & 63 & 1.799 & & 01/13/2013 14:56 & 55 & 1.740 & 84 & -0.099 \\
\hline 01/15/2013 15:00 & 05586300 & 920 & 59 & 1.771 & & 01/15/2013 14:56 & 44 & 1.643 & 66 & -0.019 \\
\hline 01/28/2013 15:00 & 05586300 & 920 & 28 & 1.447 & & 01/28/2013 14:56 & 22 & 1.342 & 30 & -0.005 \\
\hline 01/30/2013 17:45 & 05586300 & 920 & 843 & 2.926 & & 01/30/2013 17:41 & 450 & 2.653 & 890 & 0.003 \\
\hline 02/03/2013 16:30 & 05586300 & 920 & 405 & 2.607 & & $02 / 03 / 201316: 26$ & 220 & 2.342 & 399 & 0.033 \\
\hline 02/04/2013 12:40 & 05586300 & 70 & 355 & 2.550 & 89 & 02/04/2013 12:41 & 150 & 2.176 & 259 & 0.163 \\
\hline 02/05/2013 10:55 & 05586300 & 920 & 440 & 2.643 & & $02 / 05 / 201310: 56$ & 140 & 2.146 & 240 & 0.289 \\
\hline 02/05/2013 11:09 & 05586300 & 20 & 375 & 2.574 & & 02/05/2013 11:11 & 130 & 2.114 & 221 & 0.256 \\
\hline 02/05/2013 11:22 & 05586300 & 920 & 382 & 2.582 & & $02 / 05 / 201311: 26$ & 140 & 2.146 & 240 & 0.228 \\
\hline 02/05/2013 15:00 & 05586300 & 920 & 361 & 2.558 & & $02 / 05 / 201314: 56$ & 130 & 2.114 & 221 & 0.240 \\
\hline 02/06/2013 15:00 & 05586300 & 920 & 328 & 2.516 & & $02 / 06 / 201314: 56$ & 100 & 2.000 & 165 & 0.326 \\
\hline $02 / 10 / 201316: 30$ & 05586300 & 920 & 122 & 2.086 & & $02 / 10 / 201316: 26$ & 75 & 1.875 & 119 & 0.037 \\
\hline
\end{tabular}


Appendix 2. Estimating Suspended Sediment Concentration from In-situ Turbidity Measurements in Formazin Nephelometric Units (FNU)—Model Information and Data (YSI 6136 Instrument to Measure Turbidity).-Continued

[CST, central standard time; SSC, suspended-sediment concentration; mg/L, milligrams per liter; $\log _{10}$, base-10 logarithmic transform; mm, millimeter; FNU, formazin nephelometric units]

\begin{tabular}{|c|c|c|c|c|c|c|c|c|c|c|}
\hline \multicolumn{5}{|c|}{ Suspended sediment } & \multirow{3}{*}{$\begin{array}{l}\text { Percent finer } \\
\text { than } 0.0625 \mathrm{~mm}\end{array}$} & \multicolumn{5}{|c|}{ YSI } \\
\hline \multirow{2}{*}{$\begin{array}{l}\text { Date and time } \\
\text { (CST) }\end{array}$} & \multirow{2}{*}{$\begin{array}{l}\text { Station } \\
\text { number }\end{array}$} & \multirow{2}{*}{$\begin{array}{l}\text { Method } \\
\text { code }^{1}\end{array}$} & \multicolumn{2}{|c|}{ Concentration (SSC) } & & \multirow{2}{*}{$\begin{array}{l}\text { Date and time } \\
\text { (CST) }\end{array}$} & \multicolumn{2}{|c|}{ Turbidity } & \multirow{2}{*}{$\begin{array}{l}\text { Regression estimate } \\
\text { SSC (mg/L) }\end{array}$} & \multirow{2}{*}{$\begin{array}{r}\text { Regression } \\
\text { residual } \log _{10}\end{array}$} \\
\hline & & & (mg/L) & $\log _{10}(\mathrm{mg} / \mathrm{L})$ & & & (FNU) & $\log _{10}(\mathrm{FNU})$ & & \\
\hline $02 / 13 / 201316: 31$ & 05586100 & 10 & 372 & 2.571 & 98 & 02/13/2013 16:26 & 210 & 2.322 & 379 & 0.019 \\
\hline 02/17/2013 15:00 & 05586300 & 920 & 373 & 2.572 & & $02 / 17 / 201314: 56$ & 96 & 1.982 & 157 & 0.402 \\
\hline 02/19/2013 11:00 & 05586300 & 70 & 137 & 2.137 & 98 & $02 / 19 / 201310: 56$ & 84 & 1.924 & 135 & 0.032 \\
\hline 02/19/2013 15:00 & 05586300 & 920 & 294 & 2.468 & & $02 / 19 / 201314: 56$ & 80 & 1.903 & 128 & 0.387 \\
\hline 02/25/2013 17:00 & 05586300 & 920 & 131 & 2.117 & & $02 / 25 / 201316: 56$ & 63 & 1.799 & 98 & 0.152 \\
\hline 03/06/2013 16:00 & 05586300 & 920 & 309 & 2.490 & & \multicolumn{5}{|c|}{ outlier not used in regression model } \\
\hline 03/08/2013 12:30 & 05586300 & 15 & 26 & 1.415 & & \multicolumn{5}{|c|}{ outlier not used in regression model } \\
\hline 03/08/2013 13:00 & 05586300 & 70 & 75 & 1.875 & & $03 / 08 / 201312: 56$ & 41 & 1.613 & 61 & 0.120 \\
\hline 03/08/2013 13:20 & 05586300 & 10 & 80 & 1.903 & & 03/08/2013 13:26 & 39 & 1.591 & 57 & 0.172 \\
\hline 03/08/2013 14:52 & 05586100 & 10 & 79 & 1.898 & 95 & 03/08/2013 14:56 & 40 & 1.602 & 59 & 0.154 \\
\hline 03/11/2013 17:30 & 05586300 & 920 & 826 & 2.917 & & 03/11/2013 17:26 & 400 & 2.602 & 780 & 0.051 \\
\hline 03/13/2013 15:00 & 05586300 & 920 & 728 & 2.862 & & 03/13/2013 14:56 & 320 & 2.505 & 607 & 0.105 \\
\hline 03/20/2013 16:00 & 05586300 & 920 & 154 & 2.188 & & 03/20/2013 15:56 & 67 & 1.826 & 105 & 0.193 \\
\hline 03/21/2013 11:30 & 05586300 & 50 & 113 & 2.053 & & 03/21/2013 11:26 & 58 & 1.763 & 89 & 0.129 \\
\hline $03 / 21 / 201314: 47$ & 05586100 & 10 & 121 & 2.083 & 75 & 03/21/2013 14:41 & 58 & 1.763 & 89 & 0.158 \\
\hline 03/25/2013 18:30 & 05586300 & 920 & 88 & 1.944 & & 03/25/2013 18:26 & 41 & 1.613 & 61 & 0.189 \\
\hline 03/27/2013 15:00 & 05586300 & 920 & 76 & 1.881 & & $03 / 27 / 201314: 56$ & 35 & 1.544 & 51 & 0.202 \\
\hline 04/01/2013 16:00 & 05586300 & 920 & 95 & 1.978 & & 04/01/2013 15:56 & 43 & 1.633 & 64 & 0.199 \\
\hline 04/03/2013 17:00 & 05586300 & 920 & 109 & 2.037 & & $04 / 03 / 2013 \quad 16: 56$ & 56 & 1.748 & 86 & 0.130 \\
\hline $04 / 11 / 201312: 56$ & 05586100 & 10 & 1,970 & 3.294 & 100 & $04 / 11 / 2013$ 12:56 & 1,130 & 3.053 & 2,502 & -0.077 \\
\hline 04/15/2013 18:00 & 05586300 & 920 & & & & bottle broken at lab & & & & \\
\hline $04 / 17 / 2013 \quad 17: 30$ & 05586300 & 920 & & & & bottle broken at lab & & & & \\
\hline $04 / 21 / 2013 \quad 15: 30$ & 05586300 & 920 & & & & bottle broken at lab & & & & \\
\hline 04/22/2013 19:30 & 05586300 & 920 & 409 & 2.612 & & 04/22/2013 19:26 & 260 & 2.415 & 481 & -0.044 \\
\hline $04 / 23 / 201310: 53$ & 05586300 & 920 & 326 & 2.513 & 91 & $04 / 23 / 201310: 56$ & 230 & 2.362 & 419 & -0.083 \\
\hline 04/23/2013 11:19 & 05586300 & 10 & 320 & 2.505 & 89 & $04 / 23 / 201311: 26$ & 240 & 2.380 & 440 & -0.112 \\
\hline $04 / 23 / 201311: 23$ & 05586300 & 10 & 280 & 2.447 & 87 & $04 / 23 / 201311: 26$ & 240 & 2.380 & 440 & -0.170 \\
\hline 04/23/2013 11:33 & 05586300 & 920 & 309 & 2.490 & & 04/23/2013 11:26 & 240 & 2.380 & 440 & -0.127 \\
\hline $04 / 24 / 201314: 50$ & 05586300 & 10 & 274 & 2.438 & & $04 / 24 / 201314: 56$ & 210 & 2.322 & 379 & -0.114 \\
\hline
\end{tabular}


Appendix 2. Estimating Suspended Sediment Concentration from In-situ Turbidity Measurements in Formazin Nephelometric Units (FNU)—Model Information and Data (YSI 6136 Instrument to Measure Turbidity).-Continued

[CST, central standard time; SSC, suspended-sediment concentration; mg/L, milligrams per liter; $\log _{10}$, base-10 logarithmic transform; mm, millimeter; FNU, formazin nephelometric units]

\begin{tabular}{|c|c|c|c|c|c|c|c|c|c|c|}
\hline \multicolumn{6}{|c|}{ Suspended sediment } & \multicolumn{5}{|c|}{ YSI } \\
\hline \multirow{2}{*}{$\begin{array}{l}\text { Date and time } \\
\text { (CST) }\end{array}$} & \multirow{2}{*}{$\begin{array}{l}\text { Station } \\
\text { number }\end{array}$} & \multirow{2}{*}{$\begin{array}{l}\text { Method } \\
\text { code }^{1}\end{array}$} & \multicolumn{2}{|c|}{ Concentration (SSC) } & \multirow{2}{*}{$\begin{array}{l}\text { Percent finer } \\
\text { than } 0.0625 \mathrm{~mm}\end{array}$} & \multirow{2}{*}{$\begin{array}{l}\text { Date and time } \\
\text { (CST) }\end{array}$} & \multicolumn{2}{|c|}{ Turbidity } & \multirow{2}{*}{$\begin{array}{l}\text { Regression estimate } \\
\text { SSC (mg/L) }\end{array}$} & \multirow{2}{*}{$\begin{array}{r}\text { Regression } \\
\text { residual } \log _{1}\end{array}$} \\
\hline & & & $(\mathrm{mg} / \mathrm{L})$ & $\log _{10}(\mathrm{mg} / \mathrm{L})$ & & & (FNU) & $\log _{10}(\mathrm{FNU})$ & & \\
\hline $04 / 24 / 201317: 33$ & 05586100 & 10 & 249 & 2.396 & 89 & $04 / 24 / 2013 \quad 17: 26$ & 210 & 2.322 & 379 & -0.155 \\
\hline 04/24/2013 18:00 & 05586300 & 920 & 306 & 2.486 & & $04 / 24 / 2013 \quad 17: 56$ & 220 & 2.342 & 399 & -0.089 \\
\hline 04/25/2013 15:30 & 05586300 & 50 & 228 & 2.358 & & 04/25/2013 15:26 & 160 & 2.204 & 279 & -0.061 \\
\hline $04 / 26 / 201315: 57$ & 05586100 & 20 & 128 & 2.107 & 88 & $04 / 26 / 2013 \quad 15: 56$ & 120 & 2.079 & 202 & -0.172 \\
\hline 04/26/2013 16:06 & 05586100 & 20 & 146 & 2.164 & & 04/26/2013 16:11 & 120 & 2.079 & 202 & -0.115 \\
\hline 04/28/2013 19:00 & 05586300 & 920 & 165 & 2.217 & & 04/28/2013 18:56 & 79 & 1.898 & 126 & 0.142 \\
\hline 04/29/2013 11:20 & 05586300 & 50 & 75 & 1.875 & & 04/29/2013 11:26 & 75 & 1.874 & 119 & -0.173 \\
\hline 04/30/2013 19:00 & 05586300 & 920 & 71 & 1.851 & & 04/30/2013 18:56 & 67 & 1.826 & 105 & -0.144 \\
\hline 05/01/2013 20:00 & 05586300 & 920 & 64 & 1.806 & & 05/01/2013 19:56 & 64 & 1.806 & 100 & -0.166 \\
\hline 05/05/2013 20:00 & 05586300 & 920 & 68 & 1.833 & & 05/05/2013 19:56 & 69 & 1.839 & 109 & -0.177 \\
\hline 05/07/2013 20:00 & 05586300 & 920 & 178 & 2.250 & & 05/07/2013 19:56 & 65 & 1.813 & 102 & 0.270 \\
\hline 05/08/2013 11:26 & 05586100 & 10 & 82 & 1.914 & 95 & 05/08/2013 11:26 & 62 & 1.792 & 96 & -0.043 \\
\hline 05/08/2013 14:00 & 05586300 & 50 & 60 & 1.778 & & 05/08/2013 13:56 & 64 & 1.806 & 100 & -0.194 \\
\hline $05 / 22 / 201311: 43$ & 05586100 & 10 & 119 & 2.076 & 97 & 05/22/2013 11:41 & 45 & 1.653 & 67 & 0.275 \\
\hline 05/28/2013 17:00 & 05586300 & 920 & 946 & 2.976 & 97 & $05 / 28 / 201316: 56$ & 676 & 2.830 & 1406 & -0.146 \\
\hline 05/29/2013 13:40 & 05586300 & 50 & 493 & 2.693 & & 05/29/2013 13:41 & 320 & 2.505 & 607 & -0.064 \\
\hline 06/01/2013 09:30 & 05586300 & 920 & 273 & 2.436 & 98 & 06/01/2013 09:26 & 190 & 2.279 & 338 & -0.067 \\
\hline 06/03/2013 17:30 & 05586300 & 920 & 81 & 1.908 & & 06/03/2013 17:26 & 88 & 1.944 & 143 & -0.219 \\
\hline 06/05/2013 13:01 & 05586100 & 10 & 122 & 2.086 & 96 & 06/05/2013 12:56 & 77 & 1.886 & 123 & 0.024 \\
\hline 06/05/2013 19:30 & 05586300 & 920 & 75 & 1.875 & & 06/05/2013 19:26 & 74 & 1.869 & 117 & -0.168 \\
\hline 06/09/2013 19:00 & 05586300 & 920 & 57 & 1.756 & & 06/09/2013 18:56 & 51 & 1.708 & 77 & -0.106 \\
\hline 06/11/2013 20:00 & 05586300 & 920 & 40 & 1.602 & & 06/11/2013 19:56 & 34 & 1.531 & 49 & -0.062 \\
\hline $06 / 16 / 201315: 00$ & 05586300 & 920 & 425 & 2.628 & & 06/16/2013 14:56 & 250 & 2.398 & 460 & -0.008 \\
\hline 06/18/2013 17:20 & 05586300 & 50 & 74 & 1.869 & 99 & 06/18/2013 17:26 & 53 & 1.724 & 81 & -0.011 \\
\hline 06/19/2013 09:44 & 05586100 & 10 & 64 & 1.806 & 94 & 06/19/2013 09:41 & 42 & 1.623 & 62 & 0.039 \\
\hline $06 / 19 / 2013 \quad 17: 30$ & 05586300 & 920 & 56 & 1.748 & & $06 / 19 / 2013 \quad 17: 26$ & 38 & 1.580 & 56 & 0.030 \\
\hline $06 / 24 / 201318: 30$ & 05586300 & 920 & 80 & 1.903 & & 06/24/2013 18:26 & 53 & 1.724 & 81 & 0.023 \\
\hline 06/26/2013 20:00 & 05586300 & 920 & 130 & 2.114 & & 06/26/2013 19:56 & 71 & 1.851 & 112 & 0.091 \\
\hline $06 / 30 / 201318: 30$ & 05586300 & 920 & 193 & 2.286 & & 06/30/2013 18:26 & 96 & 1.982 & 157 & 0.115 \\
\hline
\end{tabular}

${ }^{1}$ Method code for sampling methods: Equal Width Increment (EWI)-10, EWI non-isokinetic-15, Equal Discharge Increment (EDI)-20, Single-Vertical-30, Point-50, Fixed Single Vertical-BOX-920. 


\section{Appendix 3. Estimating Suspended Sediment Concentration from Streamflow-Model Information and Data}

\begin{tabular}{|c|c|c|c|c|}
\hline \multirow{2}{*}{\multicolumn{5}{|c|}{ Model form }} \\
\hline & & & & \\
\hline \multicolumn{5}{|c|}{$\log _{10} \mathrm{SSC}=-0.551+0.578 \log _{10}$ Discharge } \\
\hline & \multicolumn{2}{|c|}{ Predictor variable summary statistics } & \multicolumn{2}{|c|}{ Response variable summary statistics } \\
\hline & Streamflow $\left(\mathrm{ft}^{3} / \mathrm{s}\right)$ & $\log _{10}($ Streamflow $)$ & SSC (mg/L) & $\log _{10}(S S C)$ \\
\hline Minimum & 3,370 & 3.528 & 15 & 1.176 \\
\hline 1st Quartile & 5,345 & 3.728 & 33 & 1.519 \\
\hline Median & 8,190 & 3.913 & 54 & 1.732 \\
\hline Mean & 28,890 & 4.154 & 139 & 1.852 \\
\hline 3rd Quartile & 40,950 & 4.612 & 129 & 2.111 \\
\hline Maximum & 112,000 & 5.049 & 1,970 & 3.295 \\
\hline
\end{tabular}

\section{Model calibration}

\begin{tabular}{lc}
\hline \multicolumn{1}{c}{ Basic data } \\
\hline Number of observations & 108 \\
Error degrees of freedom & 106 \\
Root mean squared error (Standard error of & 0.34108 \\
$\quad$ regression) & \\
R-squared & 0.428 \\
Adjusted R-squared & 0.423 \\
F-statistic versus constant model & 79.3 \\
p-value & $1.62 \mathrm{E}-14$ \\
Non-parametric smearing bias correction factor & 1.4778 \\
Probability plot correlation coefficient & 0.97057 \\
\hline
\end{tabular}

\section{Estimated coefficients}

\begin{tabular}{lcccccc}
\hline & Estimate & SE & tStat & pValue & Lower 90 percent & Upper 90 percent \\
\hline (Intercept) & -0.55057 & 0.27176 & -2.0259 & 0.045284 & -1.00152 & -0.09962 \\
$\log _{10}$ Discharge & 0.57837 & 0.064941 & 8.9061 & $1.6172 \mathrm{E}-14$ & 0.470609 & 0.686128 \\
\hline
\end{tabular}


Appendix 3. Estimating Suspended Sediment Concentration from Streamflow-Model Information and Data.

[CST, central standard time; SSC, suspended-sediment concentration; $\mathrm{mg} / \mathrm{L}$, milligrams per liter; $\log _{10}$, base-10 logarithmic transform; mm, millimeter; $\mathrm{ft}^{3} / \mathrm{s}$, cubic feet per second]

\begin{tabular}{|c|c|c|c|c|c|c|c|c|c|c|}
\hline \multirow{3}{*}{$\begin{array}{l}\text { Date and time } \\
\text { (CST) }\end{array}$} & \multicolumn{5}{|c|}{ Suspended sediment } & \multirow{3}{*}{$\begin{array}{l}\text { Date and time } \\
\text { (CST) }\end{array}$} & & & \multirow{3}{*}{$\begin{array}{l}\text { Regression estimate } \\
\text { SSC (mg/L) }\end{array}$} & \multirow{3}{*}{$\begin{array}{c}\text { Regression residua } \\
\log _{10} S S C\end{array}$} \\
\hline & \multirow{2}{*}{$\begin{array}{l}\text { Station } \\
\text { number }\end{array}$} & \multirow{2}{*}{$\begin{array}{l}\text { Method } \\
\text { code }^{1}\end{array}$} & \multicolumn{2}{|c|}{ Concentration (SSC) } & \multirow{2}{*}{$\begin{array}{c}\text { Percent finer than } \\
0.0625 \mathrm{~mm}\end{array}$} & & \multicolumn{2}{|c|}{ Streamflow } & & \\
\hline & & & (mg/L) & $\log _{10}(\mathrm{mg} / \mathrm{L})$ & & & $\left(\mathrm{ft}^{3} / \mathrm{s}\right)$ & $\log _{10}\left(\mathrm{ft}^{3} / \mathrm{s}\right)$ & & \\
\hline 07/09/2012 17:20 & 05586300 & 920 & 50 & 1.699 & & 07/09/2012 17:00 & 5,690 & 3.755 & 62 & 0.078 \\
\hline 07/17/2012 19:00 & 05586300 & 920 & 47 & 1.672 & & 07/17/2012 19:00 & 4,460 & 3.649 & 54 & 0.112 \\
\hline 07/18/2012 18:00 & 05586300 & 920 & 45 & 1.653 & & 07/18/2012 18:00 & 4,510 & 3.654 & 54 & 0.090 \\
\hline 07/22/2012 16:00 & 05586300 & 920 & 75 & 1.875 & & 07/22/2012 16:00 & 7,580 & 3.880 & 73 & 0.182 \\
\hline 07/25/2012 19:00 & 05586300 & 920 & 42 & 1.623 & & 07/25/2012 19:00 & 4,660 & 3.668 & 55 & 0.052 \\
\hline 07/29/2012 16:00 & 05586300 & 920 & 53 & 1.724 & & 07/29/2012 16:00 & 6,460 & 3.810 & 66 & 0.071 \\
\hline 08/01/2012 16:00 & 05586300 & 920 & 48 & 1.681 & & 08/01/2012 16:00 & 4,710 & 3.673 & 55 & 0.107 \\
\hline 08/03/2012 08:44 & 05586300 & 30 & 130 & 2.114 & & 08/03/2012 09:00 & 4,830 & 3.684 & 56 & 0.534 \\
\hline 08/03/2012 08:53 & 05586300 & 20 & 69 & 1.839 & & 08/03/2012 09:00 & 4,830 & 3.684 & 56 & 0.259 \\
\hline 08/03/2012 09:20 & 05586300 & 30 & 72 & 1.857 & 99 & 08/03/2012 09:00 & 4,830 & 3.684 & 56 & 0.277 \\
\hline 08/03/2012 09:55 & 05586300 & 10 & 97 & 1.987 & 62 & 08/03/2012 10:00 & 4,860 & 3.687 & 56 & 0.405 \\
\hline 08/04/2012 00:44 & 05586100 & 10 & 54 & 1.732 & 87 & 08/04/2012 01:00 & 4,540 & 3.657 & 54 & 0.168 \\
\hline 08/05/2012 18:00 & 05586300 & 920 & 48 & 1.681 & & 08/05/2012 18:00 & 3,370 & 3.528 & 46 & 0.192 \\
\hline 08/12/2012 18:00 & 05586300 & 920 & 52 & 1.716 & & 08/12/2012 18:00 & 5,910 & 3.772 & 63 & 0.085 \\
\hline 08/21/2012 14:45 & 05586300 & 10 & 113 & 2.053 & 97 & 08/21/2012 15:00 & 4,460 & 3.649 & 54 & 0.493 \\
\hline 08/22/2012 16:00 & 05586300 & 920 & 40 & 1.602 & & 08/22/2012 16:00 & 4,540 & 3.657 & 54 & 0.038 \\
\hline 08/26/2012 15:00 & 05586300 & 920 & 26 & 1.415 & & 08/26/2012 15:00 & 5,430 & 3.735 & 60 & -0.195 \\
\hline 09/04/2012 15:00 & 05586300 & 920 & 49 & 1.690 & & 09/04/2012 15:00 & 5,940 & 3.774 & 63 & 0.058 \\
\hline 09/05/2012 17:00 & 05586300 & 920 & 52 & 1.716 & & 09/05/2012 17:00 & 5,510 & 3.741 & 61 & 0.103 \\
\hline 09/09/2012 16:00 & 05586300 & 920 & 47 & 1.672 & & 09/09/2012 16:00 & 6,700 & 3.826 & 68 & 0.010 \\
\hline 09/11/2012 19:00 & 05586300 & 920 & 35 & 1.544 & & 09/11/2012 19:00 & 5,400 & 3.732 & 60 & -0.064 \\
\hline 09/17/2012 15:00 & 05586300 & 920 & 36 & 1.556 & & 09/17/2012 15:00 & 6,070 & 3.783 & 64 & -0.081 \\
\hline 09/19/2012 17:00 & 05586300 & 920 & 32 & 1.505 & & 09/19/2012 17:00 & 6,520 & 3.814 & 67 & -0.150 \\
\hline 09/23/2012 16:00 & 05586300 & 920 & 39 & 1.591 & & 09/23/2012 16:00 & 5,290 & 3.723 & 59 & -0.012 \\
\hline 09/26/2012 19:00 & 05586300 & 920 & 54 & 1.732 & & 09/26/2012 19:00 & 5,940 & 3.774 & 63 & 0.100 \\
\hline 10/07/2012 18:00 & 05586300 & 920 & 33 & 1.519 & & 10/07/2012 18:00 & 5,110 & 3.708 & 58 & -0.076 \\
\hline 10/10/2012 19:00 & 05586300 & 920 & 34 & 1.531 & & 10/10/2012 19:00 & 3,430 & 3.535 & 46 & 0.037 \\
\hline 10/14/2012 15:00 & 05586300 & 920 & 46 & 1.663 & & 10/14/2012 15:00 & 7,440 & 3.872 & 72 & -0.026 \\
\hline $10 / 18 / 2012 \quad 15: 55$ & 05586300 & 30 & 31 & 1.491 & & 10/18/2012 16:00 & 5,970 & 3.776 & 64 & -0.142 \\
\hline 10/18/2012 15:58 & 05586300 & 30 & 33 & 1.519 & & 10/18/2012 16:00 & 5,970 & 3.776 & 64 & -0.115 \\
\hline
\end{tabular}


Appendix 3. Estimating Suspended Sediment Concentration from Streamflow—Model Information and Data.—Continued

[CST, central standard time; SSC, suspended-sediment concentration; $\mathrm{mg} / \mathrm{L}$, milligrams per liter; $\log _{10}$, base-10 logarithmic transform; mm, millimeter; $\mathrm{ft}^{3} / \mathrm{s}$, cubic feet per second]

\begin{tabular}{|c|c|c|c|c|c|c|c|c|c|c|}
\hline \multirow{3}{*}{$\begin{array}{l}\text { Date and time } \\
\text { (CST) }\end{array}$} & \multicolumn{5}{|c|}{ Suspended sediment } & \multirow{3}{*}{$\begin{array}{l}\text { Date and time } \\
\text { (CST) }\end{array}$} & & & \multirow{3}{*}{$\begin{array}{l}\text { Regression estimate } \\
\text { SSC (mg/L) }\end{array}$} & \multirow{3}{*}{$\begin{array}{c}\text { Regression residua } \\
\log _{10} \text { SSC }\end{array}$} \\
\hline & \multirow{2}{*}{$\begin{array}{l}\text { Station } \\
\text { number }\end{array}$} & \multirow{2}{*}{$\begin{array}{c}\text { Method } \\
\text { code }^{1}\end{array}$} & \multicolumn{2}{|c|}{ Concentration (SSC) } & \multirow{2}{*}{$\begin{array}{c}\text { Percent finer than } \\
0.0625 \mathrm{~mm}\end{array}$} & & \multicolumn{2}{|c|}{ Streamflow } & & \\
\hline & & & (mg/L) & $\log _{10}(\mathrm{mg} / \mathrm{L})$ & & & $\left(\mathrm{ft}^{3} / \mathrm{s}\right)$ & $\log _{10}\left(\mathrm{ft}^{3} / \mathrm{s}\right)$ & & \\
\hline $10 / 18 / 2012$ 16:01 & 05586300 & 30 & 30 & 1.477 & & 10/18/2012 16:00 & 5,970 & 3.776 & 64 & -0.156 \\
\hline 10/18/2012 16:06 & 05586300 & 20 & 34 & 1.531 & 98 & 10/18/2012 16:00 & 5,970 & 3.776 & 64 & -0.102 \\
\hline 10/18/2012 16:18 & 05586300 & 30 & 37 & 1.568 & & 10/18/2012 16:00 & 5,970 & 3.776 & 64 & -0.065 \\
\hline 10/21/2012 18:00 & 05586300 & 920 & 24 & 1.380 & & 10/21/2012 18:00 & 8,280 & 3.918 & 77 & -0.335 \\
\hline 10/24/2012 18:00 & 05586300 & 920 & 34 & 1.531 & & 10/24/2012 18:00 & 8,100 & 3.908 & 76 & -0.178 \\
\hline 10/28/2012 17:00 & 05586300 & 920 & 40 & 1.602 & & 10/28/2012 17:00 & 8,760 & 3.943 & 79 & -0.128 \\
\hline 10/31/2012 10:00 & 05586300 & 30 & 23 & 1.362 & & 10/31/2012 10:00 & 6,110 & 3.786 & 64 & -0.277 \\
\hline $10 / 31 / 201215: 53$ & 05586100 & 15 & 25 & 1.398 & 98 & 10/31/2012 16:00 & 5,710 & 3.757 & 62 & -0.224 \\
\hline 10/31/2012 17:00 & 05586300 & 920 & 26 & 1.415 & & 10/31/2012 17:00 & 5,690 & 3.755 & 62 & -0.206 \\
\hline $11 / 05 / 201215: 00$ & 05586300 & 920 & 17 & 1.230 & & 11/05/2012 15:00 & 4,260 & 3.629 & 52 & -0.318 \\
\hline 11/07/2012 15:00 & 05586300 & 920 & 15 & 1.176 & & 11/07/2012 15:00 & 4,570 & 3.660 & 54 & -0.390 \\
\hline $11 / 13 / 2012$ 15:00 & 05586300 & 920 & 21 & 1.322 & & 11/13/2012 15:00 & 4,710 & 3.673 & 55 & -0.252 \\
\hline 11/14/2012 17:00 & 05586300 & 920 & 32 & 1.505 & & 11/14/2012 17:00 & 8,340 & 3.921 & 77 & -0.212 \\
\hline 11/27/2012 09:40 & 05586300 & 30 & 35 & 1.544 & & 11/27/2012 10:00 & 4,910 & 3.691 & 57 & -0.040 \\
\hline $11 / 27 / 201215: 00$ & 05586300 & 920 & 29 & 1.462 & & $11 / 27 / 2012 \quad 15: 00$ & 5,400 & 3.732 & 60 & -0.146 \\
\hline $12 / 02 / 2012$ 15:00 & 05586300 & 920 & 18 & 1.255 & & 12/02/2012 15:00 & 4,230 & 3.626 & 52 & -0.292 \\
\hline $12 / 04 / 2012$ 15:00 & 05586300 & 920 & 20 & 1.301 & & 12/04/2012 15:00 & 4,340 & 3.637 & 53 & -0.252 \\
\hline $12 / 08 / 201207: 00$ & 05586300 & 920 & 18 & 1.255 & & 12/08/2012 07:00 & 4,540 & 3.657 & 54 & -0.309 \\
\hline $12 / 10 / 2012$ 15:00 & 05586300 & 920 & 26 & 1.415 & & 12/10/2012 15:00 & 4,660 & 3.668 & 55 & -0.156 \\
\hline $12 / 13 / 201209: 37$ & 05586300 & 20 & 37 & 1.568 & & 12/13/2012 10:00 & 4,910 & 3.691 & 57 & -0.016 \\
\hline $12 / 13 / 201209: 45$ & 05586300 & 920 & 29 & 1.462 & & $12 / 13 / 201210: 00$ & 4,910 & 3.691 & 57 & -0.122 \\
\hline 12/13/2012 09:50 & 05586300 & 920 & 38 & 1.580 & & 12/13/2012 10:00 & 4,910 & 3.691 & 57 & -0.004 \\
\hline $12 / 14 / 201216: 47$ & 05586100 & 10 & 26 & 1.415 & 99 & 12/14/2012 17:00 & 4,170 & 3.620 & 52 & -0.128 \\
\hline $12 / 18 / 201215: 10$ & 05586300 & 920 & 18 & 1.255 & & 12/18/2012 15:00 & 6,800 & 3.833 & 68 & -0.411 \\
\hline $12 / 23 / 201216: 00$ & 05586300 & 920 & 31 & 1.491 & & 12/23/2012 16:00 & 8,480 & 3.928 & 78 & -0.230 \\
\hline $12 / 26 / 2012$ 15:00 & 05586300 & 920 & 62 & 1.792 & & $12 / 26 / 2012$ 15:00 & 11,200 & 4.049 & 91 & 0.001 \\
\hline $12 / 30 / 2012$ 15:00 & 05586300 & 920 & 27 & 1.431 & & 12/30/2012 15:00 & 7,720 & 3.888 & 74 & -0.267 \\
\hline 01/02/2013 15:00 & 05586300 & 920 & 25 & 1.398 & & 01/02/2013 15:00 & 8,380 & 3.923 & 77 & -0.321 \\
\hline 01/08/2013 09:45 & 05586300 & 70 & 23 & 1.362 & & 01/08/2013 10:00 & 7,720 & 3.888 & 74 & -0.336 \\
\hline
\end{tabular}


Appendix 3. Estimating Suspended Sediment Concentration from Streamflow_Model Information and Data.—Continued

[CST, central standard time; SSC, suspended-sediment concentration; $\mathrm{mg} / \mathrm{L}$, milligrams per liter; $\log _{10}$, base-10 logarithmic transform; mm, millimeter; $\mathrm{ft}^{3} / \mathrm{s}$, cubic feet per second]

\begin{tabular}{|c|c|c|c|c|c|c|c|c|c|c|}
\hline \multirow{3}{*}{$\begin{array}{l}\text { Date and time } \\
\text { (CST) }\end{array}$} & \multicolumn{5}{|c|}{ Suspended sediment } & \multirow{3}{*}{$\begin{array}{l}\text { Date and time } \\
\text { (CST) }\end{array}$} & & & \multirow{3}{*}{$\begin{array}{l}\text { Regression estimate } \\
\text { SSC (mg/L) }\end{array}$} & \multirow{3}{*}{$\begin{array}{c}\text { Regression residual } \\
\log _{10} S S C\end{array}$} \\
\hline & \multirow{2}{*}{$\begin{array}{l}\text { Station } \\
\text { number }\end{array}$} & \multirow{2}{*}{$\begin{array}{l}\text { Method } \\
\text { code }^{1}\end{array}$} & \multicolumn{2}{|c|}{ Concentration (SSC) } & \multirow{2}{*}{$\begin{array}{c}\text { Percent finer than } \\
0.0625 \mathrm{~mm}\end{array}$} & & \multicolumn{2}{|c|}{ Streamflow } & & \\
\hline & & & (mg/L) & $\log _{10}(\mathrm{mg} / \mathrm{L})$ & & & $\left(\mathrm{ft}^{3} / \mathrm{s}\right)$ & $\log _{10}\left(\mathrm{ft}^{3} / \mathrm{s}\right)$ & & \\
\hline 01/09/2013 16:50 & 05586300 & 920 & 22 & 1.342 & & 01/09/2013 17:00 & 7,260 & 3.861 & 71 & -0.340 \\
\hline 01/13/2013 15:00 & 05586300 & 920 & 63 & 1.799 & & 01/13/2013 15:00 & 9,080 & 3.958 & 81 & 0.061 \\
\hline 01/15/2013 15:00 & 05586300 & 920 & 59 & 1.771 & & 01/15/2013 15:00 & 12,400 & 4.093 & 97 & -0.046 \\
\hline 01/28/2013 15:00 & 05586300 & 920 & 28 & 1.447 & & 01/28/2013 15:00 & 8,450 & 3.927 & 78 & -0.273 \\
\hline 01/30/2013 17:45 & 05586300 & 920 & 843 & 2.926 & & 01/30/2013 18:00 & 18,200 & 4.260 & 121 & 1.013 \\
\hline 02/04/2013 12:40 & 05586300 & 70 & 355 & 2.550 & 89 & 02/04/2013 13:00 & 25,400 & 4.405 & 147 & 0.553 \\
\hline 02/05/2013 10:55 & 05586300 & 920 & 440 & 2.643 & & 02/05/2013 11:00 & 26,000 & 4.415 & 149 & 0.641 \\
\hline 02/05/2013 11:09 & 05586300 & 20 & 375 & 2.574 & & 02/05/2013 11:00 & 26,000 & 4.415 & 149 & 0.571 \\
\hline 02/05/2013 11:22 & 05586300 & 920 & 382 & 2.582 & & 02/05/2013 11:00 & 26,000 & 4.415 & 149 & 0.579 \\
\hline 02/05/2013 15:00 & 05586300 & 920 & 361 & 2.558 & & 02/05/2013 15:00 & 26,100 & 4.417 & 149 & 0.554 \\
\hline 02/06/2013 15:00 & 05586300 & 920 & 328 & 2.516 & & 02/06/2013 15:00 & 26,000 & 4.415 & 149 & 0.513 \\
\hline 02/17/2013 15:00 & 05586300 & 920 & 373 & 2.572 & & 02/17/2013 15:00 & 26,100 & 4.417 & 149 & 0.568 \\
\hline 02/19/2013 11:00 & 05586300 & 70 & 137 & 2.137 & 98 & 02/19/2013 11:00 & 22,100 & 4.344 & 135 & 0.175 \\
\hline 02/19/2013 15:00 & 05586300 & 920 & 294 & 2.468 & & 02/19/2013 15:00 & 19,900 & 4.299 & 127 & 0.533 \\
\hline 02/25/2013 17:00 & 05586300 & 920 & 131 & 2.117 & & 02/25/2013 17:00 & 15,800 & 4.199 & 112 & 0.239 \\
\hline 03/06/2013 16:00 & 05586300 & 920 & 309 & 2.490 & & \multicolumn{3}{|c|}{ outlier not used in regression model } & & \\
\hline 03/08/2013 12:30 & 05586300 & 15 & 26 & 1.415 & & \multicolumn{3}{|c|}{ outlier not used in regression model } & & \\
\hline 03/08/2013 13:00 & 05586300 & 70 & 75 & 1.875 & & 03/08/2013 13:00 & 21,400 & 4.330 & 133 & -0.079 \\
\hline 03/08/2013 13:20 & 05586300 & 10 & 80 & 1.903 & & 03/08/2013 13:00 & 21,400 & 4.330 & 133 & -0.051 \\
\hline 03/08/2013 14:52 & 05586100 & 10 & 79 & 1.898 & 95 & 03/08/2013 15:00 & 21,400 & 4.330 & 133 & -0.056 \\
\hline 03/13/2013 15:00 & 05586300 & 920 & 728 & 2.862 & & 03/13/2013 15:00 & 42,300 & 4.626 & 197 & 0.737 \\
\hline 03/20/2013 16:00 & 05586300 & 920 & 154 & 2.188 & & 03/20/2013 16:00 & 48,000 & 4.681 & 212 & 0.031 \\
\hline 03/21/2013 14:47 & 05586100 & 10 & 121 & 2.083 & 75 & 03/21/2013 15:00 & 47,400 & 4.676 & 211 & -0.071 \\
\hline 03/27/2013 15:00 & 05586300 & 920 & 76 & 1.881 & & 03/27/2013 15:00 & 39,600 & 4.598 & 190 & -0.228 \\
\hline 04/01/2013 16:00 & 05586300 & 920 & 95 & 1.978 & & 04/01/2013 16:00 & 34,400 & 4.537 & 175 & -0.096 \\
\hline 04/03/2013 17:00 & 05586300 & 920 & 109 & 2.037 & & 04/03/2013 17:00 & 32,700 & 4.515 & 170 & -0.023 \\
\hline $04 / 11 / 2013 \quad 12: 56$ & 05586100 & 10 & 1,970 & 3.294 & 100 & 04/11/2013 13:00 & 34,000 & 4.531 & 174 & 1.224 \\
\hline 04/15/2013 18:00 & 05586300 & 920 & & & & bottle broken at lab & & & & \\
\hline 04/17/2013 17:30 & 05586300 & 920 & & & & bottle broken at lab & & & & \\
\hline
\end{tabular}


Appendix 3. Estimating Suspended Sediment Concentration from Streamflow—Model Information and Data.-Continued

[CST, central standard time; SSC, suspended-sediment concentration; $\mathrm{mg} / \mathrm{L}$, milligrams per liter; $\log _{10}$, base-10 logarithmic transform; mm, millimeter; $\mathrm{ft}^{3} / \mathrm{s}$, cubic feet per second]

\begin{tabular}{|c|c|c|c|c|c|c|c|c|c|c|}
\hline \multirow{3}{*}{$\begin{array}{l}\text { Date and time } \\
\text { (CST) }\end{array}$} & \multicolumn{5}{|c|}{ Suspended sediment } & \multirow{3}{*}{$\begin{array}{l}\text { Date and time } \\
\text { (CST) }\end{array}$} & & & \multirow{3}{*}{$\begin{array}{l}\text { Regression estimate } \\
\text { SSC (mg/L) }\end{array}$} & \multirow{3}{*}{$\begin{array}{c}\text { Regression residua } \\
\log _{10} S S C\end{array}$} \\
\hline & \multirow{2}{*}{$\begin{array}{l}\text { Station } \\
\text { number }\end{array}$} & \multirow{2}{*}{$\begin{array}{l}\text { Method } \\
\text { code }^{1}\end{array}$} & \multicolumn{2}{|c|}{ Concentration (SSC) } & \multirow{2}{*}{$\begin{array}{l}\text { Percent finer than } \\
0.0625 \mathrm{~mm}\end{array}$} & & \multicolumn{2}{|c|}{ Streamflow } & & \\
\hline & & & (mg/L) & $\log _{10}(\mathrm{mg} / \mathrm{L})$ & & & $\left(\mathrm{ft}^{3} / \mathbf{s}\right)$ & $\log _{10}\left(\mathrm{ft}^{3} / \mathrm{s}\right)$ & & \\
\hline 04/21/2013 15:30 & 05586300 & 920 & & & & bottle broken at lab & & & & \\
\hline $04 / 23 / 201310: 53$ & 05586300 & 920 & 326 & 2.513 & 91 & 04/23/2013 11:00 & 103,000 & 5.013 & 330 & 0.165 \\
\hline 04/23/2013 11:19 & 05586300 & 10 & 320 & 2.505 & 89 & 04/23/2013 11:00 & 103,000 & 5.013 & 330 & 0.156 \\
\hline 04/23/2013 11:23 & 05586300 & 10 & 280 & 2.447 & 87 & 04/23/2013 11:00 & 103,000 & 5.013 & 330 & 0.098 \\
\hline 04/24/2013 14:50 & 05586300 & 10 & 274 & 2.438 & & 04/24/2013 15:00 & 110,000 & 5.041 & 343 & 0.073 \\
\hline 04/24/2013 18:00 & 05586300 & 920 & 306 & 2.486 & & 04/24/2013 18:00 & 111,000 & 5.045 & 344 & 0.118 \\
\hline $04 / 26 / 201315: 57$ & 05586100 & 20 & 128 & 2.107 & 88 & 04/26/2013 16:00 & 111,000 & 5.045 & 344 & -0.260 \\
\hline 04/26/2013 16:06 & 05586100 & 20 & 146 & 2.164 & & 04/26/2013 16:00 & 111,000 & 5.045 & 344 & -0.203 \\
\hline 04/28/2013 19:00 & 05586300 & 920 & 165 & 2.217 & & 04/28/2013 19:00 & 112,000 & 5.049 & 346 & -0.152 \\
\hline 04/29/2013 11:20 & 05586300 & 50 & 75 & 1.875 & & 04/29/2013 11:00 & 110,000 & 5.041 & 343 & -0.490 \\
\hline 04/30/2013 19:00 & 05586300 & 920 & 71 & 1.851 & & 04/30/2013 19:00 & 106,000 & 5.025 & 335 & -0.505 \\
\hline 05/01/2013 20:00 & 05586300 & 920 & 64 & 1.806 & & 05/01/2013 20:00 & 104,000 & 5.017 & 332 & -0.545 \\
\hline 05/05/2013 20:00 & 05586300 & 920 & 68 & 1.833 & & 05/05/2013 20:00 & 95,300 & 4.979 & 315 & -0.497 \\
\hline 05/07/2013 20:00 & 05586300 & 920 & 178 & 2.250 & & 05/07/2013 20:00 & 94,500 & 4.975 & 314 & -0.077 \\
\hline 05/08/2013 14:00 & 05586300 & 50 & 60 & 1.778 & & 05/08/2013 14:00 & 93,700 & 4.972 & 312 & -0.547 \\
\hline 05/22/2013 11:43 & 05586100 & 10 & 119 & 2.076 & 97 & 05/22/2013 12:00 & 52,100 & 4.717 & 222 & -0.102 \\
\hline 05/28/2013 17:00 & 05586300 & 920 & 946 & 2.976 & 97 & 05/28/2013 17:00 & 58,000 & 4.763 & 237 & 0.771 \\
\hline 05/29/2013 13:40 & 05586300 & 50 & 493 & 2.693 & & 05/29/2013 14:00 & 61,900 & 4.792 & 246 & 0.472 \\
\hline 06/05/2013 13:01 & 05586100 & 10 & 122 & 2.086 & 96 & 06/05/2013 13:00 & 85,800 & 4.933 & 297 & -0.216 \\
\hline 06/09/2013 19:00 & 05586300 & 920 & 57 & 1.756 & & 06/09/2013 19:00 & 85,000 & 4.929 & 295 & -0.545 \\
\hline 06/11/2013 20:00 & 05586300 & 920 & 40 & 1.602 & & 06/11/2013 20:00 & 79,600 & 4.901 & 284 & -0.682 \\
\hline 06/16/2013 15:00 & 05586300 & 920 & 425 & 2.628 & & 06/16/2013 15:00 & 69,200 & 4.840 & 262 & 0.380 \\
\hline $06 / 18 / 2013 \quad 17: 20$ & 05586300 & 50 & 74 & 1.869 & 99 & 06/18/2013 17:00 & 66,900 & 4.825 & 257 & -0.371 \\
\hline 06/19/2013 09:44 & 05586100 & 10 & 64 & 1.806 & 94 & 06/19/2013 10:00 & 64,700 & 4.811 & 252 & -0.426 \\
\hline 06/26/2013 20:00 & 05586300 & 920 & 130 & 2.114 & & 06/26/2013 20:00 & 51,400 & 4.711 & 221 & -0.060 \\
\hline
\end{tabular}

${ }^{1}$ Method code for sampling methods: Equal Width-Increment (EWI)-10, EWI non-isokinetic-15, Equal Discharge Increment(EDI)-20, Single-Vertical-30, Point-50, Fixed Single Vertical-BOX-920. 


\section{Appendix 4. Estimating Total Phosphorus Concentration from Orthophosphate and Suspended-Sediment Concentrations at USGS station number 05586100—Model Information and Data}

\section{Model form}

Total phosphorus $=0.0816+1.10($ Orthophosphate $)+0.00063(\mathrm{SSC})$

\begin{tabular}{lccc}
\cline { 2 - 4 } & \multicolumn{2}{c}{ Predictor variable summary statistics } & Response variable summary statistics \\
\cline { 2 - 4 } & Orthphosphate & (SSC) & Total phosphorus \\
\hline Minimum & 0.051 & 29 & 0.11 \\
1st Quartile & 0.139 & 78 & 0.30 \\
Median & 0.176 & 116 & 0.39 \\
Mean & 0.201 & 178 & 0.41 \\
3rd Quartile & 0.241 & 200 & 0.48 \\
Maximum & 0.600 & 1,970 & 1.38 \\
\hline
\end{tabular}

\section{Model calibration}

\begin{tabular}{lc}
\hline \multicolumn{1}{c}{ Basic data } \\
\hline Number of observations & 246 \\
Error degrees of freedom & 243 \\
Root mean squared error (Standard error of & 0.079 \\
$\quad$ regression) & \\
R-squared & 0.803 \\
Adjusted R-squared & 0.802 \\
F-statistic versus constant model & 497 \\
p-value & $1.45 \mathrm{E}-86$ \\
Probability plot correlation coefficient & 0.88 \\
\hline
\end{tabular}

Estimated coefficients

\begin{tabular}{llllccc}
\hline & Estimate & \multicolumn{1}{c}{ SE } & tStat & pValue & Lower 90 percent & Upper 90 percent \\
\hline (Intercept) & 0.081552 & 0.012871 & 6.3362 & $1.133 \mathrm{E}-09$ & 0.0603005 & 0.102804 \\
Orthophosphate & 1.0987 & 0.05144 & 21.36 & $1.072 \mathrm{E}-57$ & 1.0138 & 1.18367 \\
SSC & 0.000629 & $2.3715 \mathrm{e}^{-05}$ & 26.546 & $9.122 \mathrm{E}-74$ & 0.000590 & 0.000669 \\
\hline
\end{tabular}


Appendix 4. Estimating Total Phosphorus Concentration from Orthophosphate and Suspended-Sediment Concentrations at USGS station number 05586100-Model Information and Data.

\begin{tabular}{|c|c|c|c|c|}
\hline $\begin{array}{c}\text { Date and time } \\
\text { (Central Standard Time) }\end{array}$ & Method code ${ }^{1}$ & $\begin{array}{c}\text { Total } \\
\text { phosphorus }\end{array}$ & Orthophosphate & $\begin{array}{c}\text { Suspended- } \\
\text { sediment } \\
\text { concentration }\end{array}$ \\
\hline 06/27/1991 11:00 & --- & 0.280 & 0.110 & 124 \\
\hline 07/01/1991 09:30 & --- & 0.277 & 0.130 & 83 \\
\hline 07/03/1991 11:00 & --- & 0.257 & 0.110 & 86 \\
\hline 07/09/1991 10:00 & --- & 0.240 & 0.110 & 59 \\
\hline 07/11/1991 10:45 & --- & 0.288 & 0.150 & 66 \\
\hline 07/18/1991 11:15 & --- & 0.248 & 0.080 & 124 \\
\hline 07/25/1991 13:40 & --- & 0.237 & 0.120 & 38 \\
\hline 08/06/1991 10:15 & --- & 0.278 & 0.140 & 68 \\
\hline 08/13/1991 12:00 & --- & 0.416 & 0.270 & 60 \\
\hline 08/21/1991 12:30 & --- & 0.262 & 0.130 & 59 \\
\hline 08/28/1991 10:15 & --- & 0.253 & 0.130 & 45 \\
\hline 09/03/1991 10:50 & --- & 0.283 & 0.160 & 41 \\
\hline 09/10/1991 12:00 & --- & 0.313 & 0.160 & 88 \\
\hline 09/17/1991 11:00 & --- & 0.322 & 0.160 & 102 \\
\hline 09/24/1991 11:00 & --- & 0.291 & 0.160 & 53 \\
\hline 10/01/1991 11:30 & --- & 0.294 & 0.150 & 76 \\
\hline 10/08/1991 13:30 & --- & 0.535 & 0.140 & 476 \\
\hline 10/15/1991 12:15 & --- & 0.410 & 0.250 & 86 \\
\hline 10/22/1991 11:30 & --- & 0.369 & 0.240 & 38 \\
\hline 11/05/1991 12:00 & --- & 0.790 & 0.240 & 707 \\
\hline 11/15/1991 11:30 & --- & 0.336 & 0.180 & 90 \\
\hline 12/03/1991 10:30 & --- & 0.452 & 0.140 & 344 \\
\hline 12/18/1991 12:00 & --- & 0.328 & 0.140 & 147 \\
\hline 01/02/1992 13:30 & --- & 0.288 & 0.130 & 101 \\
\hline 01/30/1992 13:45 & --- & 0.359 & 0.200 & 92 \\
\hline 02/12/1992 12:00 & --- & 0.331 & 0.170 & 100 \\
\hline $02 / 28 / 199212: 45$ & --- & 0.314 & 0.150 & 108 \\
\hline 03/03/1992 11:00 & --- & 0.261 & 0.100 & 111 \\
\hline 03/17/1992 10:50 & --- & 0.315 & 0.160 & 92 \\
\hline 03/25/1992 10:45 & --- & 0.286 & 0.120 & 115 \\
\hline 05/16/1996 14:50 & 10 & 0.283 & 0.100 & 146 \\
\hline 06/04/1996 15:20 & 10 & 0.231 & 0.090 & 81 \\
\hline 07/09/1996 17:00 & 10 & 0.440 & 0.150 & 308 \\
\hline 08/05/1996 14:00 & 10 & 0.297 & 0.130 & 116 \\
\hline 09/10/1996 12:30 & 10 & 0.336 & 0.200 & 55 \\
\hline 10/31/1996 15:10 & 10 & 0.372 & 0.220 & 78 \\
\hline $11 / 22 / 199612: 40$ & 10 & 0.540 & 0.380 & 65 \\
\hline $12 / 13 / 199612: 30$ & 10 & 0.535 & 0.360 & 92 \\
\hline 01/21/1997 16:00 & 30 & 0.427 & 0.270 & 77 \\
\hline 02/11/1997 16:40 & 10 & 0.472 & 0.210 & 253 \\
\hline
\end{tabular}


Appendix 4. Estimating Total Phosphorus Concentration from Orthophosphate and Suspended-Sediment Concentrations at USGS station number 05586100-Model Information and Data.-Continued

\begin{tabular}{|c|c|c|c|c|}
\hline $\begin{array}{c}\text { Date and time } \\
\text { (Central Standard Time) }\end{array}$ & Method code' & $\begin{array}{c}\text { Total } \\
\text { phosphorus }\end{array}$ & Orthophosphate & $\begin{array}{l}\text { Suspended- } \\
\text { sediment } \\
\text { concentration }\end{array}$ \\
\hline 03/18/1997 15:40 & 10 & 0.290 & 0.140 & 87 \\
\hline 04/01/1997 12:30 & 10 & 0.371 & 0.140 & 215 \\
\hline 04/15/1997 14:20 & 10 & 0.415 & 0.140 & 286 \\
\hline 04/29/1997 12:30 & 10 & 0.276 & 0.120 & 100 \\
\hline 05/13/1997 12:50 & 10 & 0.436 & 0.180 & 249 \\
\hline 05/28/1997 13:40 & 10 & 0.481 & 0.160 & 356 \\
\hline 06/10/1997 12:50 & 10 & 0.668 & 0.140 & 687 \\
\hline 06/17/1997 13:00 & 10 & 0.615 & 0.140 & 603 \\
\hline 06/26/1997 13:00 & 10 & 0.370 & 0.140 & 214 \\
\hline 07/08/1997 16:10 & 10 & 0.372 & 0.180 & 147 \\
\hline 07/22/1997 14:40 & 10 & 0.345 & 0.160 & 139 \\
\hline 08/05/1997 13:50 & 10 & 0.396 & 0.190 & 168 \\
\hline 08/19/1997 12:50 & 10 & 0.490 & 0.210 & 282 \\
\hline 09/02/1997 17:21 & 10 & 0.337 & 0.180 & 92 \\
\hline 09/16/1997 14:11 & 10 & 0.297 & 0.160 & 63 \\
\hline 10/21/1997 13:11 & 10 & 0.376 & 0.230 & 66 \\
\hline 11/18/1997 13:31 & 10 & 0.488 & 0.340 & 53 \\
\hline $12 / 16 / 1997$ 13:21 & 10 & 0.447 & 0.290 & 75 \\
\hline 01/13/1998 14:51 & 10 & 0.479 & 0.230 & 230 \\
\hline 02/04/1998 13:31 & 10 & 0.306 & 0.150 & 95 \\
\hline 03/10/1998 15:31 & 10 & 0.418 & 0.130 & 307 \\
\hline 04/01/1998 16:01 & 10 & 0.274 & 0.150 & 44 \\
\hline 04/14/1998 12:51 & 10 & 0.331 & 0.110 & 204 \\
\hline 04/28/1998 12:21 & 10 & 0.194 & 0.070 & 56 \\
\hline 05/12/1998 12:51 & 10 & 0.209 & 0.080 & 63 \\
\hline 05/27/1998 12:41 & 10 & 0.281 & 0.120 & 108 \\
\hline 06/09/1998 18:31 & 10 & 0.670 & 0.140 & 690 \\
\hline 06/18/1998 13:31 & 10 & 0.404 & 0.150 & 251 \\
\hline 06/23/1998 13:51 & 10 & 0.295 & 0.120 & 130 \\
\hline 07/07/1998 12:51 & 10 & 0.255 & 0.110 & 83 \\
\hline 07/21/1998 14:01 & 10 & 0.871 & 0.140 & 1,010 \\
\hline 08/04/1998 15:11 & 10 & 0.346 & 0.180 & 106 \\
\hline 08/12/1998 17:51 & 10 & 0.628 & 0.320 & 310 \\
\hline 08/18/1998 12:31 & 10 & 0.423 & 0.240 & 123 \\
\hline 09/01/1998 12:31 & 10 & 0.427 & 0.240 & 130 \\
\hline 09/15/1998 12:31 & 10 & 0.382 & 0.220 & 94 \\
\hline 10/15/1998 14:11 & 10 & 0.461 & 0.230 & 202 \\
\hline $11 / 17 / 1998$ 15:31 & 10 & 0.621 & 0.300 & 333 \\
\hline $12 / 22 / 1998$ 15:21 & 10 & 0.499 & 0.290 & 157 \\
\hline 01/20/1999 15:01 & 60 & 0.382 & 0.200 & 128 \\
\hline
\end{tabular}


Appendix 4. Estimating Total Phosphorus Concentration from Orthophosphate and Suspended-Sediment Concentrations at USGS station number 05586100—Model Information and Data.-Continued

\begin{tabular}{|c|c|c|c|c|}
\hline $\begin{array}{c}\text { Date and time } \\
\text { (Central Standard Time) }\end{array}$ & Method code ${ }^{1}$ & $\begin{array}{c}\text { Total } \\
\text { phosphorus }\end{array}$ & Orthophosphate & $\begin{array}{c}\text { Suspended- } \\
\text { sediment } \\
\text { concentration }\end{array}$ \\
\hline 03/10/1999 15:41 & 10 & 0.347 & 0.140 & 177 \\
\hline 04/12/1999 14:41 & 10 & 0.462 & 0.130 & 378 \\
\hline 05/19/1999 14:51 & 10 & 0.285 & 0.070 & 201 \\
\hline 06/08/1999 14:31 & 10 & 0.485 & 0.140 & 397 \\
\hline 07/13/1999 14:01 & 10 & 0.384 & 0.170 & 184 \\
\hline 08/09/1999 14:01 & 10 & 0.460 & 0.280 & 112 \\
\hline 09/07/1999 14:51 & 10 & 0.440 & 0.260 & 115 \\
\hline 10/12/1999 13:31 & 10 & 0.650 & 0.430 & 152 \\
\hline 11/16/1999 14:01 & 10 & 0.398 & 0.240 & 84 \\
\hline $12 / 13 / 199914: 46$ & 10 & 0.886 & 0.600 & 231 \\
\hline $01 / 12 / 200014: 16$ & 10 & 0.502 & 0.310 & 127 \\
\hline $02 / 08 / 200014: 36$ & 10 & 0.655 & 0.430 & 160 \\
\hline $04 / 11 / 200015: 11$ & 10 & 0.419 & 0.210 & 169 \\
\hline 05/04/2000 11:51 & 10 & 0.413 & 0.150 & 265 \\
\hline 06/09/2000 19:11 & 10 & 0.488 & 0.190 & 314 \\
\hline $06 / 29 / 200012: 21$ & 10 & 0.460 & 0.170 & 304 \\
\hline 08/11/2000 12:01 & 10 & 0.545 & 0.270 & 265 \\
\hline $09 / 14 / 200015: 31$ & 10 & 0.561 & 0.320 & 203 \\
\hline $10 / 10 / 200014: 31$ & 10 & 0.545 & 0.330 & 160 \\
\hline $11 / 15 / 200014: 31$ & 10 & 0.698 & 0.430 & 228 \\
\hline $12 / 11 / 200014: 51$ & 10 & 0.495 & 0.280 & 168 \\
\hline 02/13/2001 15:01 & 10 & 0.478 & 0.180 & 315 \\
\hline 03/20/2001 14:01 & 10 & 0.339 & 0.140 & 165 \\
\hline 04/25/2001 11:51 & 10 & 0.399 & 0.150 & 243 \\
\hline $05 / 16 / 2001 \quad 15: 21$ & 10 & 0.353 & 0.170 & 135 \\
\hline $06 / 13 / 2001 \quad 15: 21$ & 10 & 0.444 & 0.120 & 366 \\
\hline 07/19/2001 14:31 & 10 & 0.425 & 0.240 & 126 \\
\hline $08 / 22 / 2001$ 13:31 & 10 & 0.521 & 0.320 & 139 \\
\hline 10/09/2001 12:01 & 10 & 0.466 & 0.260 & 157 \\
\hline 12/17/2001 12:01 & 10 & 0.460 & 0.230 & 200 \\
\hline 02/20/2002 11:51 & 10 & 0.409 & 0.160 & 241 \\
\hline 04/10/2002 10:01 & 10 & 0.405 & 0.140 & 269 \\
\hline 05/08/2002 11:02 & 10 & 0.310 & 0.090 & 206 \\
\hline $06 / 12 / 200210: 12$ & 10 & 1.260 & 0.110 & 1,680 \\
\hline 07/17/2002 10:32 & 10 & 0.425 & 0.200 & 196 \\
\hline 08/15/2002 10:22 & 10 & 0.452 & 0.300 & 65 \\
\hline 10/16/2002 11:02 & 10 & 0.561 & 0.370 & 116 \\
\hline $12 / 16 / 200216: 47$ & 10 & 0.580 & 0.360 & 164 \\
\hline 02/18/2003 11:12 & 10 & 0.524 & 0.360 & 75 \\
\hline 04/10/2003 10:47 & 10 & 0.564 & 0.250 & 330 \\
\hline
\end{tabular}


Appendix 4. Estimating Total Phosphorus Concentration from Orthophosphate and Suspended-Sediment Concentrations at USGS station number 05586100-Model Information and Data.-Continued

\begin{tabular}{|c|c|c|c|c|}
\hline $\begin{array}{c}\text { Date and time } \\
\text { (Central Standard Time) }\end{array}$ & Method code ${ }^{1}$ & $\begin{array}{c}\text { Total } \\
\text { phosphorus }\end{array}$ & Orthophosphate & $\begin{array}{c}\text { Suspended- } \\
\text { sediment } \\
\text { concentration }\end{array}$ \\
\hline $05 / 16 / 200311: 12$ & 10 & 0.538 & 0.130 & 498 \\
\hline $06 / 11 / 2003$ 14:02 & 10 & 0.377 & 0.130 & 243 \\
\hline 07/01/2003 11:32 & 10 & 0.369 & 0.180 & 142 \\
\hline $08 / 18 / 200315: 17$ & 10 & 0.442 & 0.250 & 136 \\
\hline $10 / 15 / 200313: 52$ & 10 & 0.423 & 0.241 & 122 \\
\hline $12 / 02 / 200312: 17$ & 10 & 0.436 & 0.193 & 226 \\
\hline $02 / 25 / 200411: 32$ & 10 & 0.478 & 0.247 & 198 \\
\hline 04/07/2004 13:02 & 10 & 0.332 & 0.133 & 166 \\
\hline 05/13/2004 12:17 & 10 & 0.360 & 0.149 & 182 \\
\hline 06/10/2004 11:57 & 10 & 0.351 & 0.144 & 177 \\
\hline 07/06/2004 11:07 & 40 & 0.503 & 0.199 & 322 \\
\hline 08/03/2004 11:47 & 10 & 0.420 & 0.220 & 153 \\
\hline $10 / 19 / 200411: 42$ & 10 & 0.453 & 0.292 & 81 \\
\hline $12 / 01 / 200411: 52$ & 40 & 0.470 & 0.217 & 239 \\
\hline $02 / 23 / 200511: 32$ & 40 & 0.270 & 0.142 & 52 \\
\hline $04 / 19 / 200511: 52$ & 40 & 0.292 & 0.103 & 155 \\
\hline 06/01/2005 11:37 & 40 & 0.338 & 0.189 & 77 \\
\hline $08 / 18 / 200512: 42$ & 40 & 0.752 & 0.583 & 47 \\
\hline $10 / 12 / 200511: 42$ & 10 & 0.691 & 0.523 & 55 \\
\hline $11 / 08 / 200512: 02$ & 40 & 0.499 & 0.349 & 54 \\
\hline $12 / 21 / 200512: 17$ & 40 & 0.699 & 0.516 & 80 \\
\hline 01/12/2006 12:02 & 40 & 0.668 & 0.483 & 88 \\
\hline $02 / 14 / 200612: 17$ & 40 & 0.328 & 0.196 & 50 \\
\hline 03/14/2006 12:47 & 10 & 0.488 & 0.224 & 255 \\
\hline 03/28/2006 11:52 & 10 & 0.295 & 0.130 & 112 \\
\hline 04/12/2006 12:02 & 10 & 0.406 & 0.186 & 190 \\
\hline $04 / 25 / 200611: 57$ & 10 & 0.381 & 0.153 & 208 \\
\hline 05/09/2006 11:47 & 10 & 0.359 & 0.147 & 184 \\
\hline $05 / 23 / 200612: 42$ & 10 & 0.355 & 0.173 & 133 \\
\hline $06 / 05 / 200612: 32$ & 10 & 0.454 & 0.189 & 261 \\
\hline $06 / 20 / 200613: 12$ & 40 & 0.348 & 0.196 & 81 \\
\hline $07 / 11 / 200610: 52$ & 40 & 0.340 & 0.208 & 47 \\
\hline 07/25/2006 11:02 & 40 & 0.552 & 0.380 & 84 \\
\hline 08/14/2006 12:17 & 40 & 0.553 & 0.379 & 87 \\
\hline 08/29/2006 11:22 & 40 & 0.528 & 0.344 & 109 \\
\hline 09/19/2006 12:07 & 10 & 0.590 & 0.289 & 304 \\
\hline $11 / 06 / 200712: 02$ & 15 & 0.555 & 0.407 & 41 \\
\hline $12 / 06 / 200711: 42$ & 15 & 0.757 & 0.565 & 87 \\
\hline 02/25/2008 12:02 & 10 & 0.478 & 0.291 & 122 \\
\hline 03/19/2008 11:32 & 10 & 0.326 & 0.168 & 95 \\
\hline
\end{tabular}


Appendix 4. Estimating Total Phosphorus Concentration from Orthophosphate and Suspended-Sediment Concentrations at USGS station number 05586100—Model Information and Data.-Continued

\begin{tabular}{|c|c|c|c|c|}
\hline $\begin{array}{c}\text { Date and time } \\
\text { (Central Standard Time) }\end{array}$ & Method code ${ }^{1}$ & $\begin{array}{c}\text { Total } \\
\text { phosphorus }\end{array}$ & Orthophosphate & $\begin{array}{c}\text { Suspended- } \\
\text { sediment } \\
\text { concentration }\end{array}$ \\
\hline $04 / 08 / 200811: 52$ & 10 & 0.254 & 0.116 & 72 \\
\hline 04/21/2008 11:52 & 10 & 0.221 & 0.103 & 42 \\
\hline 05/06/2008 11:42 & 15 & 0.202 & 0.079 & 53 \\
\hline 05/19/2008 11:12 & 15 & 0.283 & 0.139 & 78 \\
\hline 06/10/2008 11:32 & 15 & 0.390 & 0.193 & 153 \\
\hline 06/20/2008 12:02 & 10 & 0.333 & 0.212 & 29 \\
\hline 07/08/2008 12:02 & 10 & 0.390 & 0.232 & 85 \\
\hline 08/19/2008 11:32 & 15 & 0.425 & 0.264 & 85 \\
\hline $10 / 20 / 200811: 52$ & 10 & 0.399 & 0.200 & 155 \\
\hline $12 / 03 / 200811: 32$ & 15 & 0.379 & 0.236 & 60 \\
\hline 02/12/2009 11:52 & 10 & 0.689 & 0.109 & 775 \\
\hline 03/03/2009 12:22 & 10 & 0.435 & 0.154 & 292 \\
\hline 03/17/2009 11:53 & 10 & 0.258 & 0.112 & 85 \\
\hline 04/08/2009 11:33 & 10 & 0.224 & 0.106 & 42 \\
\hline $04 / 21 / 200911: 33$ & 10 & 0.187 & 0.051 & 79 \\
\hline 05/05/2009 12:03 & 10 & 0.220 & 0.101 & 44 \\
\hline 05/19/2009 12:13 & 10 & 0.243 & 0.093 & 94 \\
\hline 06/10/2009 11:33 & 10 & 0.263 & 0.118 & 82 \\
\hline $06 / 23 / 200911: 43$ & 10 & 0.343 & 0.142 & 167 \\
\hline 08/11/2009 11:33 & 15 & 0.350 & 0.187 & 100 \\
\hline $10 / 15 / 200911: 33$ & 10 & 0.521 & 0.290 & 192 \\
\hline $10 / 15 / 200911: 43$ & 10 & 0.519 & 0.288 & 192 \\
\hline 11/03/2009 12:03 & 10 & 0.357 & 0.146 & 183 \\
\hline 12/08/2009 10:43 & 10 & 0.342 & 0.200 & 64 \\
\hline $12 / 08 / 200910: 53$ & 10 & 0.340 & 0.199 & 64 \\
\hline $01 / 14 / 201012: 33$ & 40 & 0.339 & 0.199 & 61 \\
\hline 02/16/2010 11:33 & 40 & 0.306 & 0.169 & 61 \\
\hline 02/16/2010 11:43 & 40 & 0.307 & 0.170 & 61 \\
\hline 03/09/2010 11:33 & 10 & 0.414 & 0.170 & 232 \\
\hline 03/24/2010 11:23 & 10 & 0.249 & 0.129 & 41 \\
\hline 03/24/2010 11:33 & 10 & 0.239 & 0.120 & 41 \\
\hline 04/06/2010 11:13 & 10 & 0.195 & 0.069 & 59 \\
\hline $04 / 21 / 201011: 13$ & 10 & 0.213 & 0.058 & 107 \\
\hline $04 / 21 / 201011: 23$ & 10 & 0.212 & 0.057 & 107 \\
\hline 05/04/2010 11:13 & 10 & 0.327 & 0.125 & 172 \\
\hline $05 / 04 / 201011: 23$ & 10 & 0.328 & 0.126 & 172 \\
\hline 05/17/2010 11:13 & 10 & 0.833 & 0.094 & 1,030 \\
\hline 05/17/2010 11:23 & 10 & 0.840 & 0.100 & 1,030 \\
\hline $06 / 02 / 201013: 13$ & 10 & 0.268 & 0.108 & 108 \\
\hline $06 / 02 / 201013: 23$ & 10 & 0.266 & 0.106 & 108 \\
\hline
\end{tabular}


Appendix 4. Estimating Total Phosphorus Concentration from Orthophosphate and Suspended-Sediment Concentrations at USGS station number 05586100-Model Information and Data.-Continued

\begin{tabular}{|c|c|c|c|c|}
\hline $\begin{array}{c}\text { Date and time } \\
\text { (Central Standard Time) }\end{array}$ & Method code ${ }^{1}$ & $\begin{array}{c}\text { Total } \\
\text { phosphorus }\end{array}$ & Orthophosphate & $\begin{array}{c}\text { Suspended- } \\
\text { sediment } \\
\text { concentration }\end{array}$ \\
\hline $06 / 16 / 201012: 13$ & 10 & 0.344 & 0.175 & 111 \\
\hline $06 / 16 / 201012: 23$ & 10 & 0.346 & 0.177 & 111 \\
\hline 07/07/2010 11:43 & 10 & 0.312 & 0.193 & 29 \\
\hline $07 / 21 / 201012: 53$ & 10 & 0.676 & 0.099 & 772 \\
\hline 08/04/2010 11:33 & 10 & 0.457 & 0.247 & 166 \\
\hline 08/04/2010 11:43 & 10 & 0.457 & 0.247 & 166 \\
\hline 08/17/2010 11:43 & 10 & 0.449 & 0.246 & 155 \\
\hline 09/01/2010 11:43 & 15 & 0.488 & 0.297 & 128 \\
\hline $10 / 19 / 201012: 03$ & 15 & 0.441 & 0.278 & 86 \\
\hline $12 / 07 / 201012: 48$ & 40 & 0.553 & 0.375 & 94 \\
\hline $02 / 22 / 201111: 53$ & 10 & 0.655 & 0.304 & 381 \\
\hline $03 / 07 / 201112: 33$ & 10 & 0.342 & 0.152 & 148 \\
\hline $03 / 29 / 201110: 53$ & 10 & 0.250 & 0.091 & 109 \\
\hline 04/05/2011 10:33 & 10 & 0.259 & 0.084 & 135 \\
\hline $04 / 18 / 201111: 33$ & 10 & 0.363 & 0.191 & 114 \\
\hline 05/05/2011 10:03 & 10 & 0.238 & 0.114 & 50 \\
\hline 05/17/2011 10:53 & 10 & 0.355 & 0.111 & 240 \\
\hline $06 / 07 / 201110: 43$ & 15 & 0.277 & 0.145 & 57 \\
\hline $06 / 21 / 201111: 23$ & 10 & 0.266 & 0.140 & 49 \\
\hline 08/24/2011 11:03 & 15 & 0.462 & 0.299 & 83 \\
\hline $10 / 19 / 201110: 53$ & 15 & 0.490 & 0.341 & 53 \\
\hline $12 / 01 / 201110: 43$ & 15 & 0.447 & 0.263 & 121 \\
\hline $02 / 24 / 201212: 03$ & 10 & 0.307 & 0.171 & 60 \\
\hline $03 / 08 / 201212: 13$ & 15 & 0.468 & 0.285 & 117 \\
\hline 03/27/2012 10:43 & 10 & 0.365 & 0.196 & 108 \\
\hline 04/11/2012 11:13 & 10 & 0.261 & 0.137 & 46 \\
\hline $04 / 24 / 2012 \quad 10: 43$ & 15 & 0.360 & 0.198 & 97 \\
\hline 05/16/2012 11:03 & 10 & 0.452 & 0.188 & 261 \\
\hline $05 / 30 / 201215: 53$ & 15 & 0.346 & 0.183 & 100 \\
\hline 06/13/2012 09:13 & 15 & 0.301 & 0.177 & 40 \\
\hline 06/27/2012 12:03 & 15 & 0.480 & 0.331 & 55 \\
\hline 08/21/2012 11:34 & 10 & 0.758 & 0.580 & 63 \\
\hline $02 / 13 / 201313: 54$ & 10 & 0.532 & 0.197 & 372 \\
\hline 03/08/2013 11:44 & 10 & 0.322 & 0.174 & 79 \\
\hline $03 / 21 / 201312: 44$ & 10 & 0.310 & 0.139 & 121 \\
\hline 04/11/2013 10:14 & 10 & 1.426 & 0.095 & 1,970 \\
\hline $04 / 24 / 2013$ 15:44 & 10 & 0.416 & 0.162 & 249 \\
\hline 05/08/2013 09:24 & 10 --- & 0.307 & 0.158 & 82 \\
\hline 05/22/2013 09:14 & 10 & 0.276 & 0.109 & 119 \\
\hline $06 / 05 / 201310: 44$ & 10 & 0.370 & 0.193 & 122 \\
\hline
\end{tabular}


Appendix 4. Estimating Total Phosphorus Concentration from Orthophosphate and Suspended-Sediment Concentrations at USGS station number 05586100-Model Information and Data.-Continued

\begin{tabular}{ccccc}
\hline $\begin{array}{c}\text { Date and time } \\
\text { (Central Standard Time) }\end{array}$ & Method code ${ }^{1}$ & $\begin{array}{c}\text { Total } \\
\text { phosphorus }\end{array}$ & Orthophosphate & $\begin{array}{c}\text { Suspended- } \\
\text { sediment } \\
\text { concentration }\end{array}$ \\
\hline $06 / 19 / 201307: 34$ & 10 & 0.295 & 0.158 & 64 \\
$07 / 10 / 201309: 14$ & 10 & 0.368 & 0.190 & 124 \\
$07 / 22 / 201309: 54$ & 10 & 0.363 & 0.219 & 65 \\
$08 / 14 / 201310: 14$ & 10 & 0.324 & 0.200 & 36 \\
$11 / 01 / 201312: 04$ & 10 & 0.558 & 0.401 & 57 \\
$12 / 13 / 201310: 44$ & 10 & 0.502 & 0.363 & 34 \\
\hline
\end{tabular}

${ }^{1}$ Method code for sampling methods: Equal Width Increment (EWI)-10, EWI non-isokinetic-15, Equal Discharge Increment (EDI)-20, Single-Vertical-30, Multiple-vertical-40, Point-50, Fixed Single Vertical-BOX-920, not in database ---. 

Publication services provided by the U.S. Geological Survey Science Publishing Network

Columbus Publishing Service Center

For more information concerning the research in this report contact the

Director, Illinois Water Science Center

U.S. Geological Survey

405 N Goodwin

Urbana, IL 61801

http://il.water.usgs.gov/ 
